\title{
UCRL-TR-219738
}

LAW RENCE LIVERMORE N A T IO N A L LABORATORY

Performance, Thermal, and Vibration Qualification Testing of Zetec Acoustic Transducers, Model Z0002659-2, Sondicator Probes

Gerard Jacobson, Steven Gemberling, Anthony Lavietes

March 13, 2006 
This document was prepared as an account of work sponsored by an agency of the United States Government. Neither the United States Government nor the University of California nor any of their employees, makes any warranty, express or implied, or assumes any legal liability or responsibility for the accuracy, completeness, or usefulness of any information, apparatus, product, or process disclosed, or represents that its use would not infringe privately owned rights. Reference herein to any specific commercial product, process, or service by trade name, trademark, manufacturer, or otherwise, does not necessarily constitute or imply its endorsement, recommendation, or favoring by the United States Government or the University of California. The views and opinions of authors expressed herein do not necessarily state or reflect those of the United States Government or the University of California, and shall not be used for advertising or product endorsement purposes.

This work was performed under the auspices of the U.S. Department of Energy by University of California, Lawrence Livermore National Laboratory under Contract W-7405-Eng-48. 


\section{Performance, Thermal, and Vibration Qualification Testing of Zetec Acoustic Transducers, Model Z0002659-2, Sondicator Probes}

Testing performed

1 November 2005 through 24 January 2006

Prepared by:

Prepared by:

\section{Gerard F. Jacobson \\ 25 January 2006 \\ Engineering Technical Associate \\ Defense Sciences Engineering Division \\ Lawrence Livermore National \\ Laboratory}

Approved by:

Defense Sciences Engineering Division Lawrence Livermore National Laboratory

Steven G. Gemberling

25 January 2006

Senior Electronic Technologist ry

y

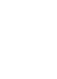




\section{Table Of Contents}

Introduction

Single Transducer Mounting Block

Multiple Transducer Mounting Block

Transducer Serial Numbers \& Organization

Transducer Performance Tester

Performance Check

Test Equipment List

Section 1 - Performance Testing

1.1 - Initial Performance Check

1.2 - 100 Turn-On/Turn-Off Cycles

Section 2 - Thermal Testing

2.1 - 100 Temperature Cycles

2.2 - 10 Temperature Shocks

Section 3 - Vibration Testing

3.1 - Short Random Vibration Test

3.1.1 - Test Setup and Procedure - Room Temperature

3.1.2 - Test Results - Room Temperature

3.1.3 - Test Setup and Procedure $-+74^{\circ} \mathrm{C}$ and $-40^{\circ} \mathrm{C}$

3.1.4 - Test Results $-+74^{\circ} \mathrm{C}$ and $-40^{\circ} \mathrm{C}$

3.2 - Mechanical Shock Test

3.2.1 - Test Setup and Procedure - Room Temperature

3.2.2 - Test Results

3.3 - Long Random Vibration Test

3.3.1 - Test Setup and Procedure - Room Temperature

3.3.2 - Test Results

3.4 - Sine Vibration Test

3.4.1 - Test Setup and Procedure - Room Temperature

3.4.2 - Test Results 
$\underline{\text { Introduction }}$

This report is a result of Qualification Test Plan \#001 prepared by Anthony Lavietes. The Qualification Test Plan outlines a list of requirements for thermal and vibrational testing of Zetac‘s Z0002659-2 Sondicator Probe acoustic transducers (hereafter called "transducers“).

The Zetec transducers are used in a system that employs an array of 7 acoustic transducers. Qualification testing of these transducers was required since they are a modified version of a standard catalog item from the manufacturer.

This report documents the thermal, vibrational, and performance testing that was performed on a sampling of these transducers in order to qualify them for flight. A total of 14 transducers were tested. All 14 passed qualification testing with no failures.

Testing was performed in Bld. 131, Rooms 2273, 2272 and 2268, at the Lawrence Livermore National Laboratory, Livermore, CA by Gerard Jacobson and Steven Gemberling.

QUALIFICATION TESTING STEPS

- Performance Check, Initial

- 100 Turn On/Turn Off Cycles

- 100 Temperature Cycles

- 10 Temperature Shocks

- Short Random Vibration Test

a. Room temperature (axial direction)

b. Room temperature (radial direction)

c. $-40^{\circ} \mathrm{C}$ (axial direction)

d. $-40^{\circ} \mathrm{C}$ (radial direction)

e. $\quad+74^{\circ} \mathrm{C}$ (axial direction)

f. $\quad+74^{\circ} \mathrm{C}$ (radial direction)

- Mechanical Shock Test

a. $50 \mathrm{G}$ 's (+axial direction)

b. 50 G's (-axial direction)

c. $50 \mathrm{G}$ 's (+radial direction)

d. $50 \mathrm{G}$ 's (-radial direction)

e. $17 \mathrm{G}$ 's (+axial direction)

f. $17 \mathrm{G}$ 's (-axial direction)

g. $17 \mathrm{G}$ 's (+radial direction)

h. $17 \mathrm{G}$ 's (-radial direction)

- Long Random Vibration Test

a. (axial direction)

b. (radial direction)

- Sine Vibration Test

a. (axial direction)

b. (radial direction) 


\section{Single Transducer Mounting Block}

The Mechanical Shock Test (Section 3 - Vibration Testing) was the only qualification test which required lightweight hardware to allow shock accelerations up to $50 \mathrm{G}$ 's. Therefore a lightweight aluminum block (Single Transducer Mounting Block) was designed which held a single transducer and permitted testing in two axis (axial and radial). The transducer was installed in the mounting block and secured in place with an aluminum cover, four \#6-32 x 1/2" sockethead cap screws, and washers. The $\mathrm{O}$ ring in the cover insured that the transducer's active tip was pressed firmly against the bottom of the bore hole in the mounting block.

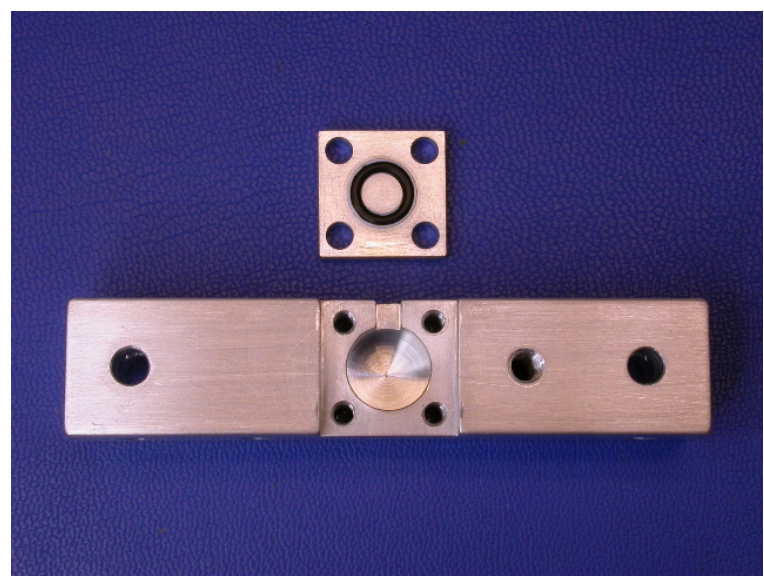

Single Transducer Mounting Block (with cover and $\mathrm{O}$ ring)

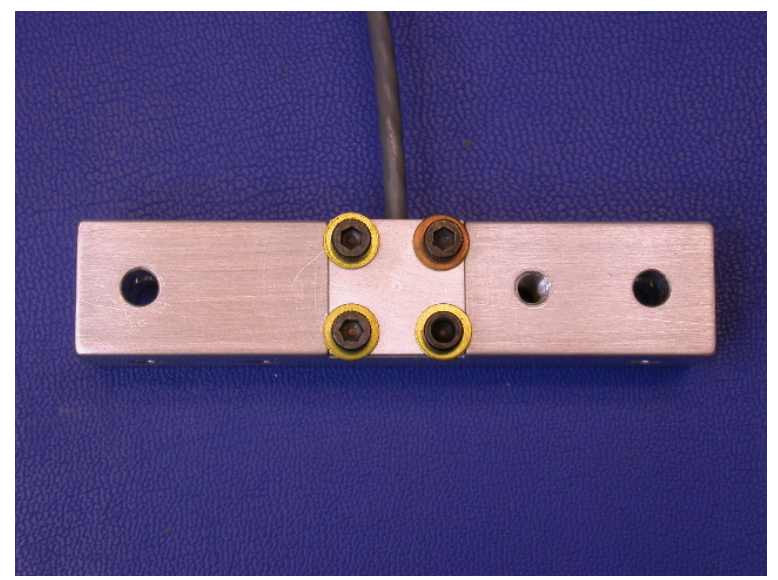

Single Transducer Mounting Block (assembled)

Multiple Transducer Mounting Block

All qualification testing (except the Mechanical Shock Test) allowed for multiple transducers to be tested at the same time. Therefore a stainless steel mounting block (Multiple Transducer Mounting Block) was designed which held seven (7) transducers and permitted testing in two axis (axial and radial). The transducers were installed in the mounting block and secured in place with a stainless steel cover, twelve \#8-32 x 3/4“ sockethead cap screws, and washers. The $\mathrm{O}$ rings in the cover insured that each transducer's active tip was pressed firmly against the bottom of the bore holes in the mounting block.

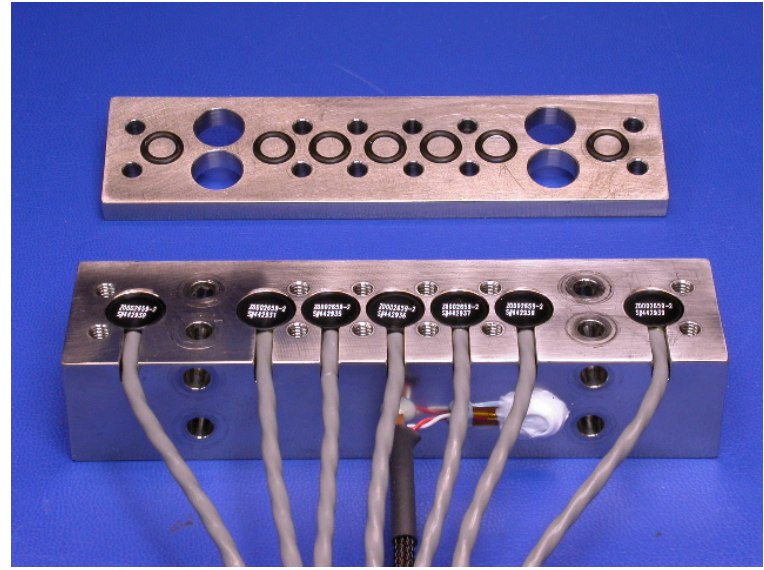

Multiple Transducer Mounting Block (with cover and $\mathrm{O}$ rings)

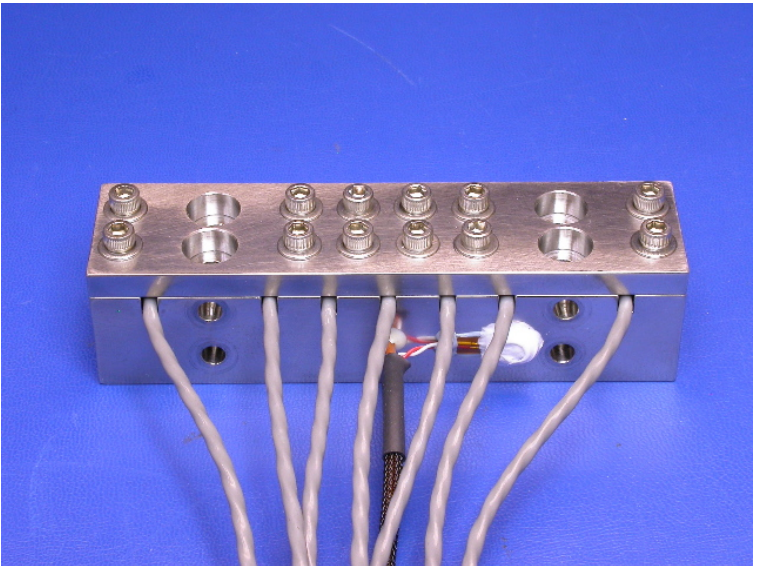

Multiple Transducer Mounting Block (assembled) 
Also, a T-type thermocouple and 1,000 ohm RTD were incorporated into each Multiple Transducer Mounting Block to provide temperature measurements.

The thermocouple, which measured internal block temperature, was glued (using thermal epoxy) into the bottom of a .300" deep hole near the center of the mounting block. The RTD, which measured surface temperature, was fastened to the surface of the block and covered with white RTV.

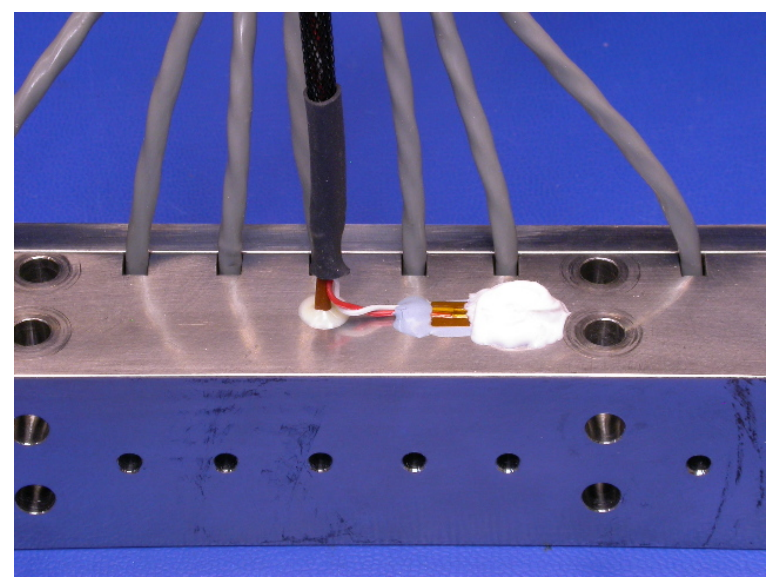

Multiple Transducer Mounting Block (showing thermocouple \& RTD)

Finally, two transducer mounting blocks (designated " $A$ “ and " $B$ ") were machined and assembled to accommedate all 14 transducers. Hereafter these blocks will be referred to as "Block A“ and "Block B“.

\section{Transducer Serial Numbers \& Organization}

Each Zetec transducer came from the manufacturer with a 6-digit serial number engraved into the back of the transducer. The 14 transducers chosen for qualification testing (out of a batch of 45 Zetec transducers) were organized in the following manner:

Transducers with these serial numbers were installed into Block A. They remained with Block $A$ and were never mixed with any of the transducers in Block B.

\section{Block A}

442930

442931

442935

442936

442937

442938

442939
Transducers with these serial numbers were installed into Block B. They remained with Block B and were never mixed with any of the transducers in Block $\mathrm{A}$.

$\underline{\text { Block B }}$

442940

442941

442945

442946

442947

442948

442949 


\section{Transducer Performance Tester}

A tester was designed so that the operation of each transducer could be quickly evaluated at the completion of each qualification test. The tester consists of the following major components:

- Transducer Mounting Block (stainless steel block, with dual retaining thumbscrews, stainless steel cover, and O ring compression)

- Acoustic emissions detector (Kistler AE-Piezotron Acoustic Emission Sensor, Type 8152B121, SN 2031248)

- Signal conditioning electronics (Kistler AE-Piezotron Acoustic Emission Coupler, Type 5125B, SN 2031670)

The heart of the tester is the Transducer Mounting Block. This block holds the transducer and Kistler acoustic emissions detector roughly opposite each other. The active tip of the transducer is pressed firmly against the bottom of the bore hole in the Transducer Mounting Block by the relatively constant pressure of an $\mathrm{O}$ ring mounted into the cover.

The leads of the transducer were connected to a $100 \mathrm{KHz} 5 \mathrm{Vpp}$ sinewave excitation source. If the transducer was operating properly, the acoustic energy generated by the transducer is transferred into the Transducer Mounting Block and picked up the the Kistler acoustic emissions detector. After some signal conditioning, the resultant waveform is available for outputting to a scope.

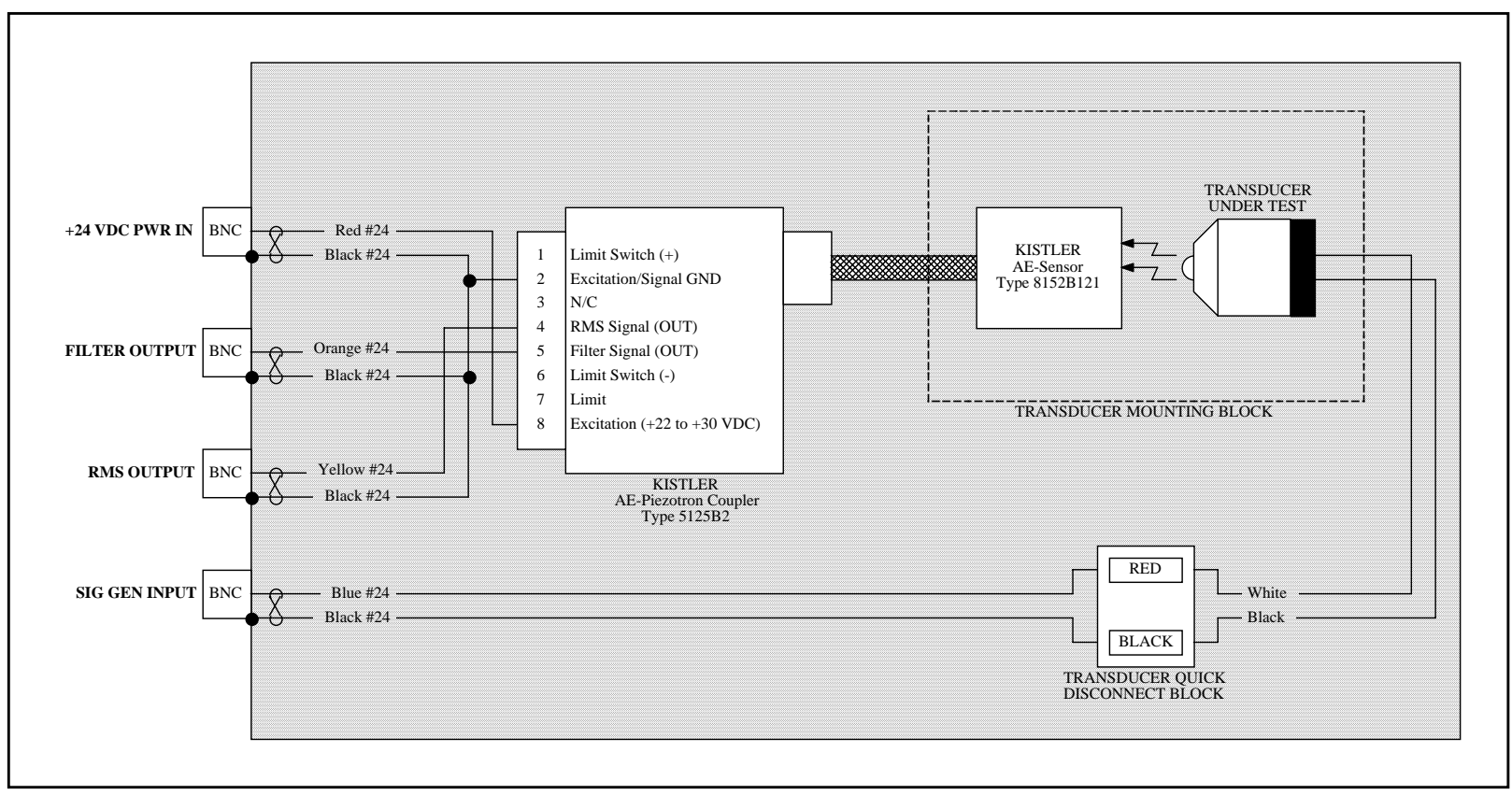

Transducer Performance Tester schematic 


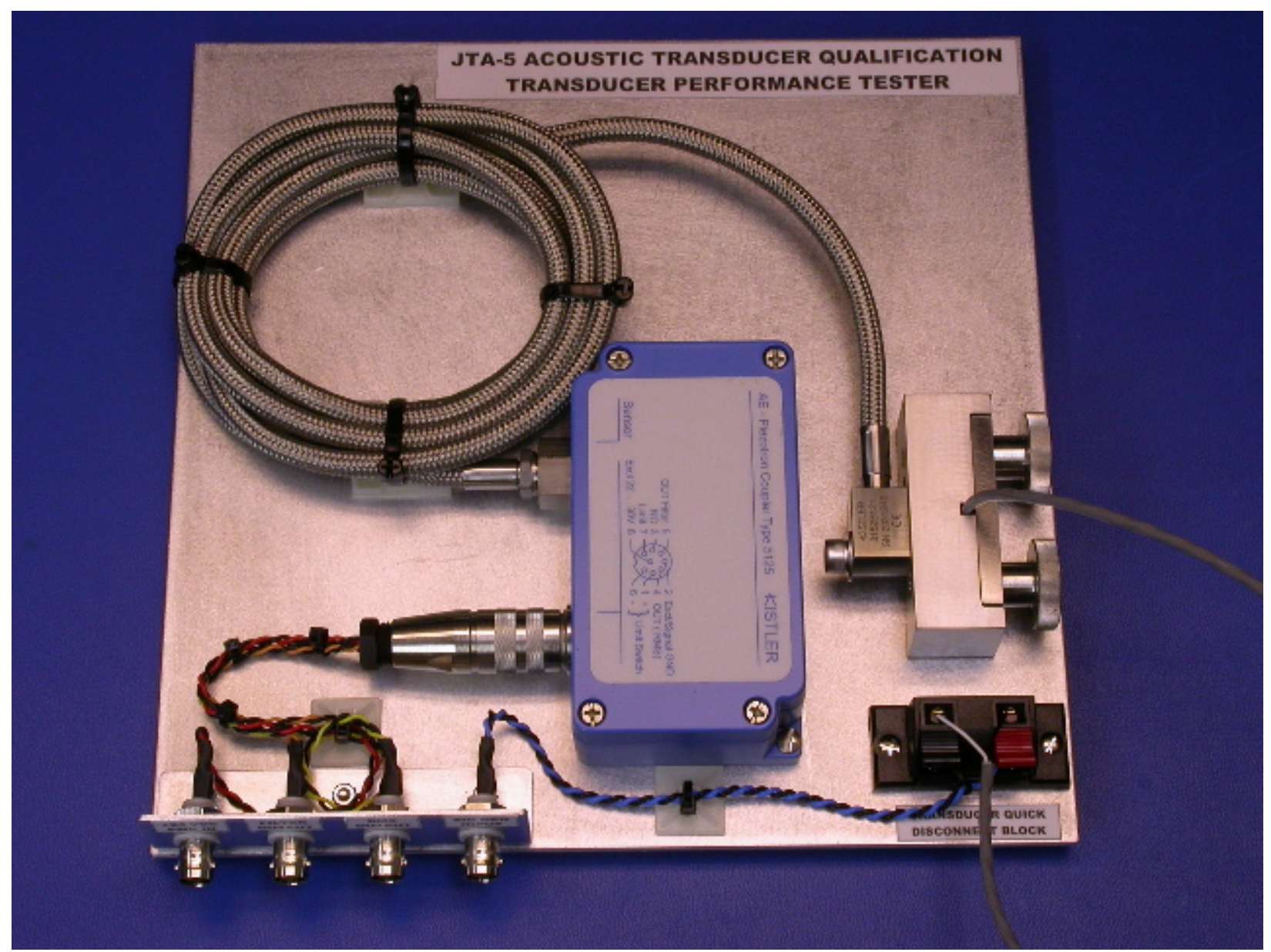

Transducer Performance Tester

(showing transducer mounted and ready for test)

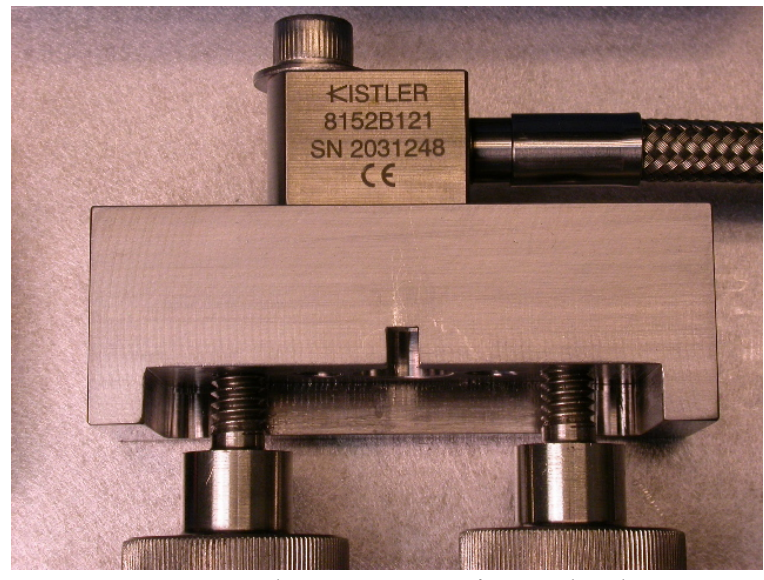

Transducer Mounting Block (showing thumb screws \& Kistler acoustic emissions sensor)
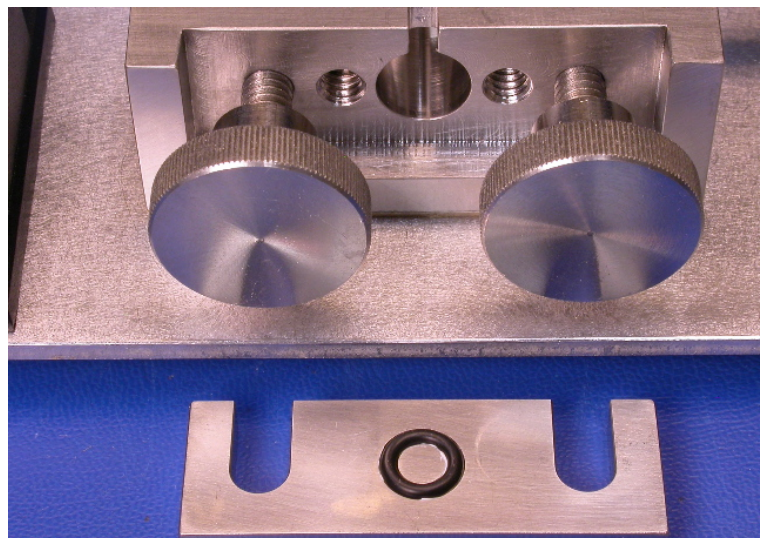

Transducer Mounting Block (showing dual thumbscrews, cover plate, and $\mathrm{O}$ ring location) 


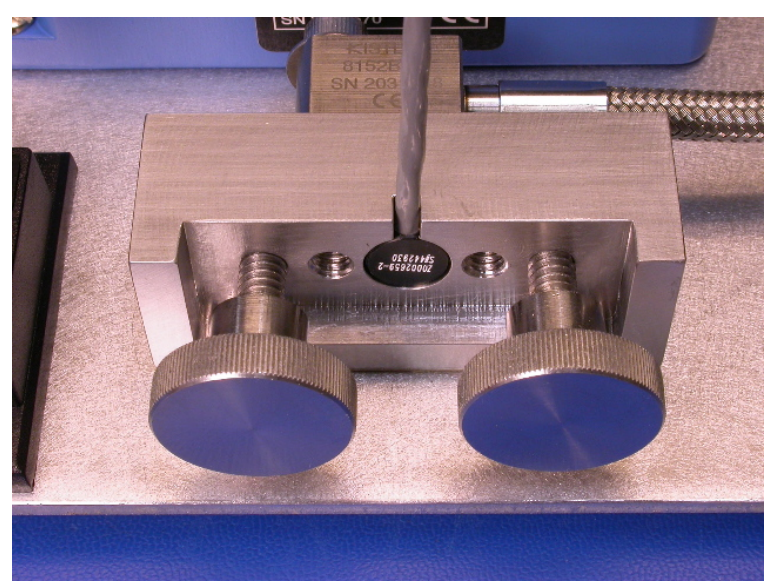

Transducer Mounting Block

(showing transducer inserted into block)

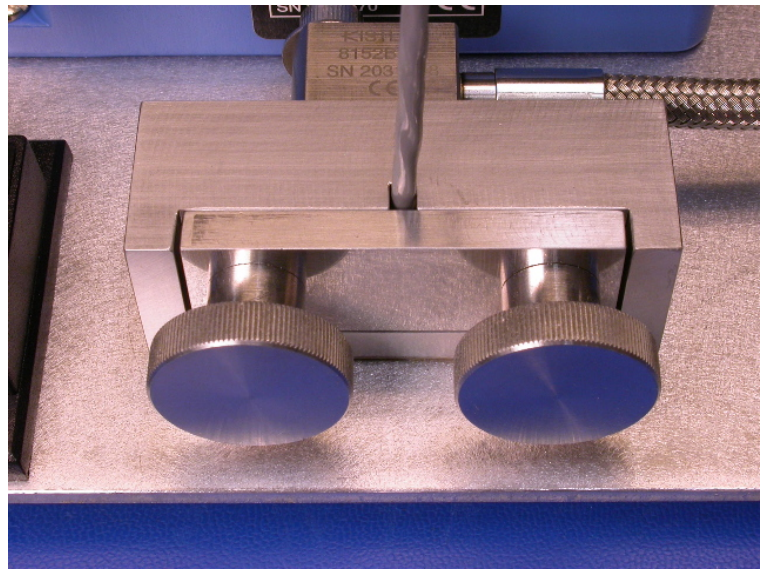

Transducer Mounting Block (showing complete assembly)

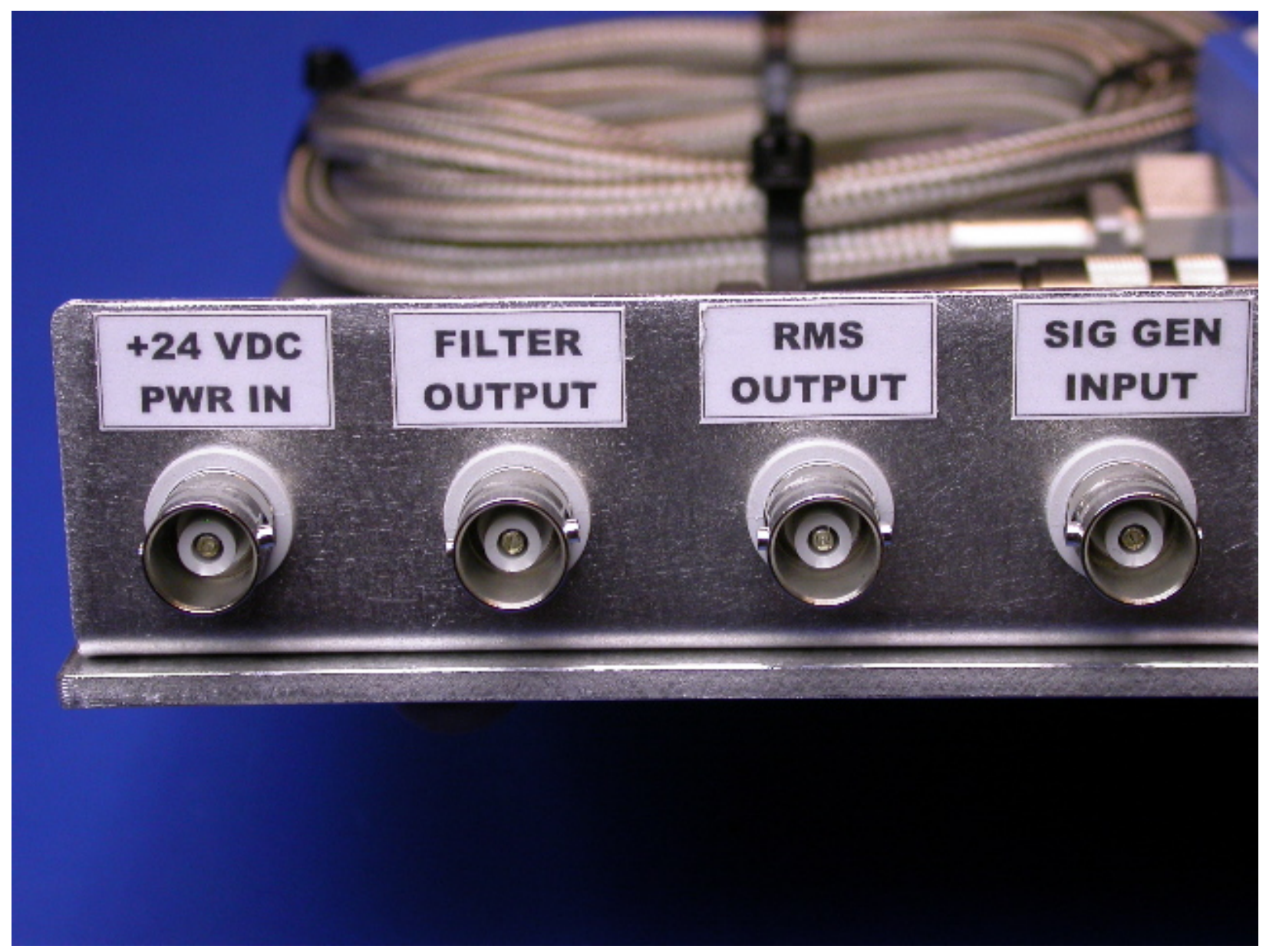

Transducer Performance Tester

(showing I/O connections) 


\section{Performance Check}

To verify and document the functionality of each transducer, and to identify any potential failure modes associated with the Zetec transducers, a performance check was done at the completion of every qualification test.

A performance check involved placing each transducer into the Transducer Performance Tester and energizing the transducer with a $100 \mathrm{KHz} 5 \mathrm{Vpp}$ sinewave signal. An oscilloscope was used to view the $100 \mathrm{KHz} 5 \mathrm{Vpp}$ sinewave signal and the output from the Transducer Performance Tester. If the amplitude of the transducer's output was greater than $1 \mathrm{Vpp}$, it "passed" the performance test.

Since the oscilloscope was able to save a snapshot of the display in TIFF format, snapshots were taken of all 14 transducers. These snapshots were later downloaded to a computer and archived.

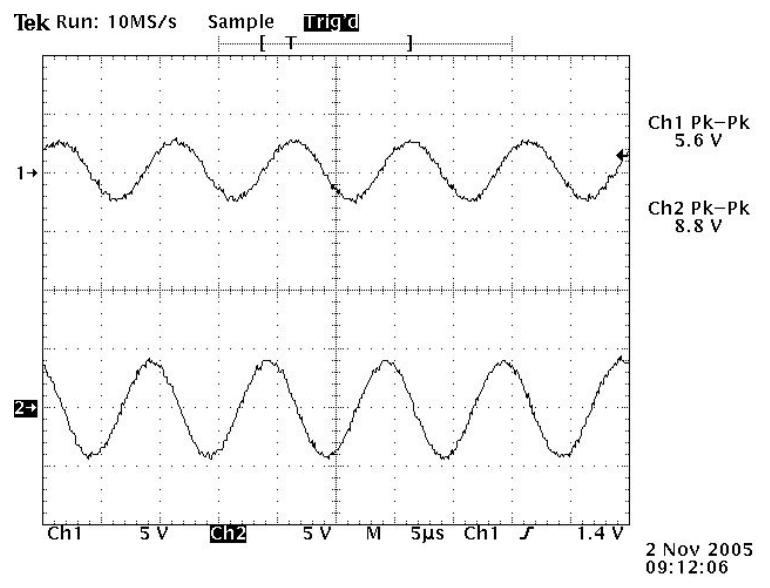

Sample picture of a performance check, showing the $100 \mathrm{KHz} 5 \mathrm{Vpp}$ sinewave excitation waveform at the top (Ch 1 ) and the Transducer Performance Tester's output waveform at the bottom (Ch 2).

Notice the measurement values on the right hand side of the display. The oscilloscope was setup to measure and display the peak-to-peak values of Ch 1 and Ch 2 .

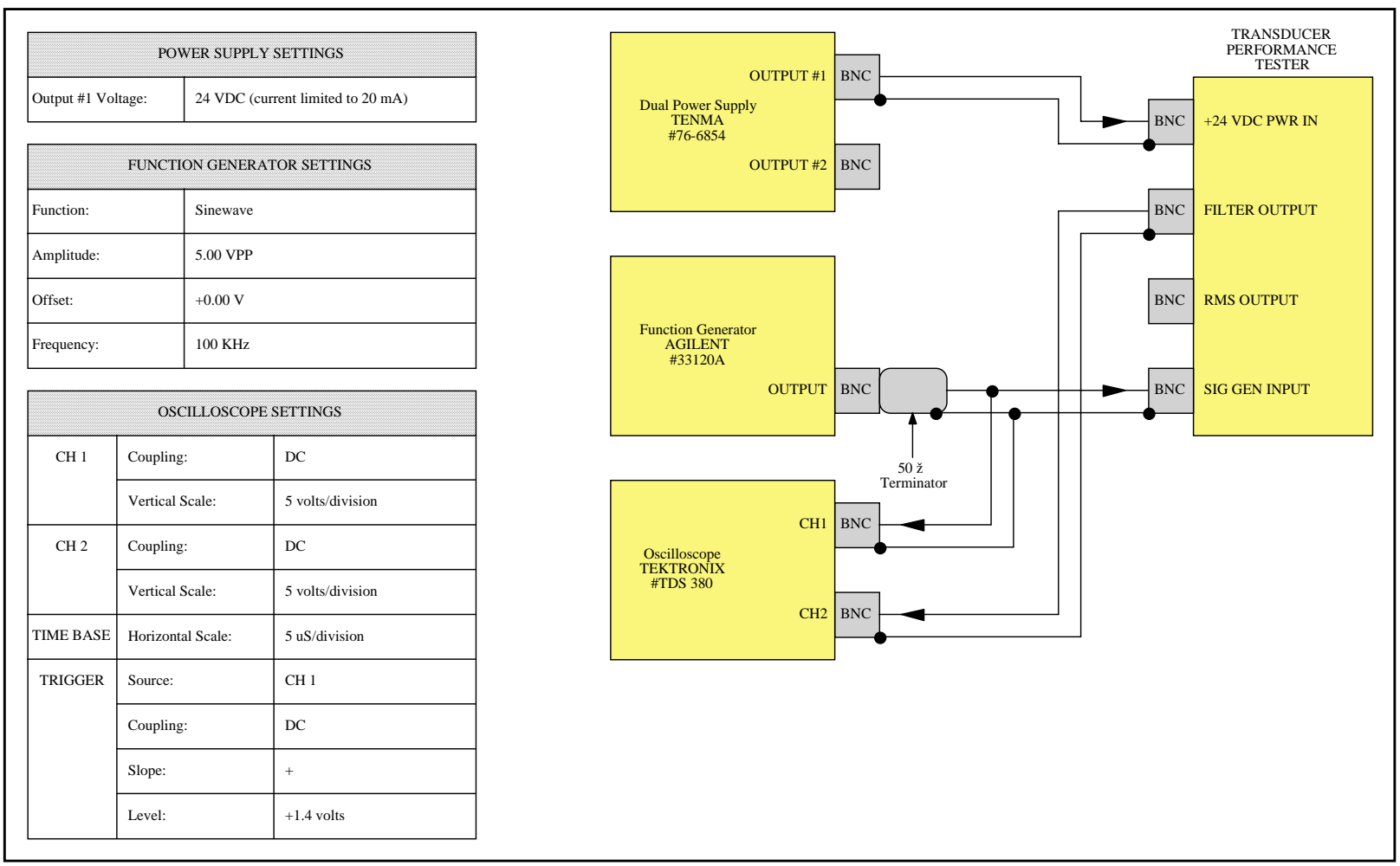

Block diagram of Performance Check setup 


\section{Test Equipment List}

The following list of equipment was employed during qualification testing:

- $\quad$ Single Transducer Mounting Block.

- $\quad$ Multiple Transducer Mounting Blocks "A“ and "B“.

- Kistler AE-Piezotron Acoustic Emission Sensor, Type 8152B121, SN 2031248, Calibration Date - None.

- Kistler AE-Piezotron Acoustic Emission Coupler, Type 5125B, SN 2031670, Calibration Date - None.

- $\quad$ Tektronix Oscilloscope, Model TDS 380, SN B017087, Calibration Date - 15 March 2000.

- Agilent Function Generator, Model 33120A, SN MY40000962, Calibration Date - None.

- Tenma Power Supply, Model 76-6854, SN 207214, Calibration Date -None.

- Thermotron Environmental Chamber, Model S-1.2V, SN 20330-S, DOE \#6859983, Calibration Date - 16 September 2005.

- Tenny Envirnomental Chamber, Model TU-JR, SN 20763-11, Calibration Date - 15 September 2005.

- Agilent Data Acquistion/Switch unit, Model 34970A, SN MY44002670, Calibration Date 15 February 2005.

- Agilent 20 Channel Multiplexer module, Model 34901A, SN MY41038419, Calibration Date - 07 March 2005.

- Agilent 20 Channel Multiplexer module, Model 34901A, SN MY41038424, Calibration Date - 07 March 2005.

- LabWorks Inc. Electro-Dynamic Vibration System, Model LW-140-110, with computer control, Calibration Date - 18 November 2005.

- $\quad$ PC, Dell Optiplex GX260, SN 7RVYT221, DOE \# 6902955 with custom LabView VI for Thermotron Environmental Chamber control and data acquistion.

- $\quad$ GPIB board, PCI-GPIB IEEE 488.2, National Instruments, plugged into Dell Optiplex

- DAQ board, PCI-6035E, National Instruments, plugged into Dell Optiplex

- DAQ input/output connector block, CB-68LP, National Instruments

- $\quad$ Software, LabView 7.1, National Instruments, used on Dell Optiplex 


\section{SECTION 1 - PERFORMANCE TESTING}

\section{1 - Initial Performance Check}

Before any qualification testing began, an initial performance check was done to verify and document the functionality of each of the 14 Zetec transducers as they came fresh out of the box. This first performance check provided a baseline with which to determine any amount of degradation or failure that might occur during subsequent qualification testing.

All 14 transducers passed this initial performance check. The oscilloscope snapshots were saved to computer and archived. To eliminate space in this report, none of these snapshots are shown. All snapshots, however, are available for inspection upon request.

\section{2 - 100 Turn-On/Turn-Off Cycles}

This part of the qualification testing required that each transducer be energized for 30 seconds and then de-energized for 30 seconds. This was done a total of 100 times. A $100 \mathrm{KHz} 5 \mathrm{Vpp}$ sinewave was used as the excitation source. Because of the high input impedance of each transducer, all seven transducers in Block A were wired in parallel (using a terminal barrier strip) so that they could be energized/de-energized together 100 times (Figure 1.2.1 and Figure 1.2.2). Afterwards the seven transducers in Block B were wired together and energized/de-energized 100 times. See Figure 1.2.3 for a block diagram of the test setup.

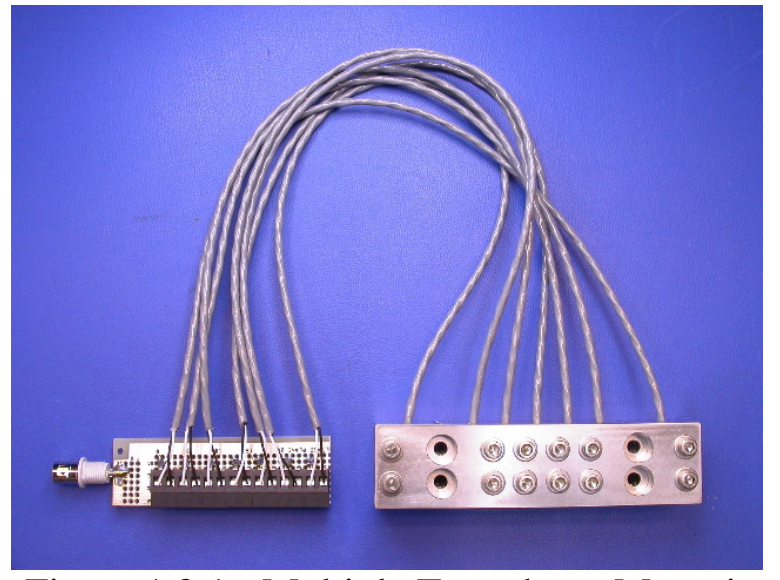

Figure 1.2.1 - Multiple Transducer Mounting Block (connected to terminal barrier strip)

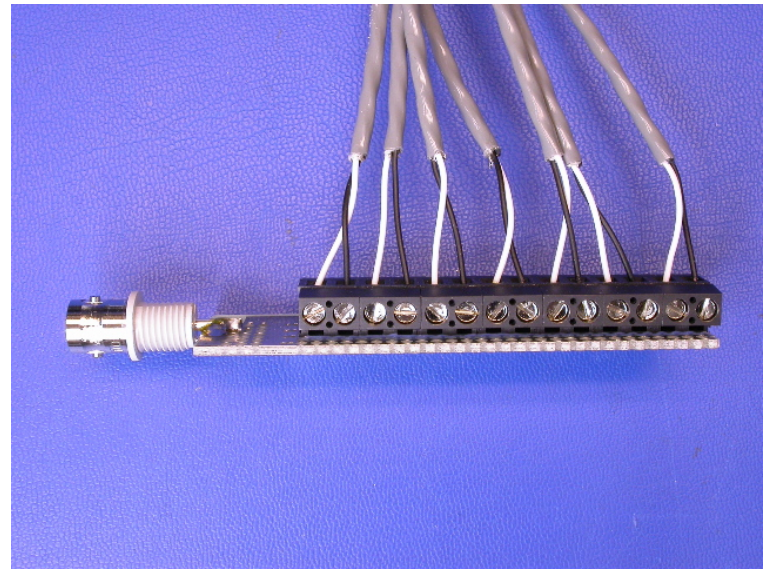

Figure 1.2.2 - Terminal barrier strip (allows common connection of all transducers)

A LabView program was written for this qualification test. The LabView vi configured a function generator to provided the $100 \mathrm{KHz} 5 \mathrm{Vpp}$ sinewave excitation source for the transducers. The LabView vi also controlled the function generator's output with a digital I/O port on a National Instruments DAQ card. Finally, the LabView vi recorded each turn-on/turn-off cycle. An oscilloscope was used to verify that the transducers were actually energized for 30 seconds and de-energized for 30 seconds.

At the completion of the 100 Turn On/Turn Off Cycles test, a performance check was done. All 14 transducers passed. The oscilloscope snapshots were saved to computer and archived. To eliminate space in this report, none of these snapshots are shown. However, all snapshots are available for inspection upon request. 


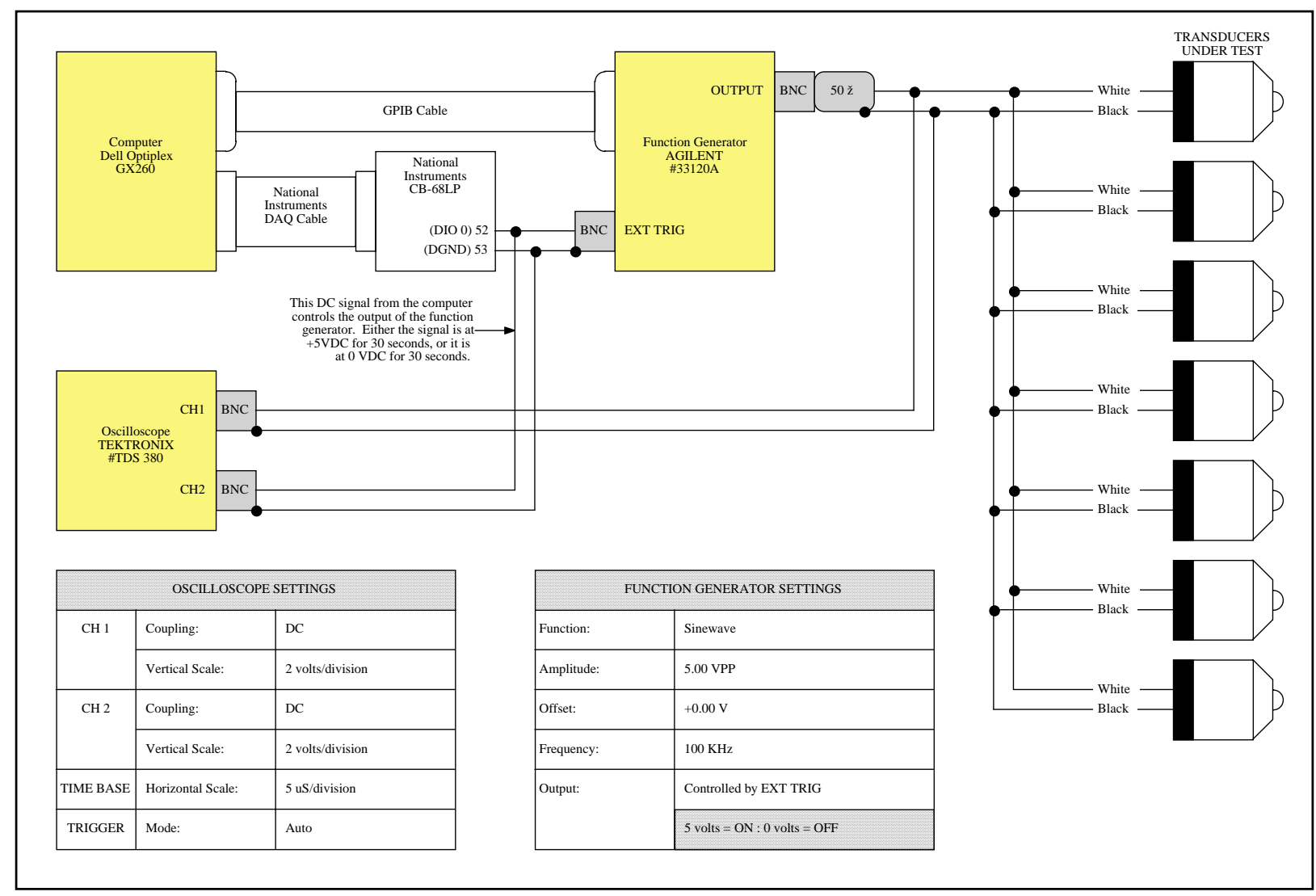

Figure 1.2.3 - Block diagram and schematic of 100 Turn-On/Turn-Off Cycle test

\section{SECTION 2 - THERMAL TESTING}

\section{1 - 100 Temperature Cycles}

This part of the qualification testing required that each transducer be cycled between $-40^{\circ} \mathrm{C}$ and $+74^{\circ} \mathrm{C}$ a total of 100 times (Figure 2.1.1). Since it was possible to test all 14 transducers at the same time, Block A and Block B were placed into an environmental chamber and tested together (Figure 2.1.2). The temperature ramp up/down time was 60 minutes and the hold time at each temperature extreme was 60 minutes. See Figure 2.1.3 for a block diagram of the test setup.

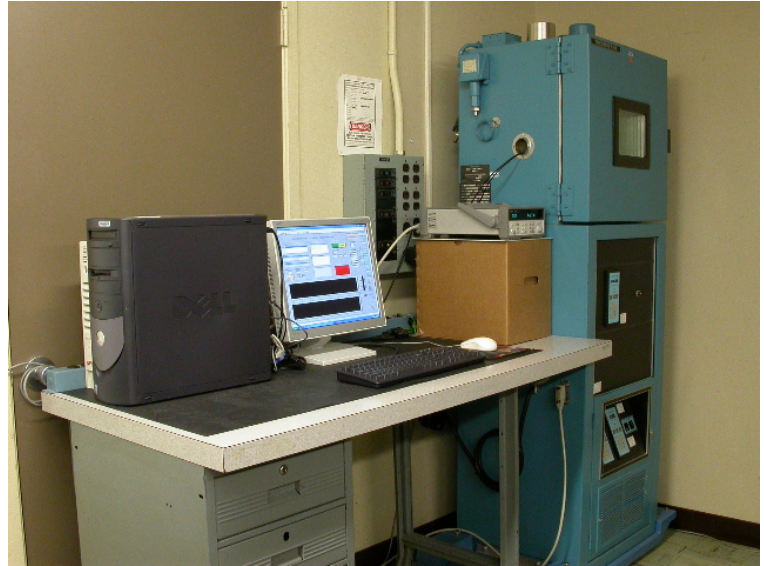

Figure 2.1.1 - Thermotron, Dell computer, and Agilent 34970A (sitting on box)

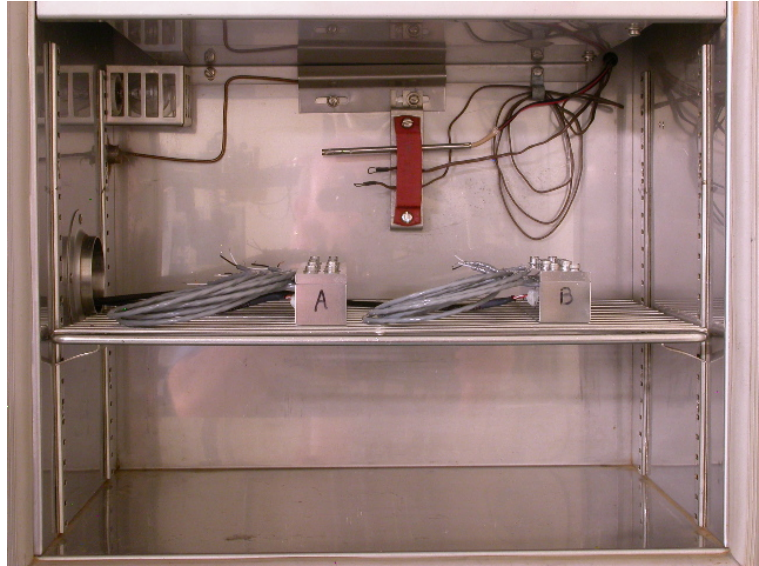

Figure 2.1.2 - Inside view of Thermotron chamber (Block A and Block B are ready for testing) 


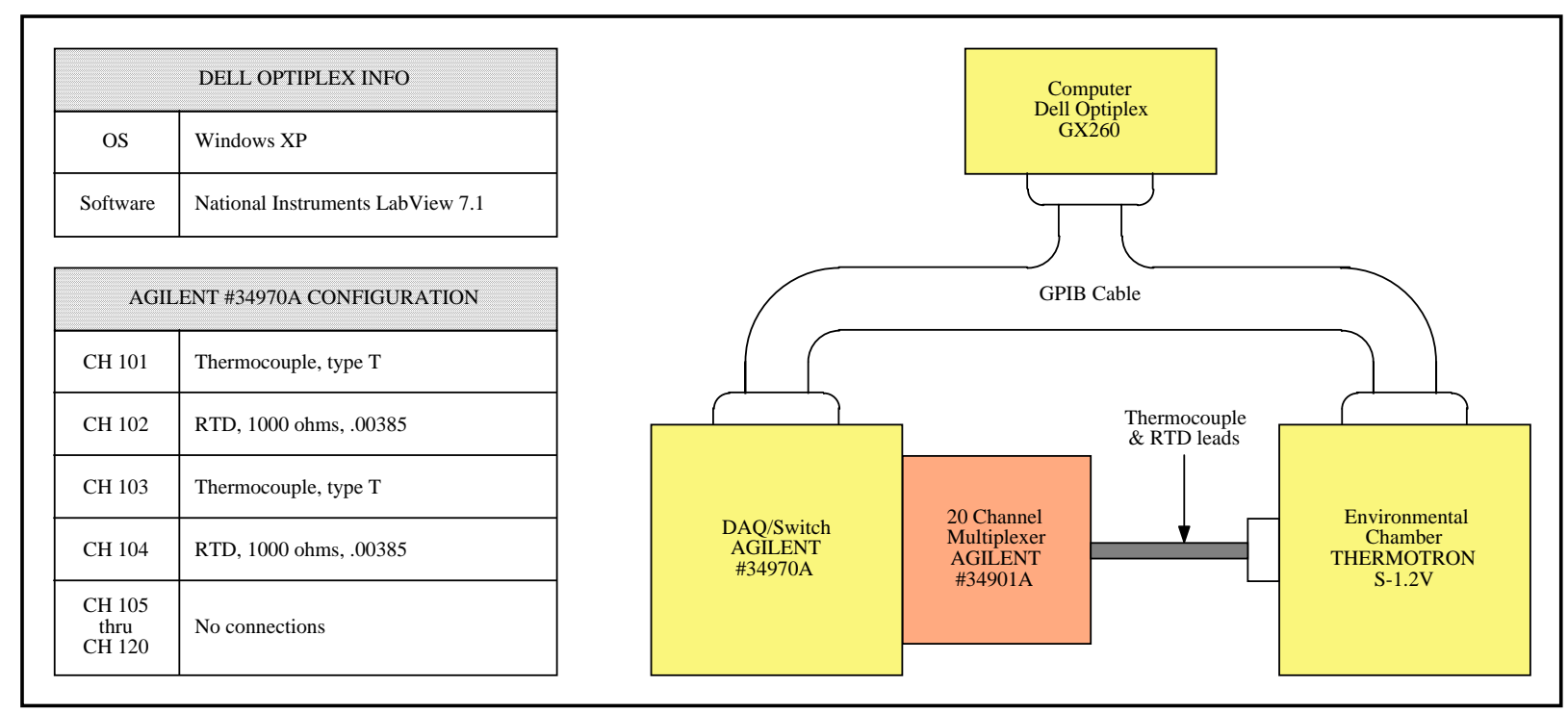

Figure 2.1.3 - 100 Temperature Cycles test setup

Communications between the Dell computer, Thermotron, and Agilent 34970A were over an IEEE 488.2 GPIB bus. A LabView vi was written that controlled the Thermotron and Agilent 34970A. The LabView vi also collected temperature data from the Thermotron and Agilent 34970A. This temperature data was written and saved to file (see Figures 2.1.4 and Figure 2.1.5).

Notice in Figure 2.1.5 that Block A's internal temperature (shown by the red line) and Block B's internal temperature (shown by the green line) follow nearly identical paths.

At the completion of the 100 Temperature Cycles test, a performance check was done. All 14 transducers passed. The oscilloscope snapshots were saved to computer and archived. To eliminate space in this report, none of these snapshots are shown. However, all snapshots are available for inspection upon request. 


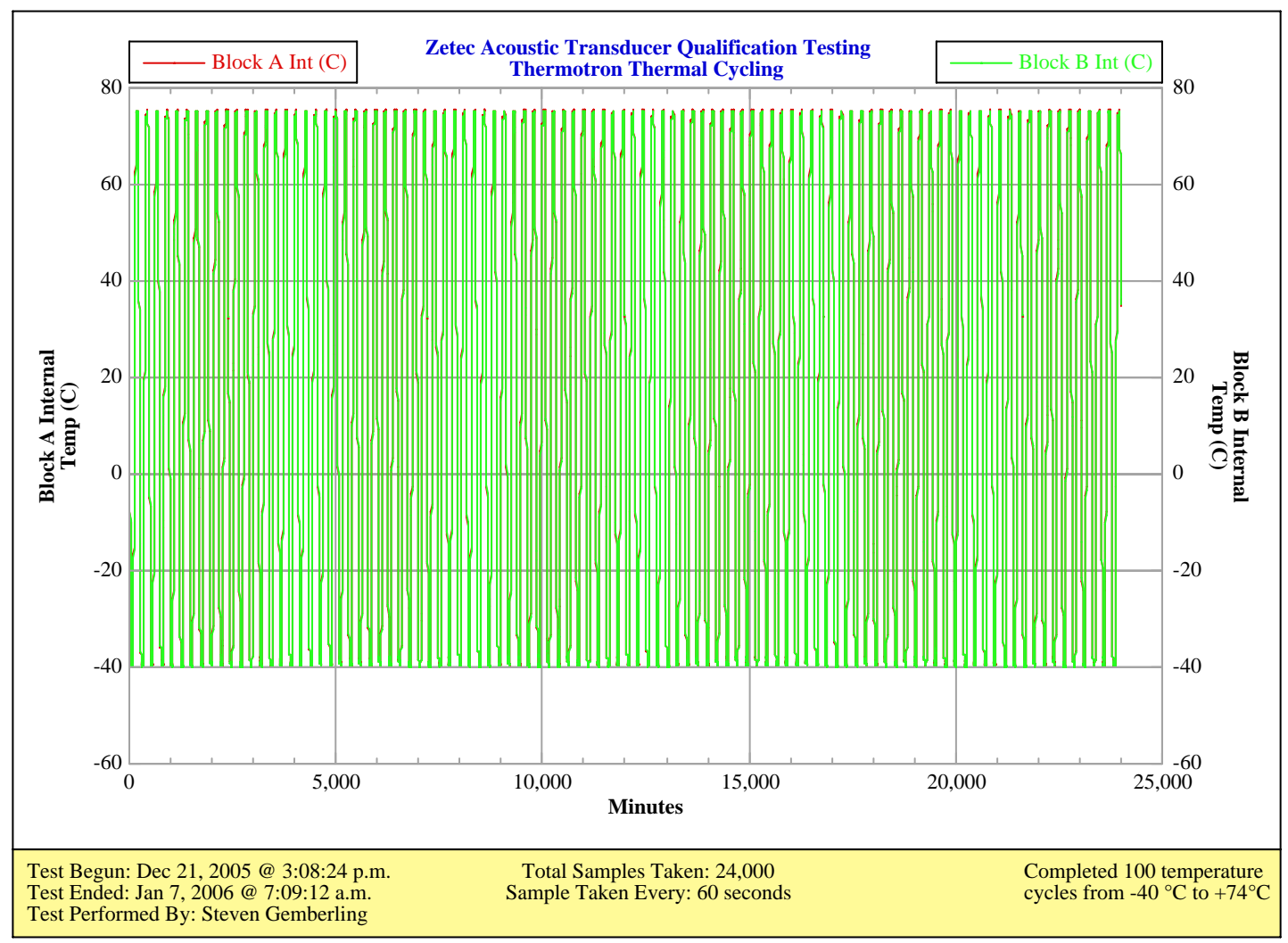

Figure 2.1.4 - Complete temperature profile from the 100 Temperature Cycles test

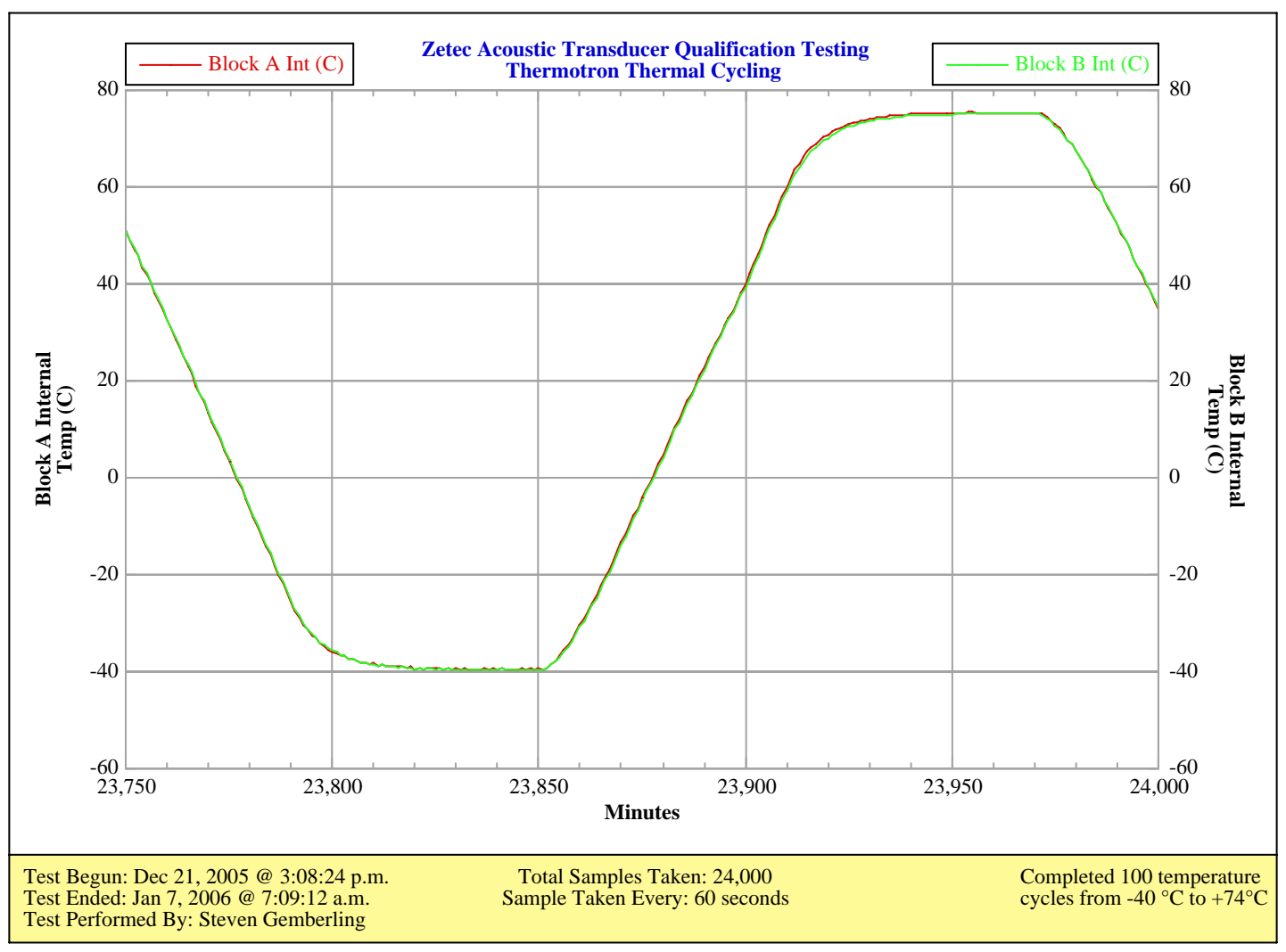

Figure 2.1.5 - Temperature profile from the 100 Temperature Cycles test (expanded to show 1 cycle) 


\section{2 - 10 Temperature Shocks}

This part of the qualification testing required that each transducer be exposed to rapid changes in temperature from $-40^{\circ} \mathrm{C}$ to $+74^{\circ} \mathrm{C}$ and from $+74^{\circ} \mathrm{C}$ to $-40^{\circ} \mathrm{C}$. The temperature was stabilized at $-40^{\circ} \mathrm{C}$ for 60 minutes and then ramped as fast as possible (limited by the capabilities of the thermal chamber) to $+74^{\circ} \mathrm{C}$. After a stabilization period of 60 minutes at $+74^{\circ} \mathrm{C}$, the chamber was rapidly ramped back to $-40^{\circ} \mathrm{C}$. This cycle was repeated 10 times. Since it was possible to test all 14 transducers at the same time, Block A and Block B were placed into an environmental chamber and temperature cycled together. See Figure 2.2.1 for a block diagram of the test setup.

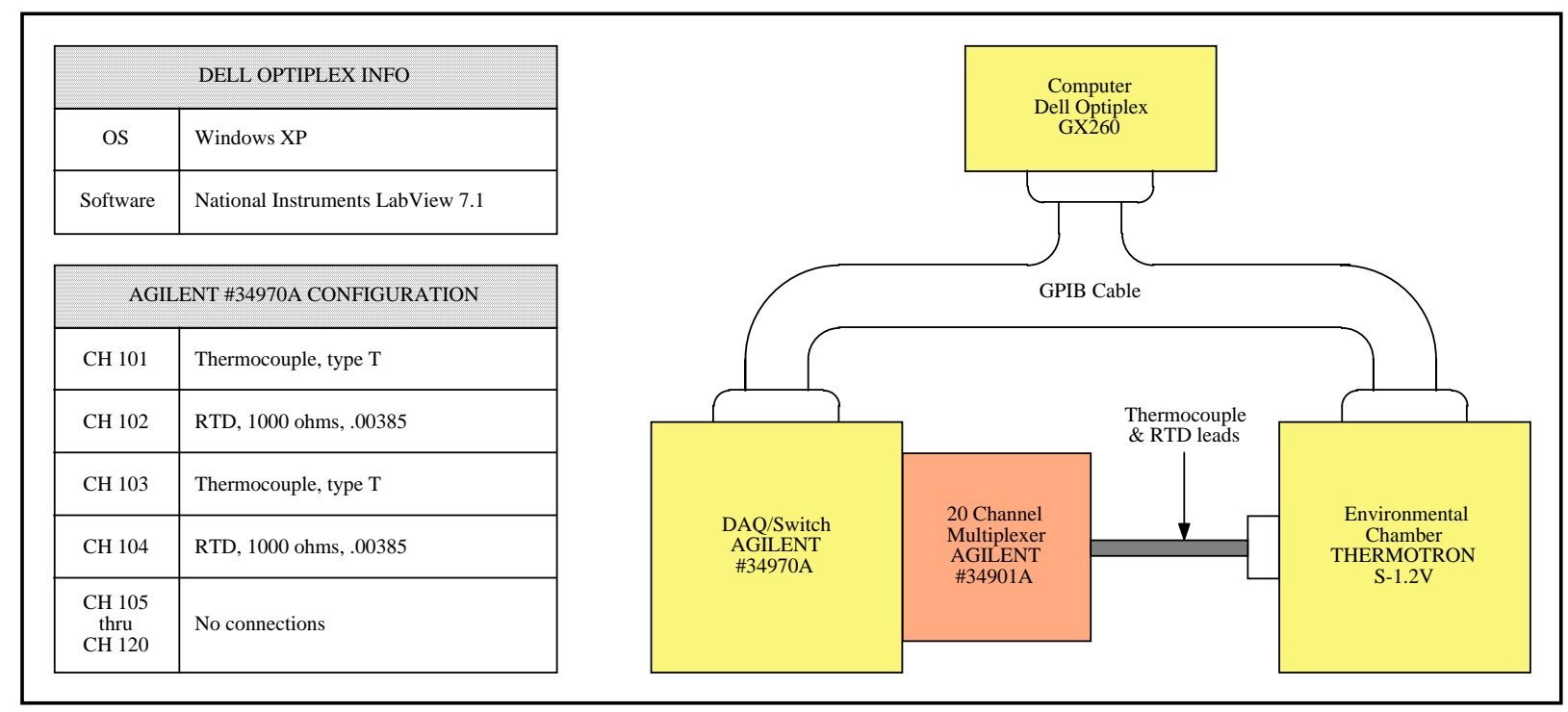

Figure 2.2.1 - 10 Temperature Shocks test setup

Communications between the Dell computer, Thermotron, and Agilent 34970A were over an IEEE 488.2 GPIB bus. A LabView vi was written that controlled the Thermotron and Agilent 34970A. The LabView vi also collected temperature data from the Thermotron and Agilent 34970A. This temperature data was written and saved to file (see Figures 2.2.2 and Figure 2.2.3).

Notice in Figure 2.2.3 that Block A's internal temperature (shown by the red line) and Block B's internal temperature (shown by the green line) follow nearly identical paths.

At the completion of the 10 Temperature Shocks test, a performance check was done. All 14 transducers passed. The oscilloscope snapshots were saved to computer and archived. To eliminate space in this report, none of these snapshots are shown. However, all snapshots are available for inspection upon request. 


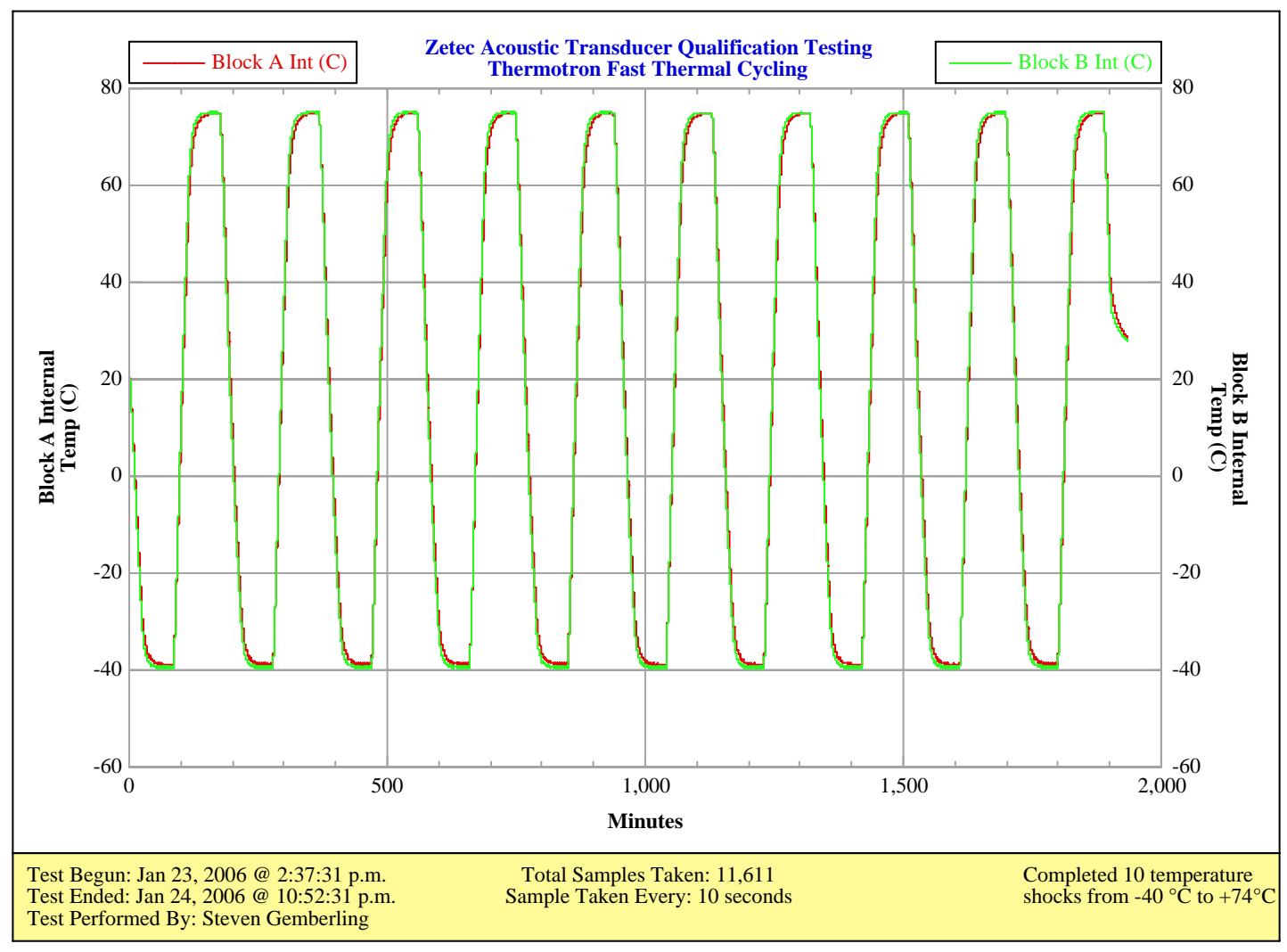

Figure 2.2.2 - Complete temperature profile from the 10 Temperature Shocks test

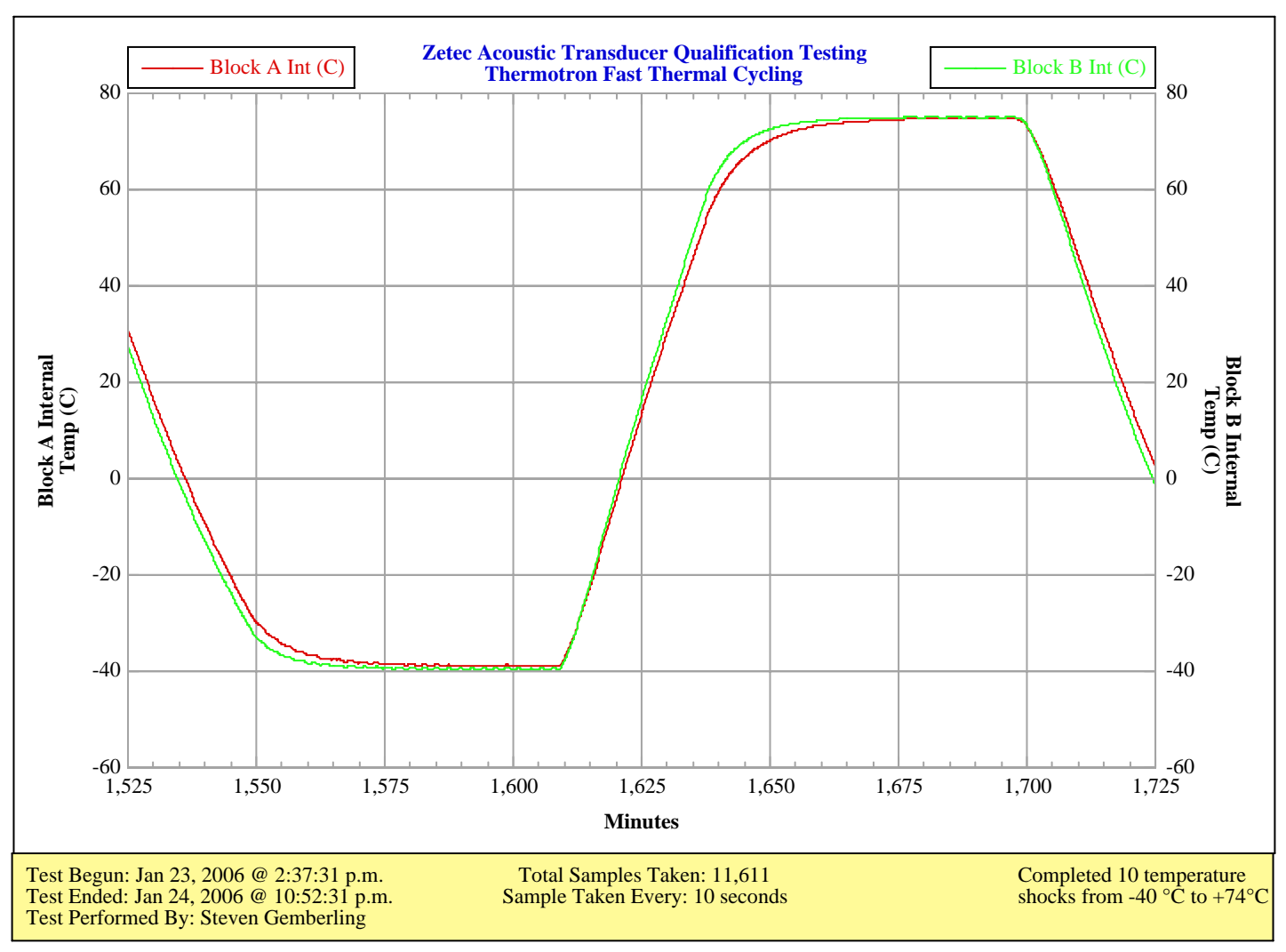

Figure 2.2.3 - Temperature profile from the 10 Temperature Shocks test (expanded to show 1 cycle) 


\section{SECTION 3 - VIBRATION TESTING}

\section{1 - Short Random Vibration Test}

This part of the qualification testing consisted of short random vibration tests of the tranducers in Block A and Block B, in the axial and radial axis, with a test duration of 10 minutes in each axis. The test was repeated at three temperature ranges: room temperature, $+74^{\circ} \mathrm{C}$ and $-40^{\circ} \mathrm{C}$.

The test spectrum used for the short random vibration qualification test is shown in Figure 3.1.1. The spectrum is defined from $10 \mathrm{~Hz}$ to $2 \mathrm{kHz}$ with a $9.17 \mathrm{~g}_{\text {rms }}$ magnitude. The spectrum was reduced from the test plan, $10 \mathrm{~Hz}$ to $3 \mathrm{kHz}$ with a $10.37 \mathrm{~g}$ rms magnitude, due to frequency limitations of the shaker system that was used for testing.

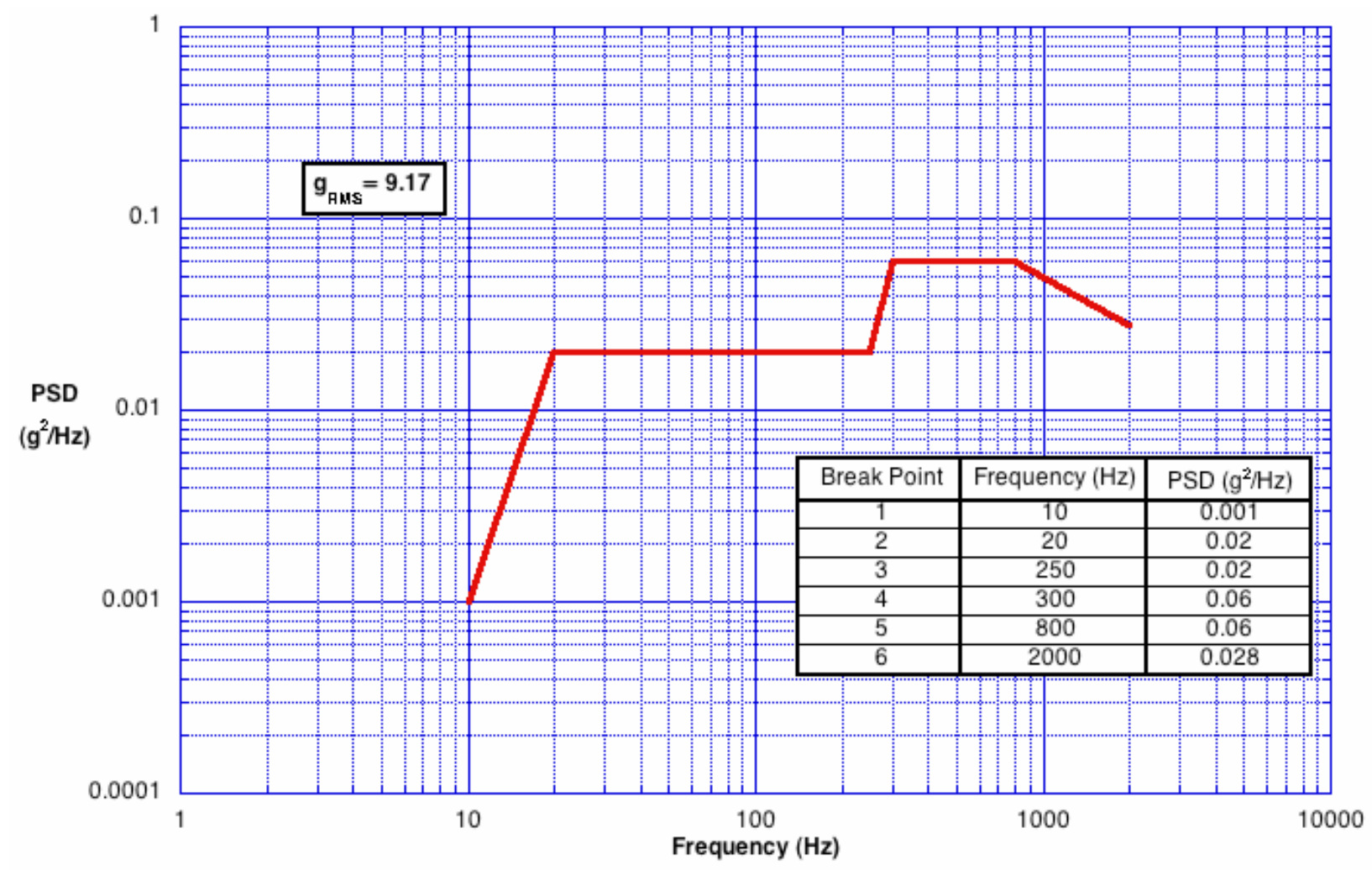

Figure 3.1.1 - Short Random Vibration Qualification Test Spectrum

\subsection{1 - Test Setup and Procedure - Room Temperature}

An aluminum adaptor ring was attached to top of the shaker head using four \#10-32 x 1" sockethead cap screws with washers. This adapter ring was designed to hold the Multiple Transducer Mounting Block under test. To reduce any thermal conduction between the Multiple Transducer Mounting Block and the aluminum adapter ring, a 5“ x 1.25“ x 0.125“ piece of G-10 fiberglass board was sandwiched between them (i.e. thermal insulator).

A Kistler accelerometer, type 8636B50M05, S/N C196770, was attached at the center position of the shaker mounting plate of the shaker head for use as the reference/control accelerometer. A second Kistler accelerometer, type 8636B50M05, S/N C196961, was attached to the top horizontal surface of the adaptor ring to measure the response of the ring and Multiple Transducer Mounting Block (Figure 3.1.1.1). 


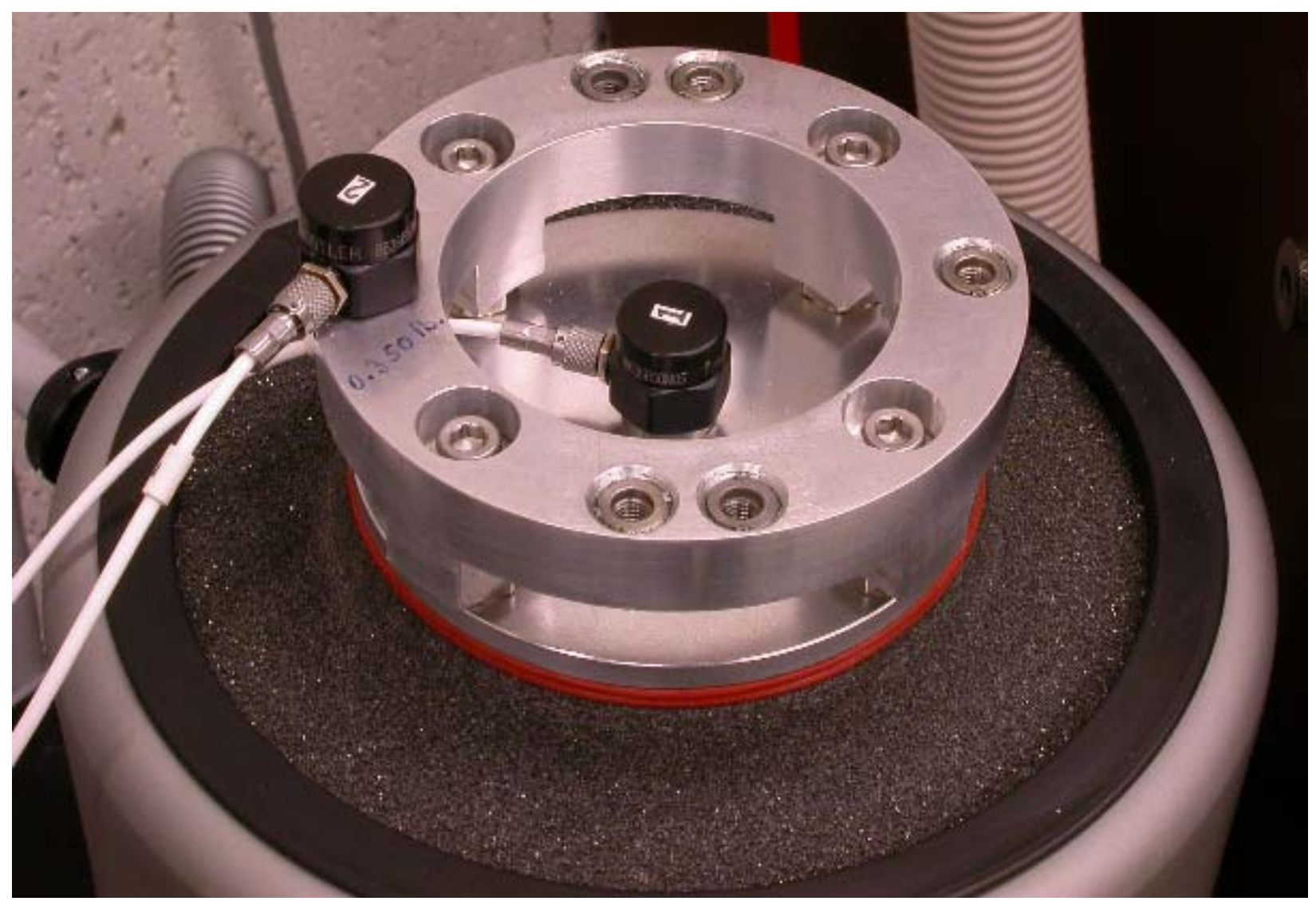

Figure 3.1.1.1 - Accelerometers and adaptor ring

Control of the shaker is accomplished via a pc-based vibration test controller running VibeLab Pro Digital Sine, Random, and Shock Vibration software.

Seven transducers were mounted in the " $A$ " designated Multiple Transducer Mounting Block (Figures 3.1.1.2 and 3.1.1.3). The other seven transducers were mounted into the " $\mathrm{B}$ " designated Multiple Transducer Mounting Block. Note the T-type thermocouple used to measure the internal block temperature (block center) and the 1,000 ohm RTD used to measure the suface temperature of the block (white RTV, right of center).

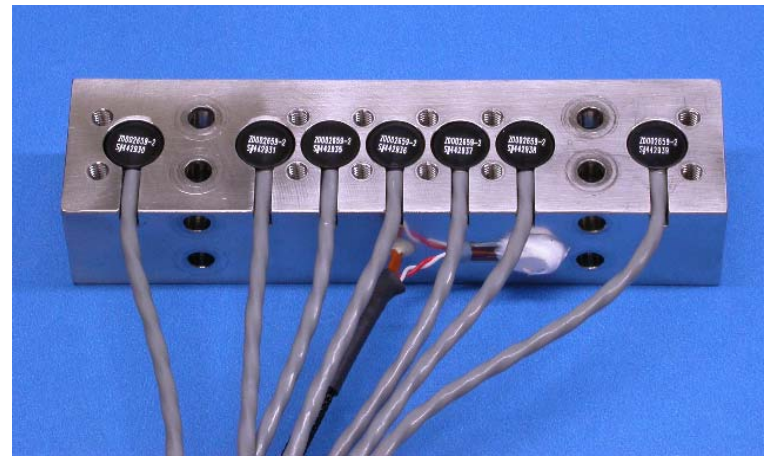

Figure 3.1.1.2 - Transducers and base

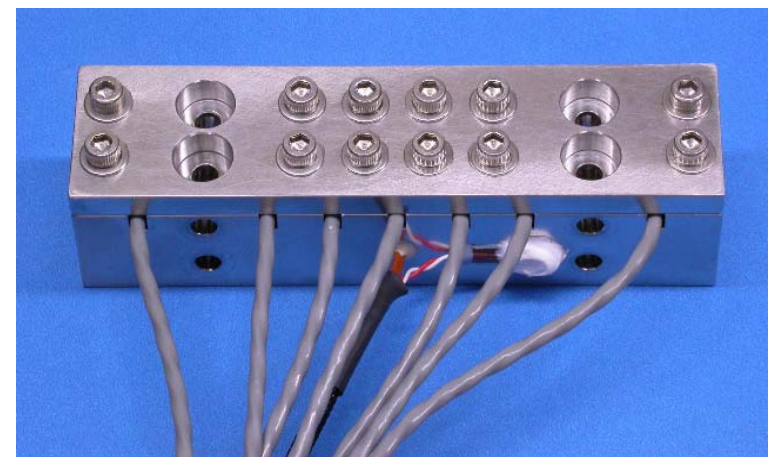

Figure 3.1.1.3 - Completed assembly 
Figure 3.1.1.4 shows a loaded Multiple Transducer Mounting Block attached to the shaker in the axial direction and the cable mounting/relief fixture. For the radial direction, the block is rotated $90^{\circ}$ counter-clockwise.

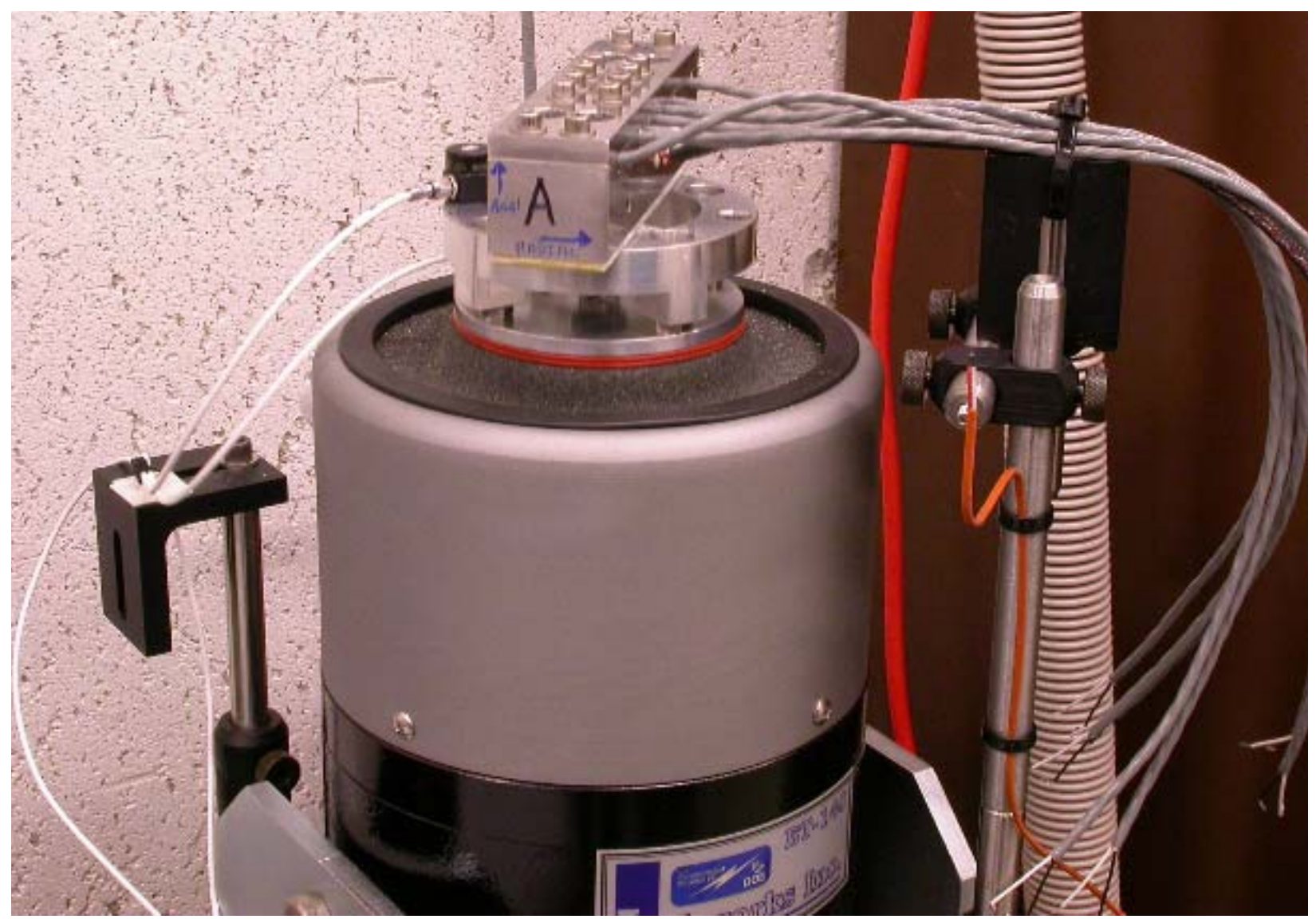

Figure 3.1.1.4 - Multiple Transducer Mounting Block mounted on shaker

Temperature data was captured using an Agilent 34970A Data Acquistion/Switch unit in conjunction with an Agilent 34901A 20 Channel Multiplexer module (Figure 3.1.1.5). The 34970A was configured with four active channels and a scan rate of 1 second:

\begin{tabular}{|c|c|}
\hline Channel & Configured For \\
\hline$\overline{\mathrm{CH}} 101$ & Temperature \\
\hline CH 102 & Temperature \\
\hline CH 103 & VDC \\
\hline CH 104 & Temperature \\
\hline
\end{tabular}

\author{
Description \\ Multiple Transducer Mounting Block internal temperature \\ Multiple Transducer Mounting Block external temperature \\ Event marker \\ Ambient air temperature
}

Temperature data was captured and logged for 30 seconds before the start of the vibration test. An external 9 volt DC signal was manually applied to channel 103 when the shaker was at full power as a start-event marker. The external 9 volts DC signal was removed at the end of the test.

The VibeLab software was set to the test position with a programmed 10 minute run time (Figure 3.1.1.6). The system performed a pretest at $6 \mathrm{~dB}$ below the desired amplitude. When the software determined that the desired spectrum was being achieved, the amplitude was raised to the test level and maintained for the programmed time. The vibration system and the Multiple Transducer Mounting Block were continuously monitored for the 10 minute test. 


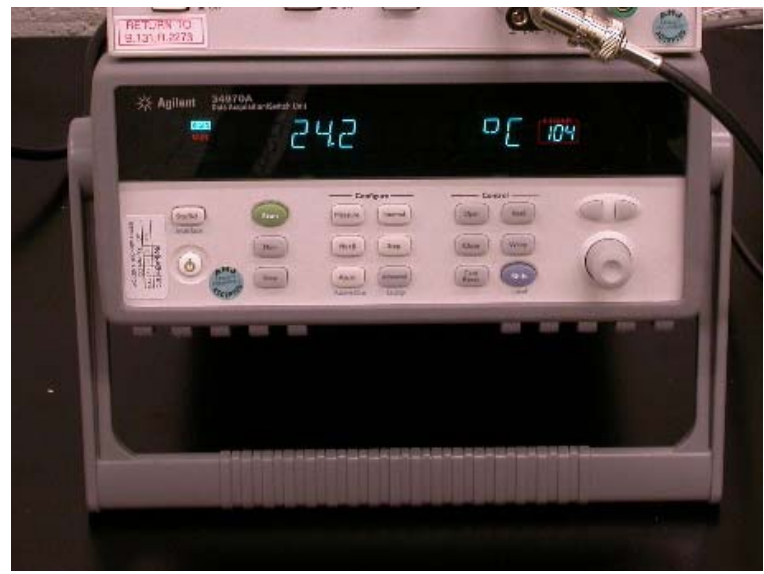

Figure 3.1.1.5 - Agilent 34970A

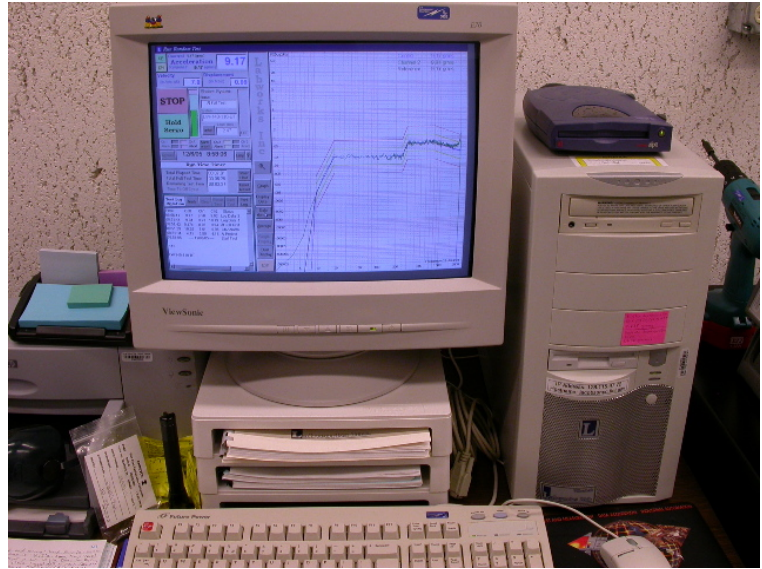

Figure 3.1.1.6 - Control computer with VibeLab Software

\subsection{2 - Test Results - Room Temperature}

The reference/control accelerometer, channel 1, is monitored continuously during the testing and provides feedback for the shaker control. Vibration amplitude and the calculated PSD were saved at the start of the test, in the middle of the test, and at the end of the test. The tests were performed on 2 December 2005.

Figures 3.1.2.1 thru Figure 3.1.2.3 show the Power Spectral Density plots for Block A, in the axial direction, at room temperature.

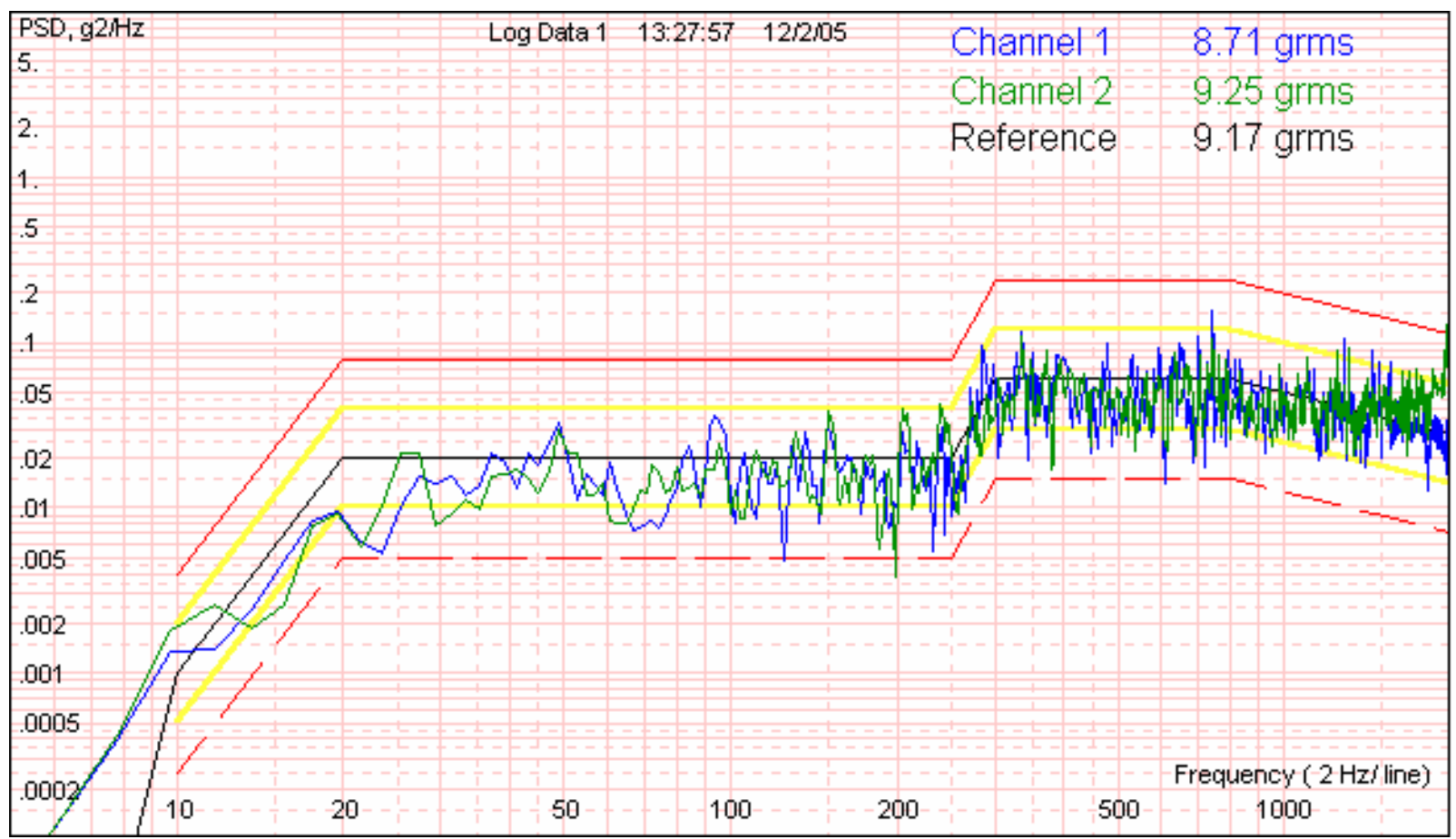

Figure 3.1.2.1 - Power Spectral Density plot taken at beginning of test

(Block A, room temperature, axial direction) 


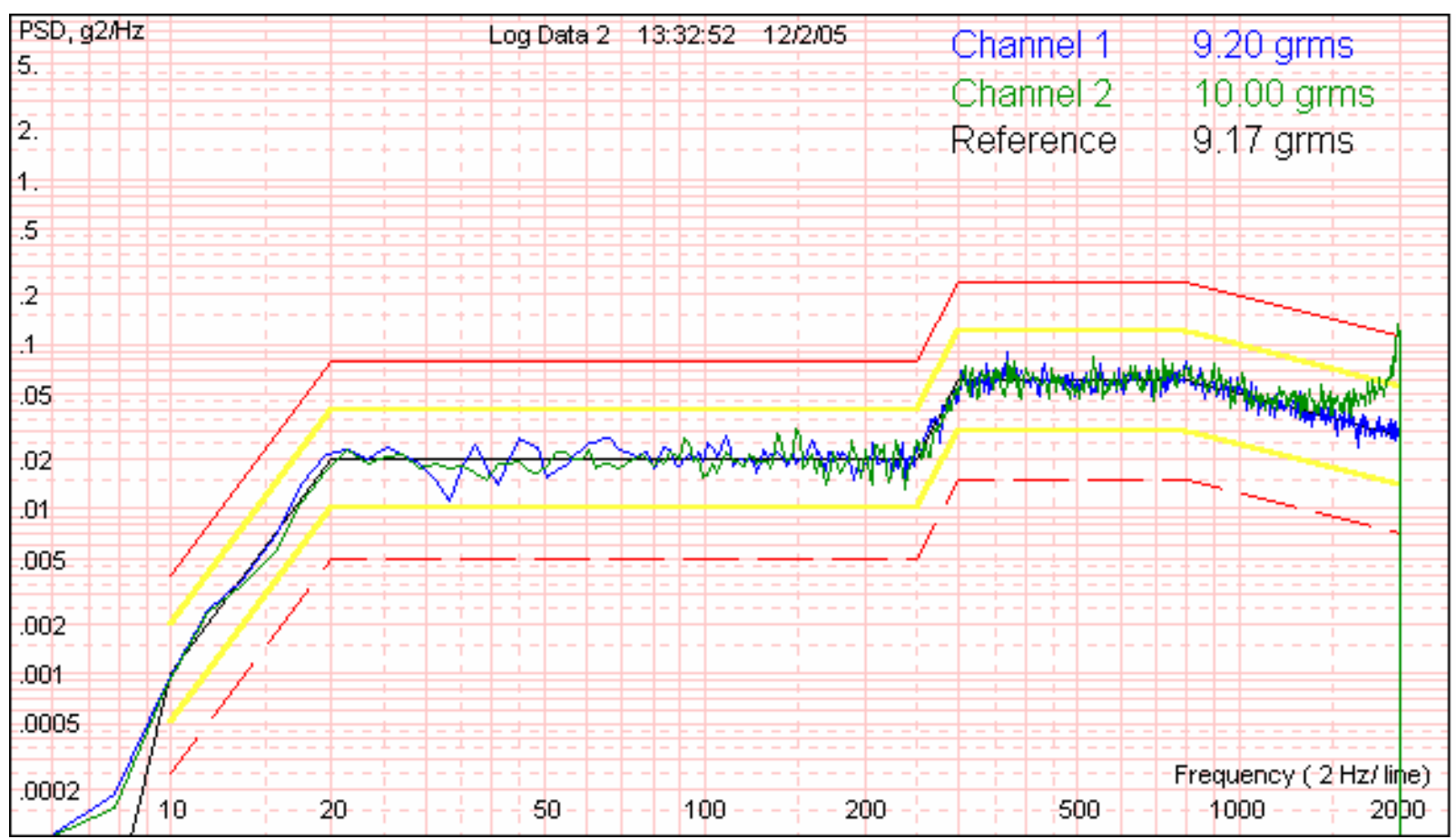

Figure 3.1.2.2 - Power Spectral Density plot taken 5 minutes into test (Block A, room temperature, axial direction)

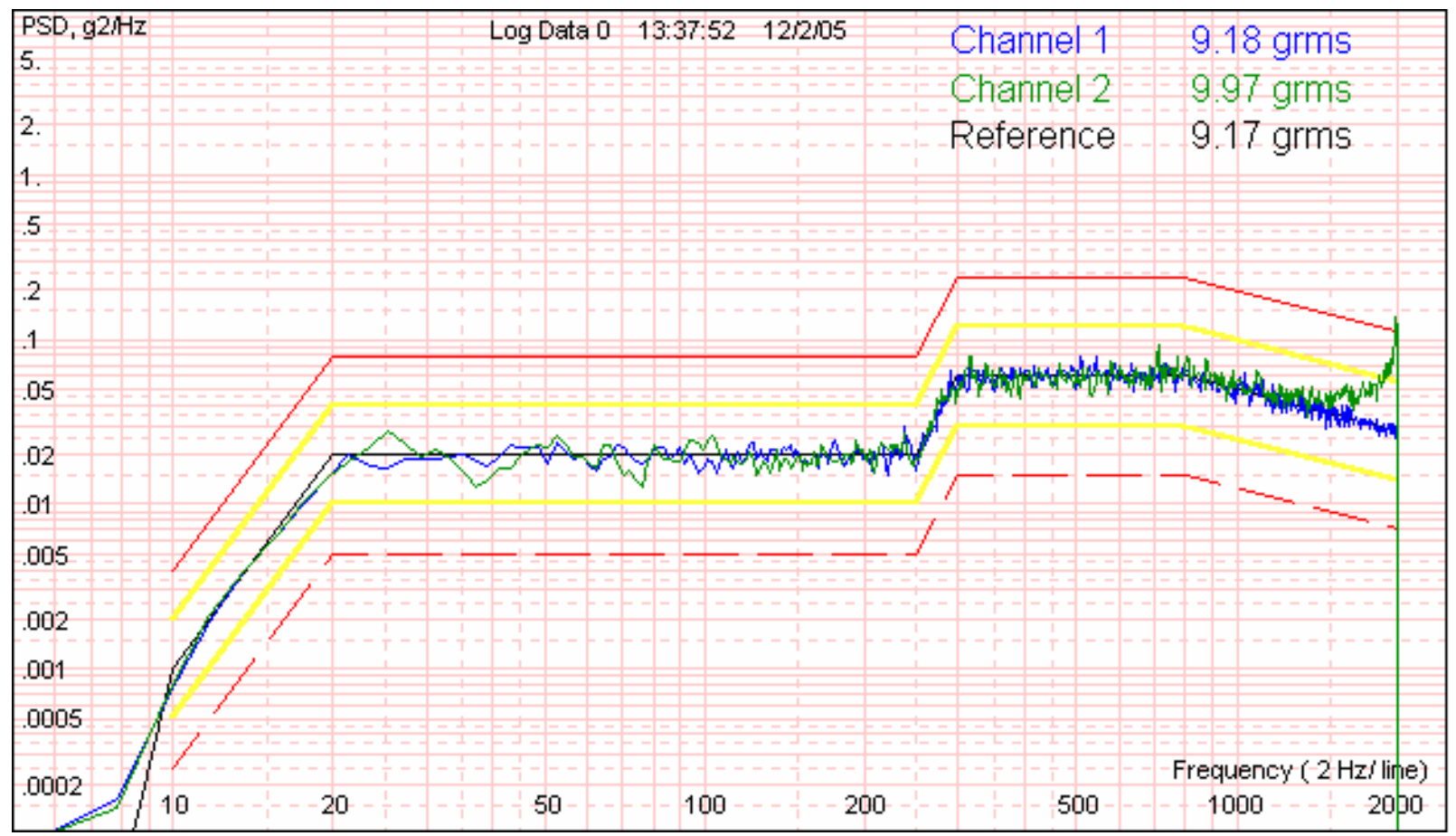

Figure 3.1.2.3 - Power Spectral Density plot taken at end of test

(Block A, room temperature, axial direction) 
After completion of the test, temperature and event marker data was downloaded from the Agilent 34970A Data Acquistion/ Switch using H/P Benchlink software and saved in tab delimited format. The data was plotted using KaleidaGraph from Synergy Software (see Figure 3.1.2.4).

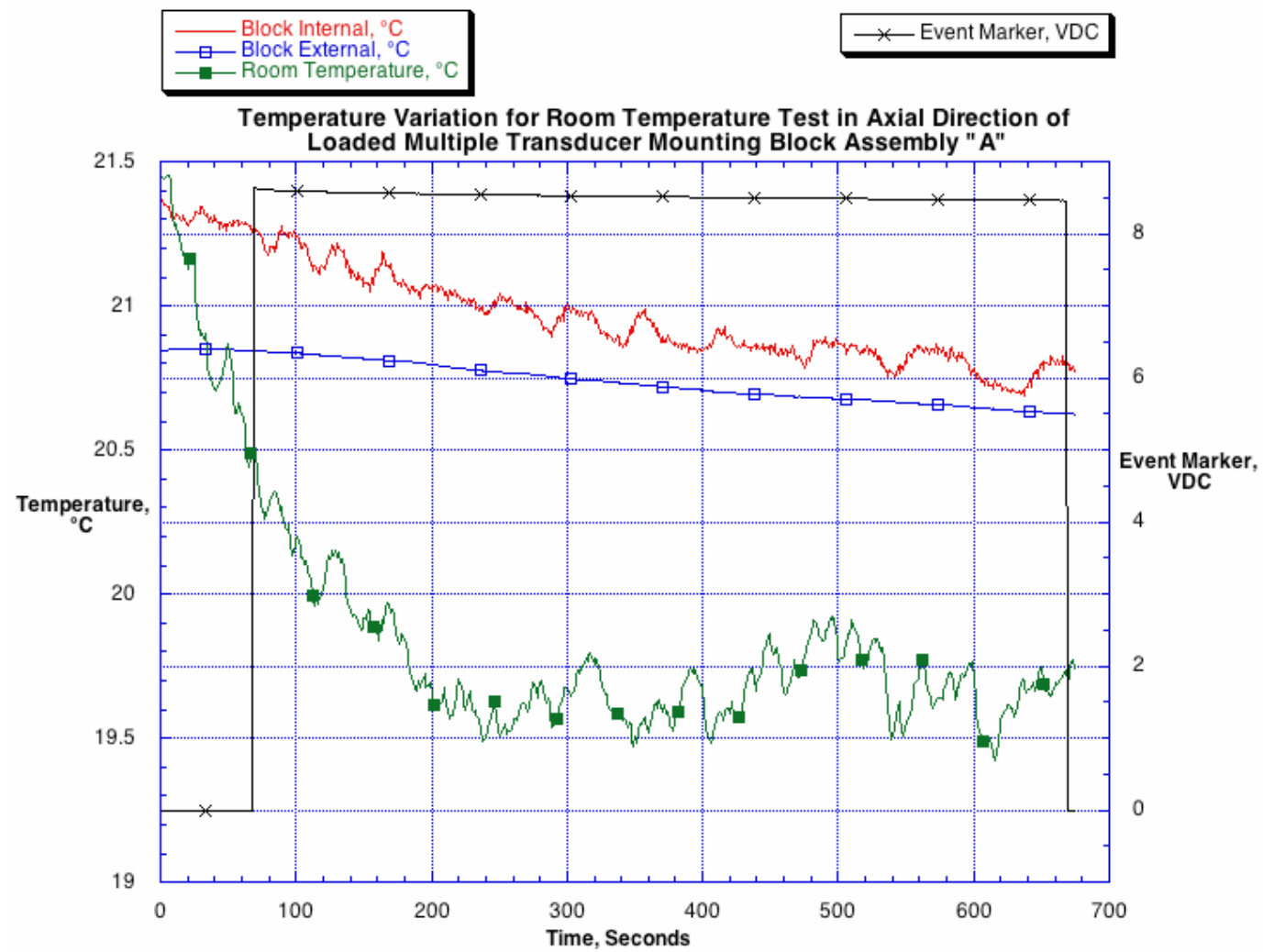

Figure 3.1.2.4 - Temperature variation plot for room temperature test

Power Spectral Density plots and temperature data for...

Block A, room temperature, radial direction

Block B, room temperature, axial direction

Block B, room temperature, radial direction

...were similar to the preceding Block A axial direction data. To eliminate space in this report, none of these Power Spectral Density plots are presented. However, all data plots are available for inspection upon request. 


\subsection{3 - Test Setup and Procedure $-+74^{\circ} \mathrm{C}$ and $-40^{\circ} \mathrm{C}$}

The test setup and procedures at $+74^{\circ} \mathrm{C}$ and $-40^{\circ} \mathrm{C}$ were the same as the test setup and procedures for the room temperature test, except that Block A and Block B were heated /cooled to the appropriate temperature in an environmental chamber prior to the shake test.

Figure 3.1.3.1 shows a loaded Multiple Transducer Mounting Block, G-10 fiberglass board, and four \#10-32 x 1.75“ sockethead cap screws with washers placed in a Tenny Jr. environmental chamber. Notice the block's thermocouple/RTD leads routed outside of the chamber. The leads are connected to an Agilent 34970A so that block temperatures can be monitored during the heating/cooling process.

Figure 3.1.3.2 shows the location and positioning of the Tenny Jr. environmental chamber, shaker head, and Agilent 34970A.

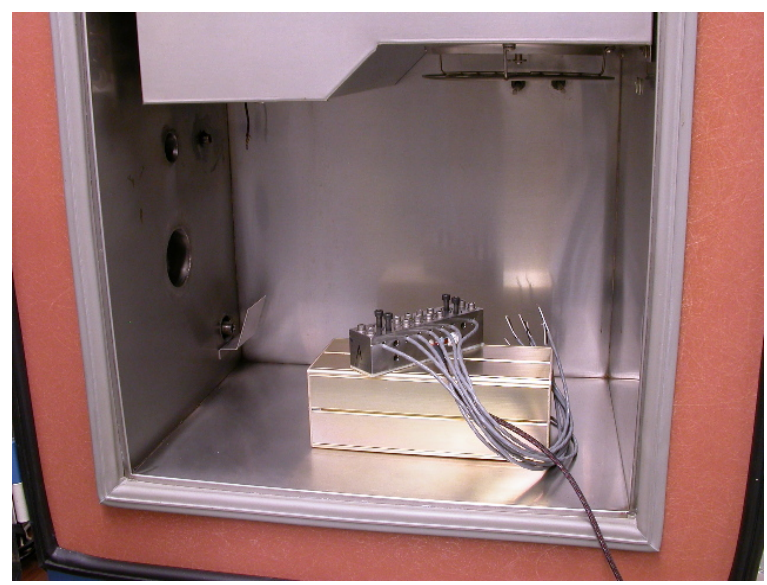

Figure 3.1.3.1 - Multiple Transducer Mounting Block, inside of environmental chamber

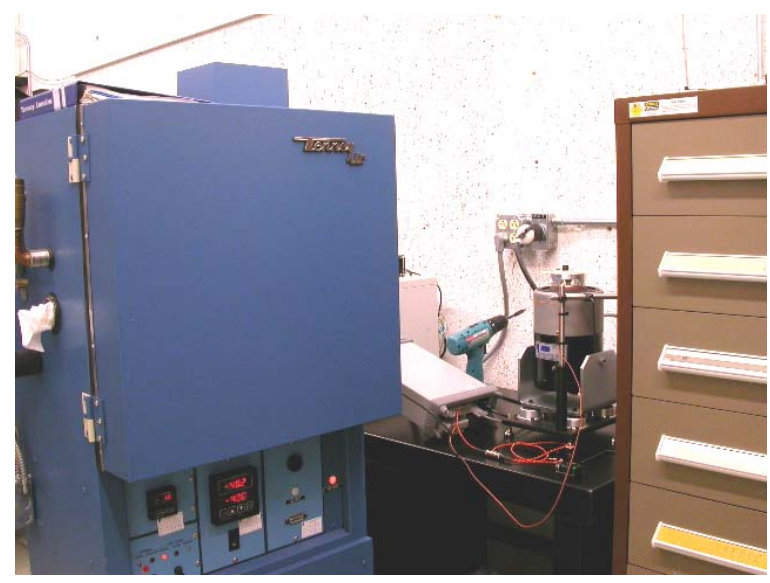

Figure 3.1.3.2 - Tenny Jr. environmental chamber, shaker head, and Agilent 34970A

Operation of the environmental chamber was done in manual mode via the front panel controls. The temperature was set and the heating or cooling process was started. Ramp time for the block's internal temperature to reach the set temperature was $\sim 60$ minutes. During ramp time, the block's internal and external temperatures, as well as the room's ambient air temperature, were visually monitored using the Agilent 34970A Data Acquistion/Switch unit. Once the set temperature was reached, the block was allowed to soak at the set temperature for an additional 30 minutes before proceeding with the test.

At the end of the 30 minute temperature soak, capturing of the temperature data was started and operation of the environmental chamber was stopped. At the instant the chamber door was opened and the block removed, an external 9 volt DC signal was manually applied to channel 103 for a few seconds (as an event marker to indicate removal from chamber). The block was quickly transferred to the shaker and the four fastening screws were snugged down using a cordless hand drill. While the bolts were securely hand tightened and transducer cables attached to the cable mounting/relief fixture, the shaker amplifier was switched on and amplifier level set. All told, it took $\sim 5$ seconds to remove the block from the chamber and securely fasten it to the shaker top in preparation for shake testing. 
Note: since the block was extremely hot/cold, insulated gloves were used to transfer the block from environmental chamber to shaker.

With the block and cables secure, the VibeLab software was set to the test position with a programmed 10 minute run time. The system performed a pretest at $6 \mathrm{~dB}$ below the desired amplitude. When the software determined that the desired spectrum was being achieved, the amplitude was raised to the test level and maintained for the programmed time (Figures 3.1.3.3 and Figure 3.1.3.4). At full test level, the external 9 volt DC signal was again manually applied to channel 103 (as an event marker for the start of full power shaking). The vibration system and the Multiple Transducer Mounting Block were continuously monitored throughout the 10 minute test. At the end of the test, the event marker voltage was turned off.

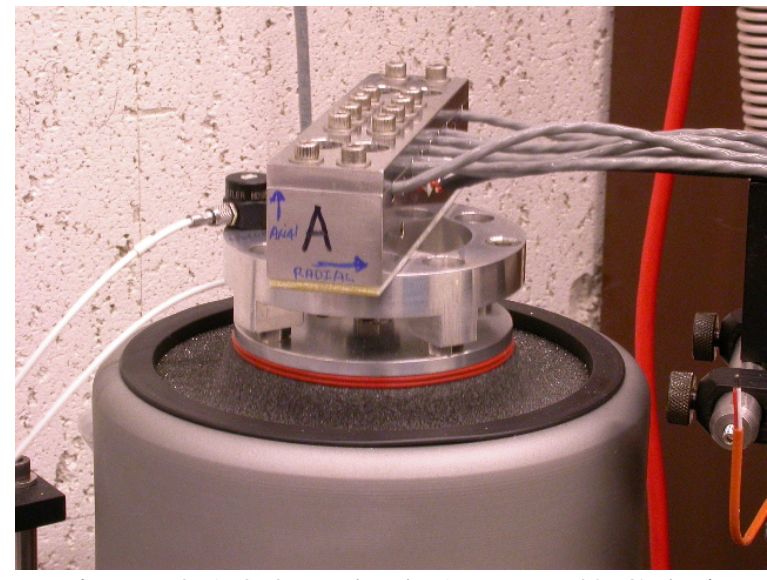

Figure 3.1.3.3 - Block A, at $+74^{\circ} \mathrm{C}$, being shaken in the axial direction

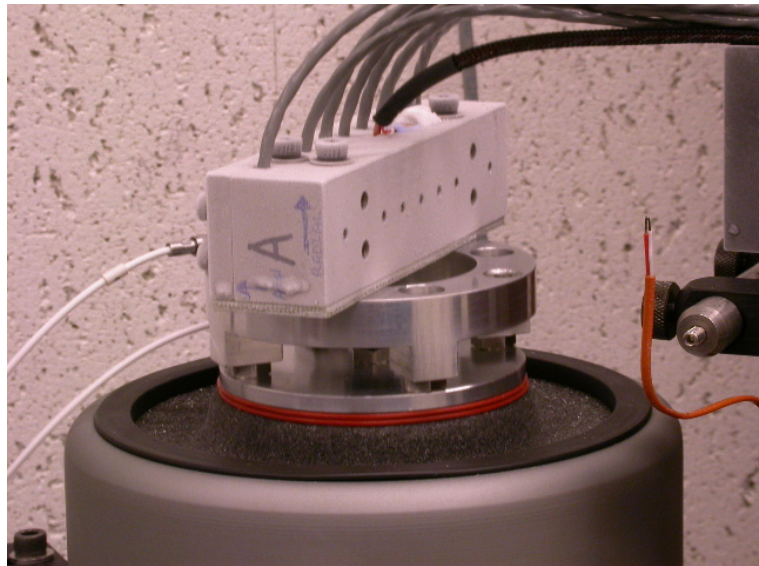

Figure 3.1.3.4 - Block A, at $-40^{\circ} \mathrm{C}$, being shaken in the radial direction

\subsection{4 - Test Results $-+74^{\circ} \mathrm{C}$ and $-40^{\circ} \mathrm{C}$}

The reference/control accelerometer, channel 1, is monitored continuously during the testing and provides feedback for the shaker control. Vibration amplitude and the calculated PSD were saved at the start of the test, in the middle of the test, and at the end of the test. The tests were performed on 5 December 2005 through 6 December 2005. 
Figures 3.1.4.1 thru Figure 3.1.4.6 show some of the Power Spectral Density plots for Block A.

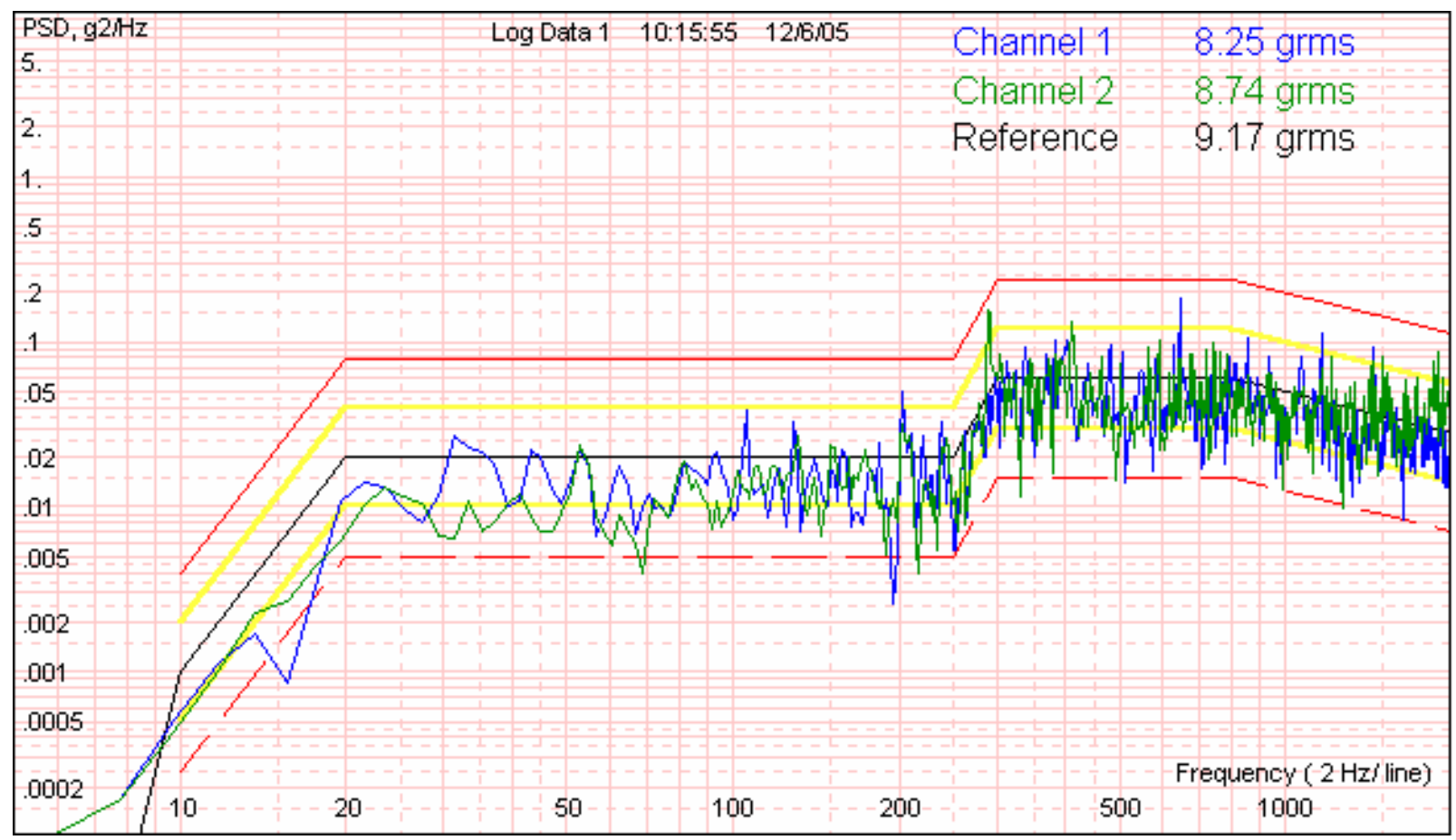

Figure 3.1.4.1 - Power Spectral Density plot taken at beginning of test (Block $\mathrm{A},+74^{\circ} \mathrm{C}$, axial direction)

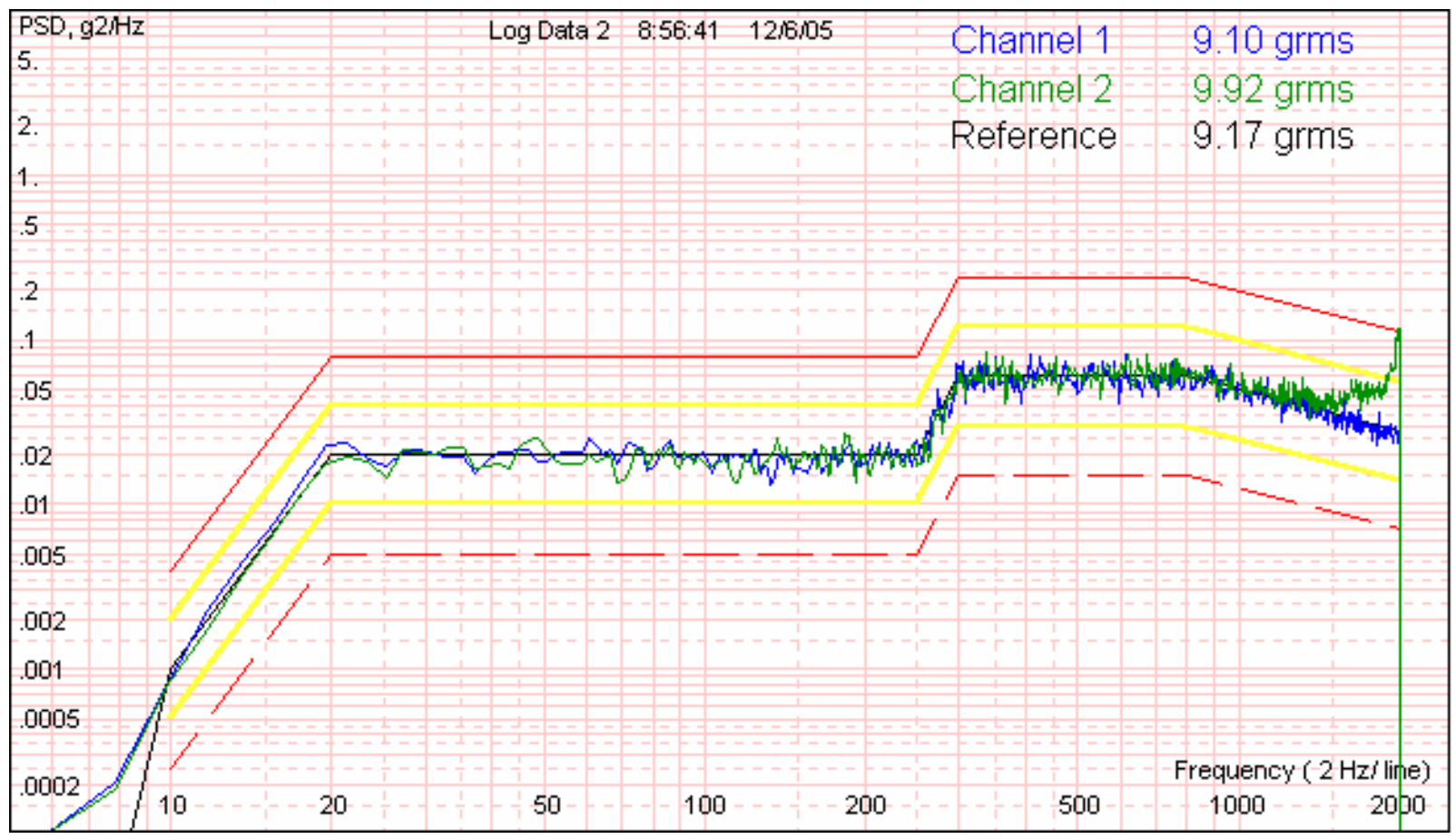

Figure 3.1.4.2 - Power Spectral Density plot taken 5 minutes into test

(Block $\mathrm{A},+74^{\circ} \mathrm{C}$, axial direction) 


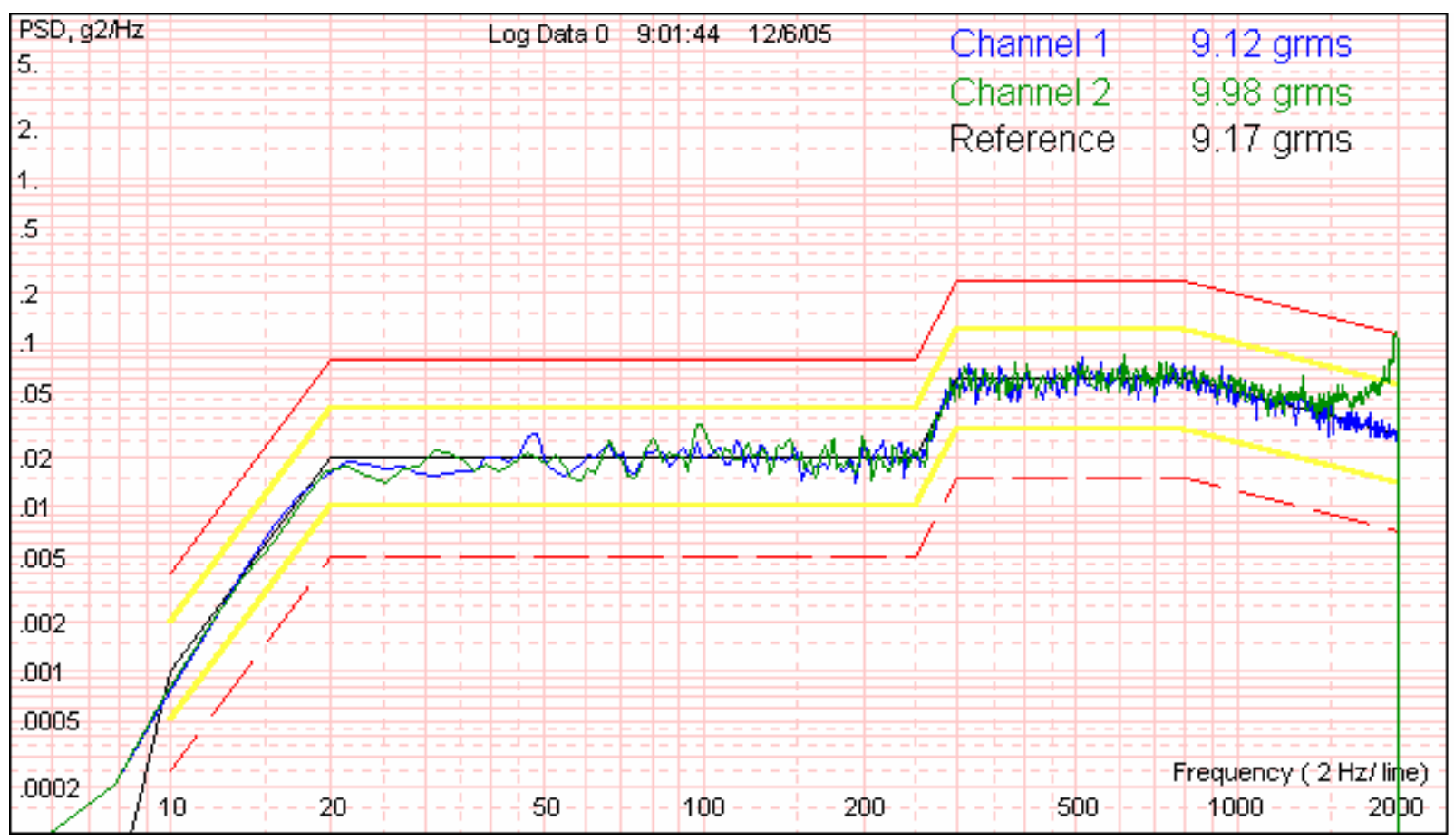

Figure 3.1.4.3 - Power Spectral Density plot taken at end of test

(Block $\mathrm{A},+74^{\circ} \mathrm{C}$, axial direction)

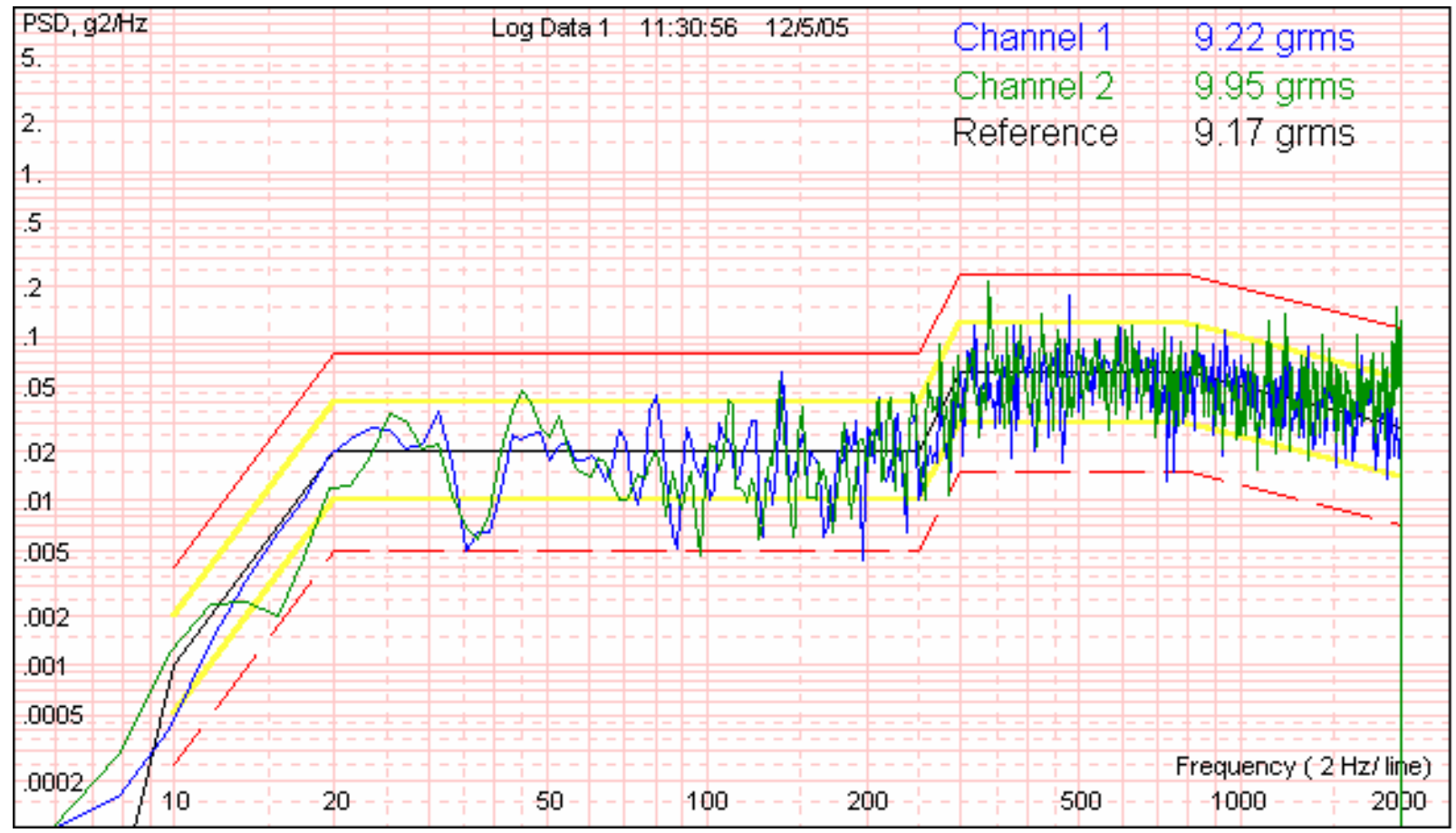

Figure 3.1.4.4 - Power Spectral Density plot taken at the beginning of the test

(Block $\mathrm{A},-40^{\circ} \mathrm{C}$, radial direction) 


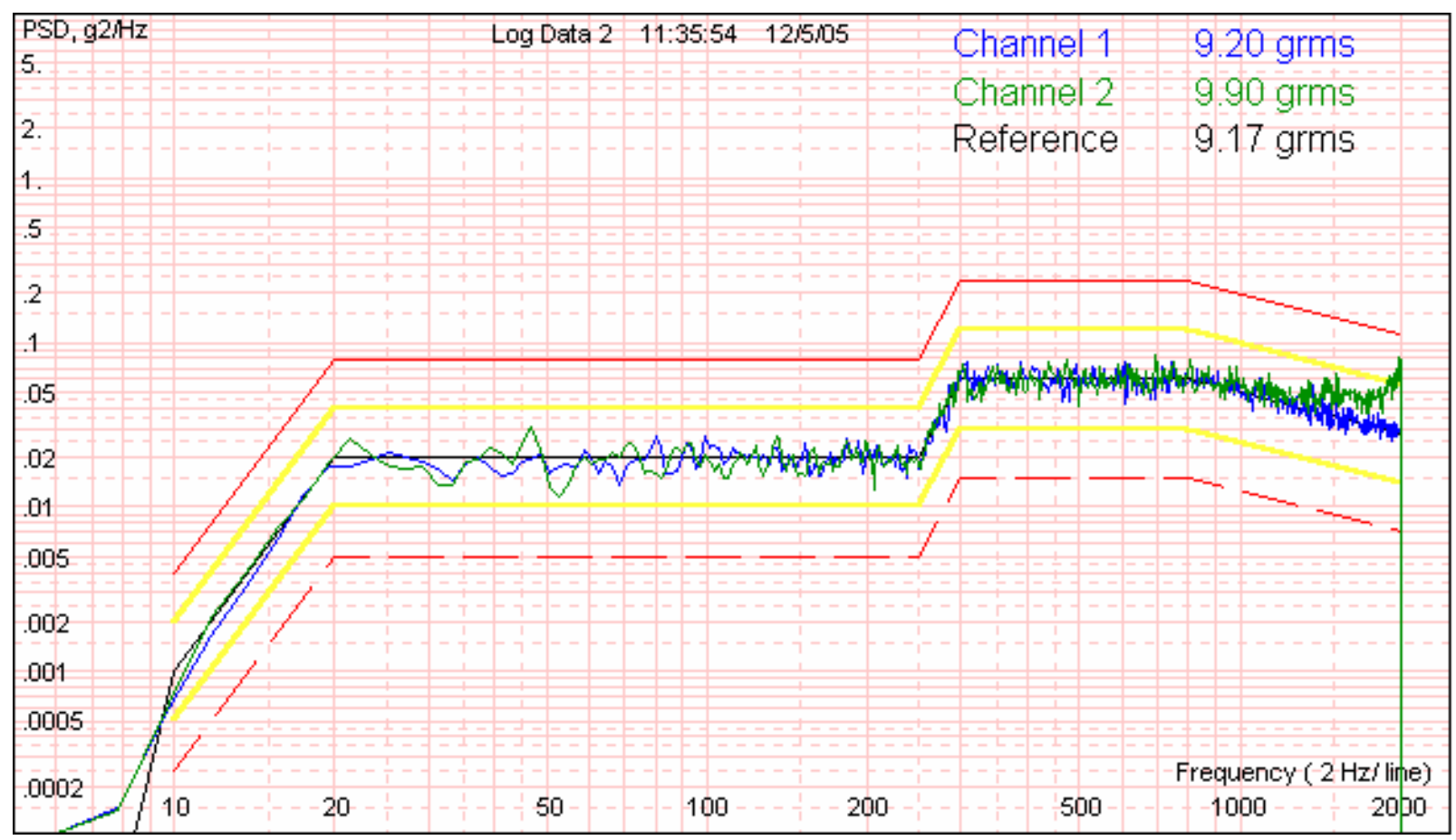

Figure 3.1.4.5 - Power Spectral Density plot taken 5 minutes into test (Block $\mathrm{A},-40^{\circ} \mathrm{C}$, radial direction)

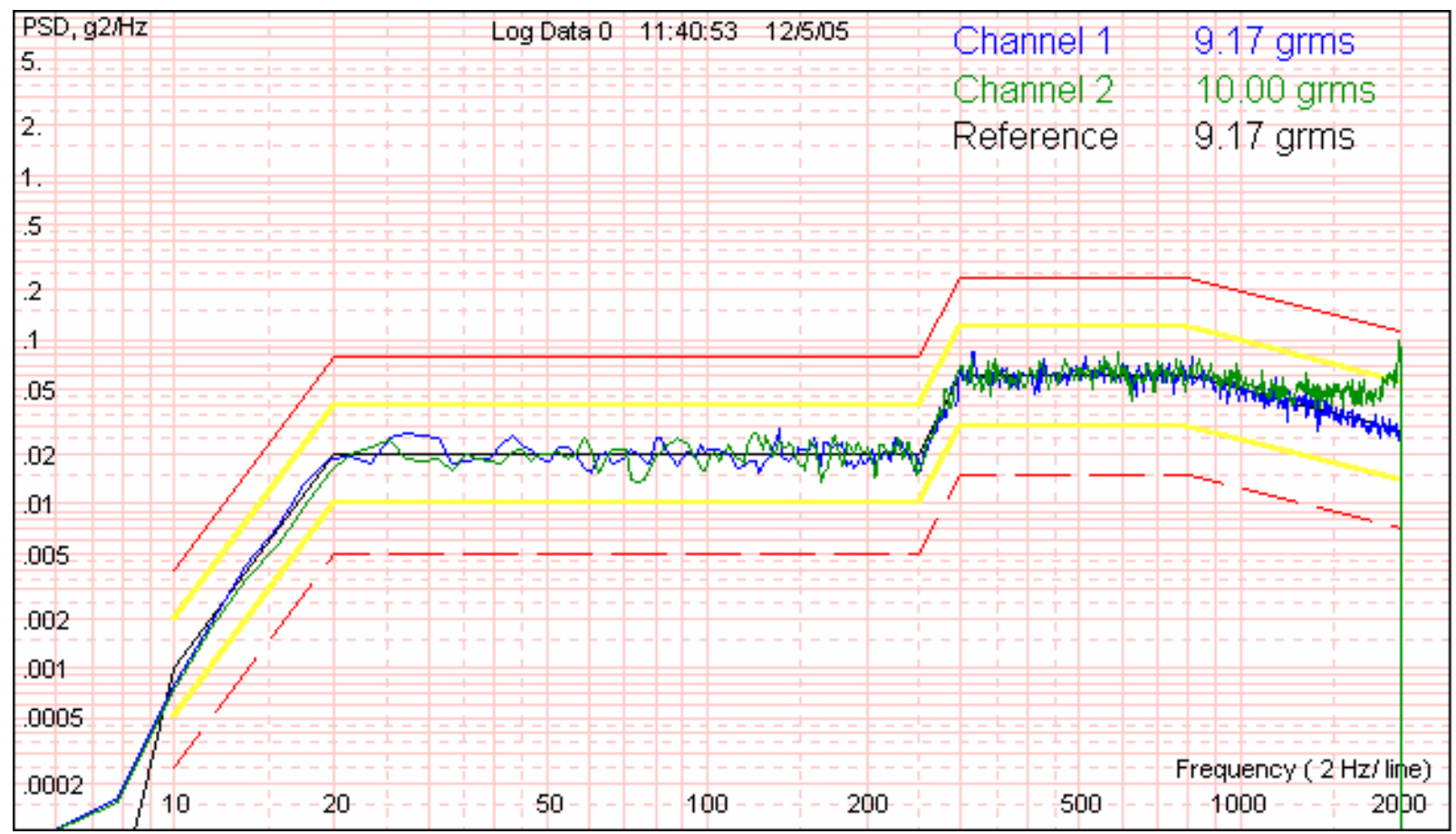

Figure 3.1.4.6 - Power Spectral Density plot taken at end of test

(Block A, $-40^{\circ} \mathrm{C}$, radial direction)

After completion of the test, temperature and event marker data was downloaded from the Agilent 34970A Data Acquistion/ Switch using H/P Benchlink software and saved in tab delimited format. The data was plotted using KaleidaGraph from Synergy Software and is shown in Figure 3.1.4.7 and Figure 3.1.4.8. 


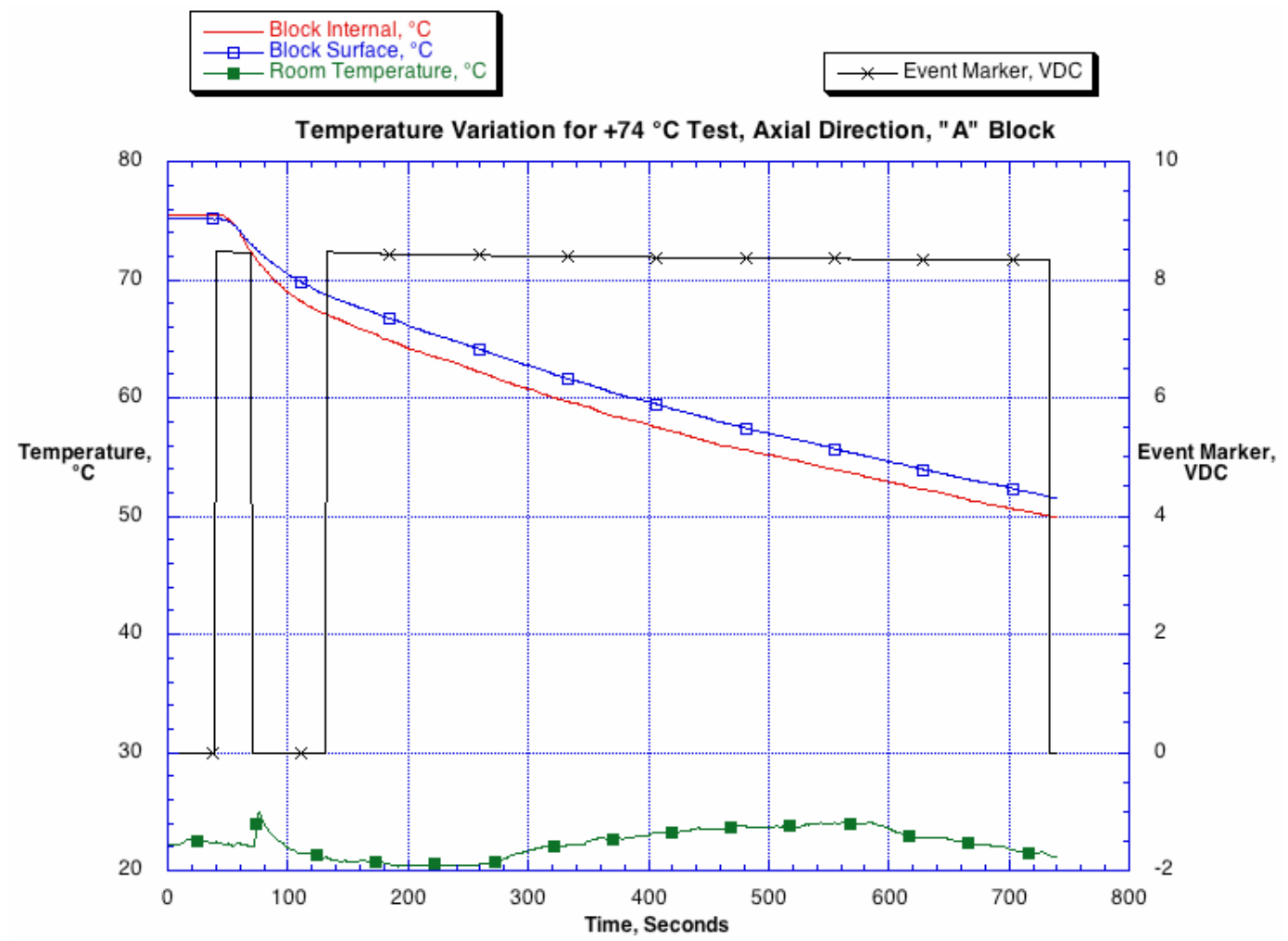

Figure 3.1.4.7 - Temperature variation plot for $+74^{\circ} \mathrm{C}$ test.

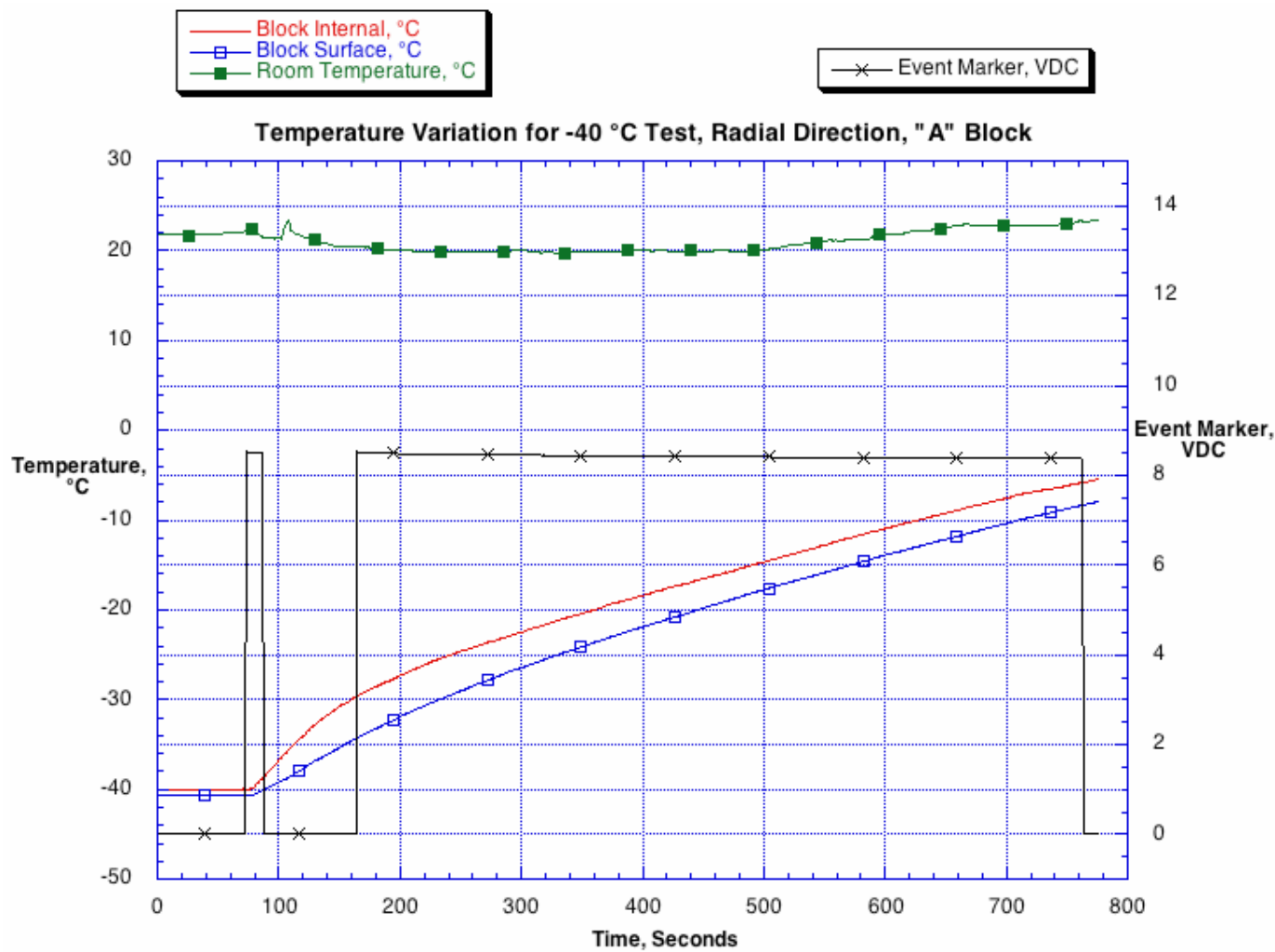

Figure 3.1.4.8 - Temperature variation plot for $-40^{\circ} \mathrm{C}$ test. 
Power Spectral Density plots and temperature data for...

Block $\mathrm{A},+74^{\circ} \mathrm{C}$, radial direction

Block $\mathrm{A},-40^{\circ} \mathrm{C}$, axial direction

Block $\mathrm{B},+74^{\circ} \mathrm{C}$, axial direction

Block $\mathrm{B},+74^{\circ} \mathrm{C}$, radial direction

Block $\mathrm{B},-40^{\circ} \mathrm{C}$, axial direction

Block $\mathrm{B},-40^{\circ} \mathrm{C}$, radial direction

....were similar to the preceding Block A axial direction data. To eliminate space in this report, none of these Power Spectral Density plots are presented. However, all data plots are available for inspection upon request.

At the completion of the Short Random Vibration Test series, a performance check was done. All 14 transducers passed. The oscilloscope snapshots were saved to computer and archived. To eliminate space in this report, none of these snapshots are shown. However, all snapshots are available for inspection upon request.

\section{2 - Mechanical Shock Test}

The mechanical shock test consists of 10 half-sine impulse shocks applied to each tranducer in each of 4 directions, +/- axial and +/-radial. Each transducer is mounted in a test fixture attached to the shaker. The test is performed at ambient room temperature.

The mechanical shock test consists of two series of tests. The tests have the following specifications:

1. $50 \mathrm{~g}$ acceleration with a 1 millisecond half-sine pulse

2. $17 \mathrm{~g}$ acceleration with a 50 millisecond half-sine pulse

Due to limitations of the shaker system employed, the pulse duration for the second test was decreased from 50 to 20.3 milliseconds. Additional parameter information for the two tests are shown in Table 3.2.1

Table 3.2.1

\begin{tabular}{|l|l|l|}
\hline & Test 1 & Test 2 \\
\hline Shock Pulse & Half Sine & Half Sine \\
\hline Peak Acceleration & $50.0 \mathrm{~g}$ & $17.0 \mathrm{~g}$ \\
\hline Pulse Duration & $1.0 \mathrm{msec}$. & $20.3 \mathrm{msec}$. \\
\hline Peak Velocity & $0.12 \mathrm{mps}$ & $0.82 \mathrm{mps}$ \\
\hline P-P Displacement & $0.16 \mathrm{~mm}$ & $22.65 \mathrm{~mm}$ \\
\hline Pre-Pulse & $1.8 \mathrm{msec}$. & $35.7 \mathrm{msec}$. \\
\hline Post-Pulse & $2.6 \mathrm{msec}$. & $53.1 \mathrm{msec}$. \\
\hline Pre/Post Pulse & Min. Displacement Ramp & Min. Displacement Ramp \\
\hline
\end{tabular}




\subsection{1 - Test Setup and Procedure - Room Temperature}

A transducer was place in the Single Transducer Mounting Block and secured in place with the cover and four \#6-32 x 1/2" sockethead cap screws with washers (Figures 3.2.1.1 and 3.2.1.2).

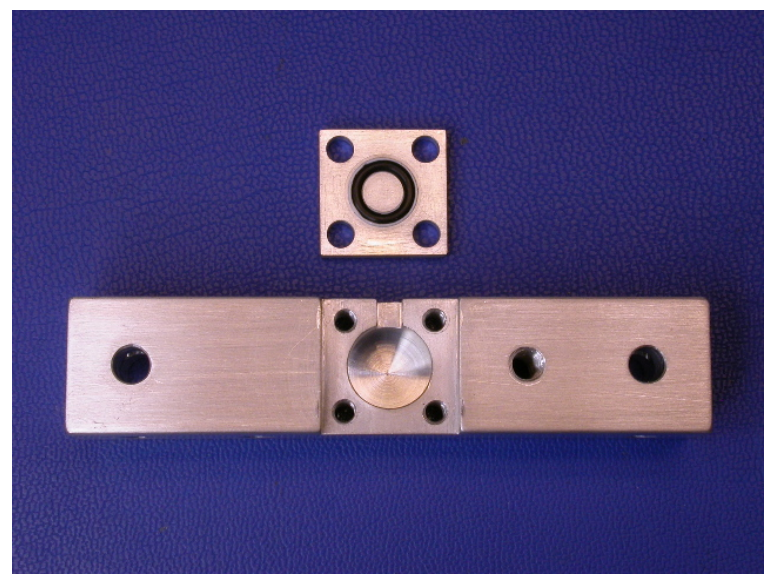

Figure 3.2.1.1 - Single Transducer Mounting Block and cover

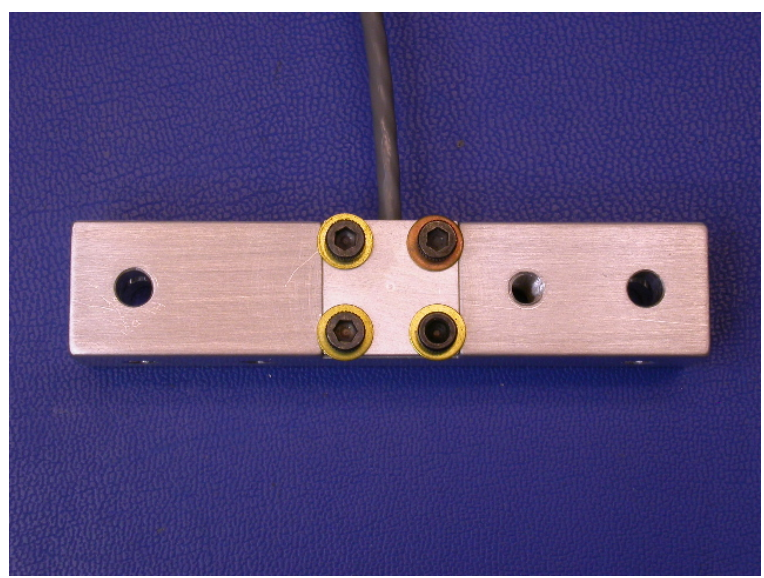

Figure 3.2.1.2 - Assembled Single Transducer Mounting Block

The assembled Single Transducer Mounting Block was attached to the shaker mounting plate using two \#10-32 x 1-1/2“, sockethead cap screws and washers.

A Kistler accelerometer, type 8636B50M05, S/N C196770, was attached at one of the outer positions of the shaker mounting plate of the shaker head for use as the reference/control accelerometer. A second Kistler accelerometer, type 8636B50M05, S/N C196961, was attached to the top horizontal surface of the Single Transducer Mounting Block. This accelerometer measures the response of the loaded Single Transducer Mounting Block assembly.

Figures 3.2.1.3 and 3.2.1.4 show the accelerometers and the Single Transducer Mounting Block Assembly in the axial and radial test postions.

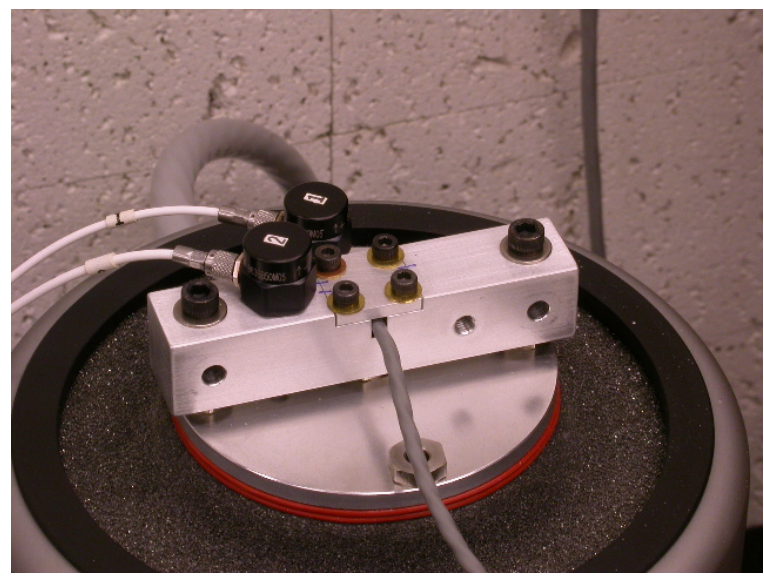

Figure 3.2.1.3 - Axial test postion

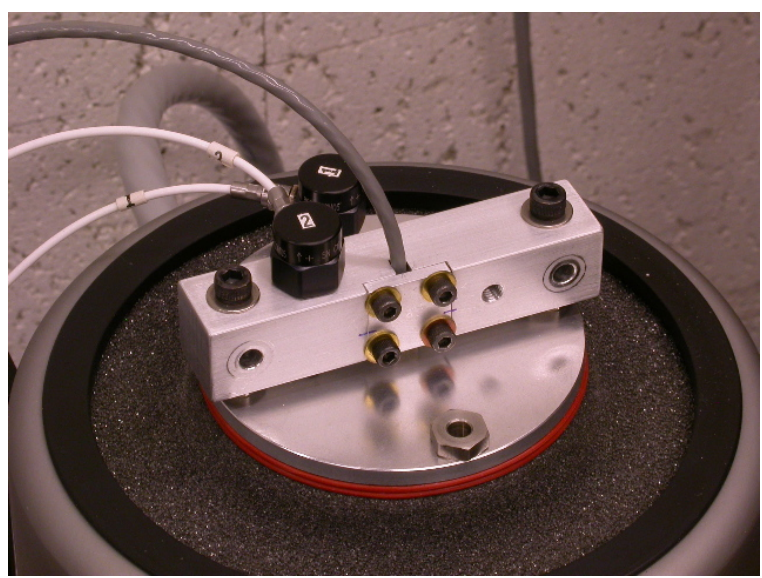

Figure 3.2.1.4 - Radial test postion

The transducer cable was attached to the cable mounting/relief fixture before the test started. Ambient room temperture was $22.0^{\circ} \mathrm{C},+/-2^{\circ} \mathrm{C}$, and was monitored, but not electronically recorded, during the test series. 
The VibeLab software was set to the test position with 10 pulses auto programmed for the test and the desired pulse polarity, + or -, was selected from the test screen (Figure 3.2.1.5). The system performed a pretest at $3 \mathrm{~dB}$ below the desired amplitude. After four equalize pulses, the software determined that the desired amplitude was being achieved, the test commenced and ran for the programmed number of pulses (Figure 3.2.1.6). The vibration system and Single Transducer Mounting Block were continuously monitored throughout the test.

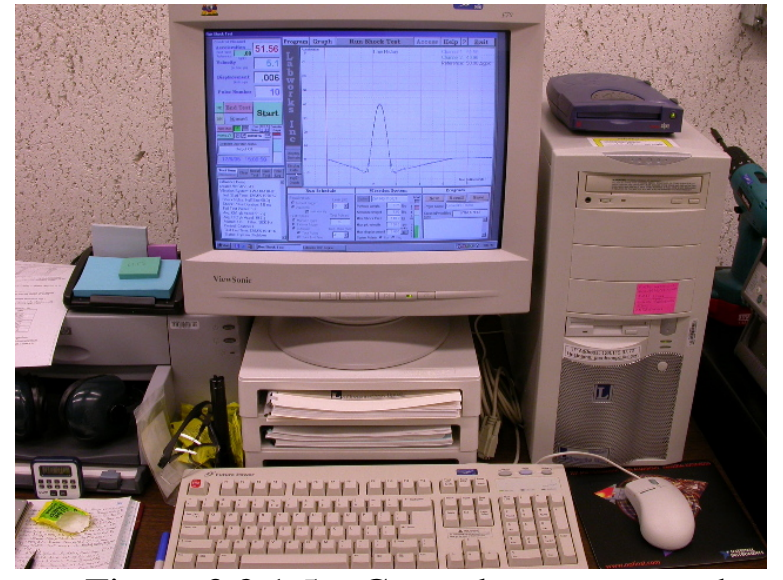

Figure 3.2.1.5 - Control computer and VibeLab software

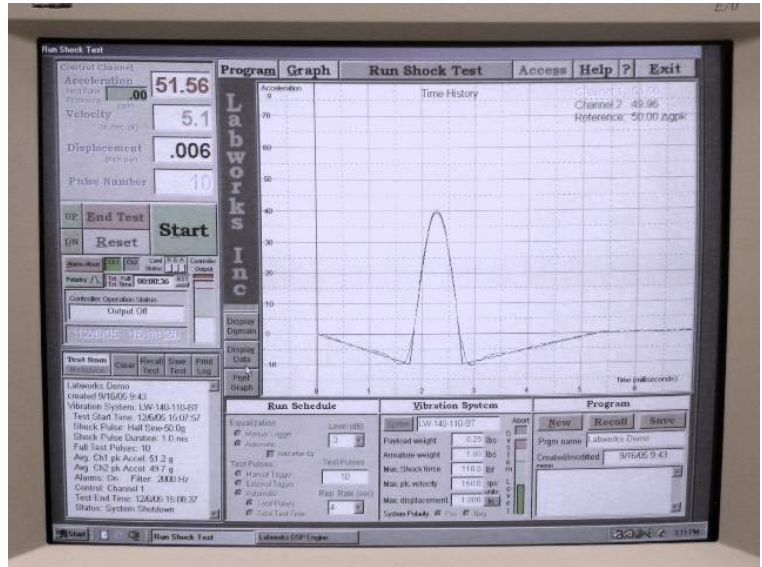

Figure 3.2.1.6 - Test screen at end of test

\subsection{2 - Test Results}

The reference/control accelerometer, channel 1, is monitored continuously during the testing and provides feedback for the shaker control. Shock pulse amplitude and shape is only saved at the end of the test. The following 16 plots show test results that were performed on 6 December 2005 through 7 December 2005.

Figures 3.2.2.1 - 3.2.2.8 show the test results for Zetec transducer, SN 442935, in the +/- axial and the +/- radial directions for $50 \mathrm{~g}, 1$ msec. pulse.

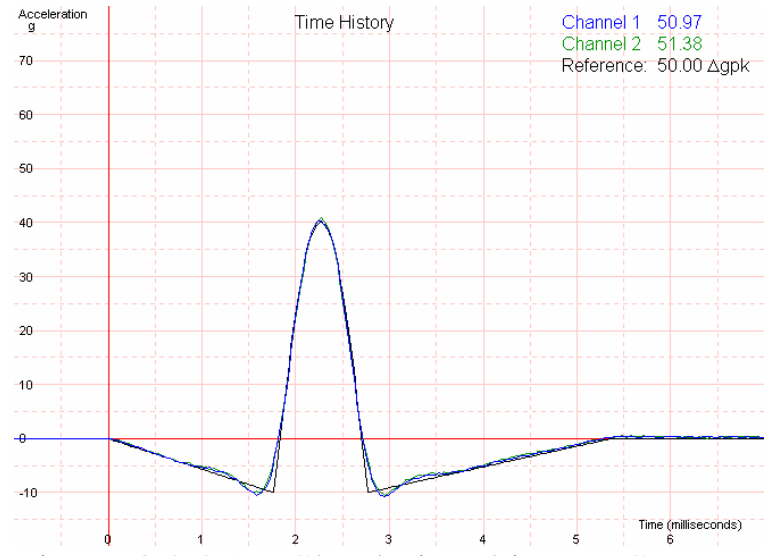

Figure 3.2.2.1 - Shock time history, SN 442935, + axial, 50 g, 1 msec

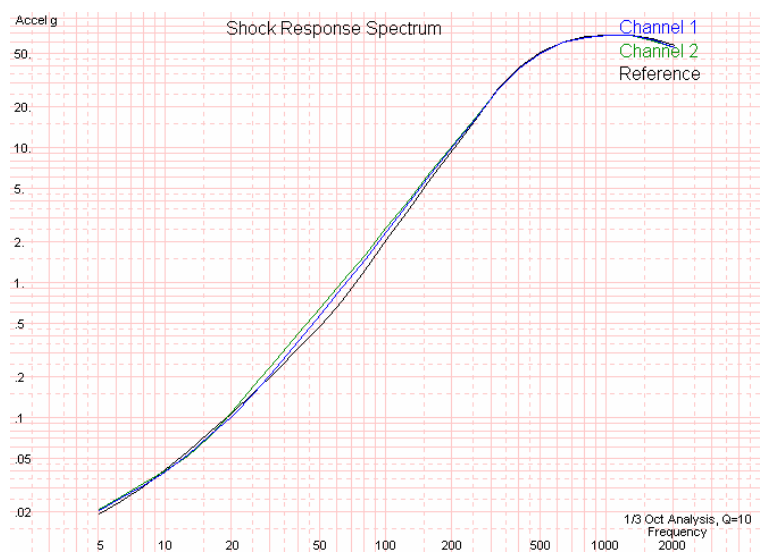

Figure 3.2.2.2 - Shock response, 1/3 Oct, Q:10, SN 442935, + axial, 50 g, 1 msec 


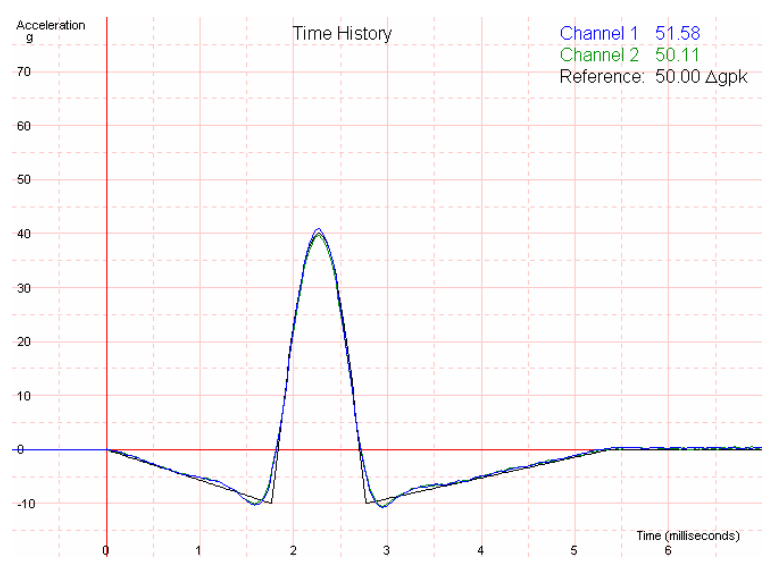

Figure 3.2.2.3 - Shock time history, SN 442935, - axial, $50 \mathrm{~g}, 1 \mathrm{msec}$

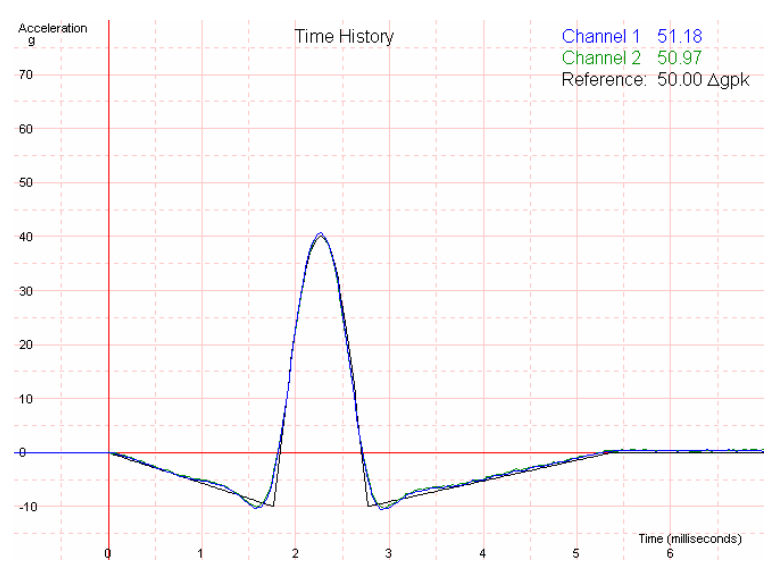

Figure 3.2.2.5 - Shock time history, SN 442935, + radial, 50 g, 1 msec

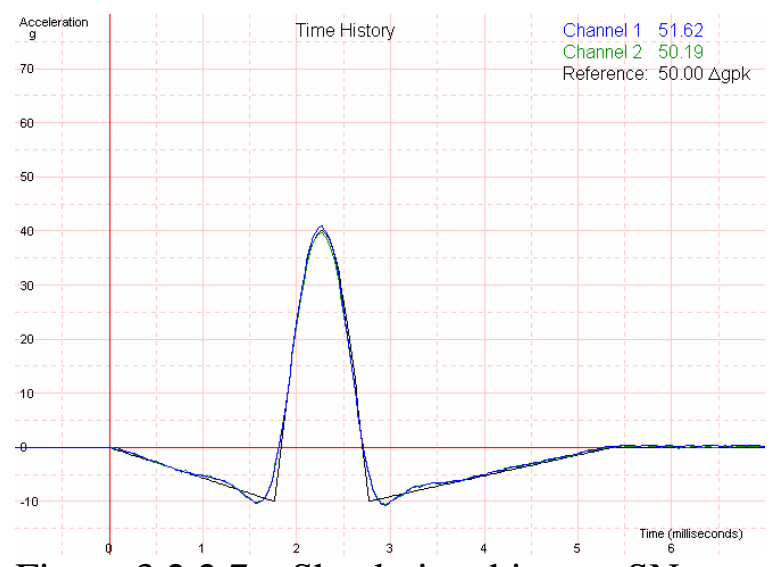

Figure 3.2.2.7 - Shock time history, SN 442935, - radial, 50 g, 1 msec

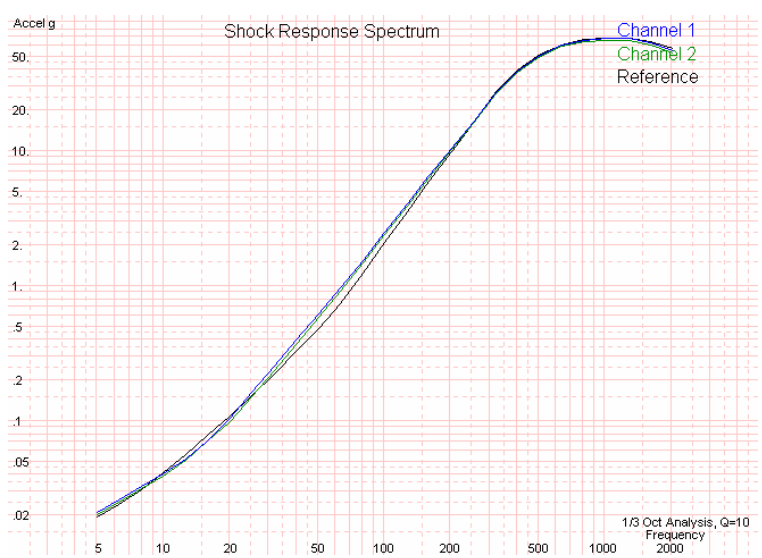

Figure 3.2.2.4 - Shock response, $1 / 3$ Oct, Q:10, SN 442935, - axial, 50 g, 1 msec

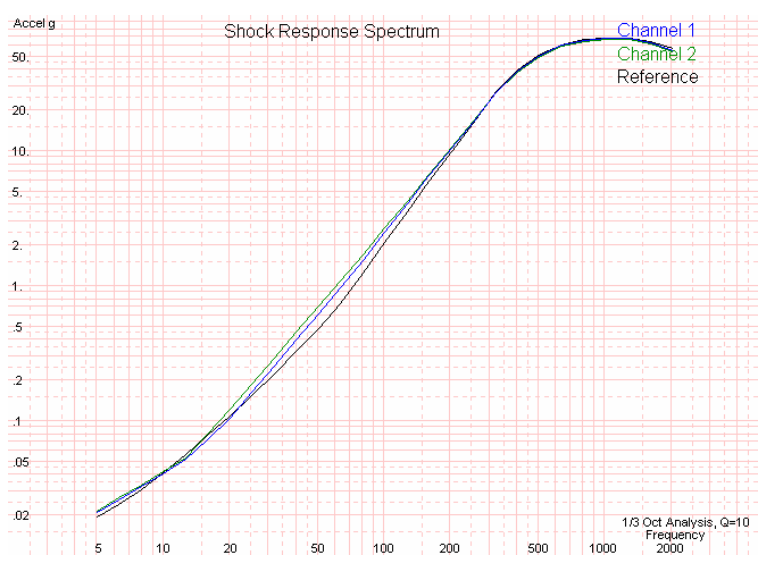

Figure 3.2.2.6 - Shock response, $1 / 3$ Oct, Q:10, SN 442935, + radial, 50 g, 1 msec

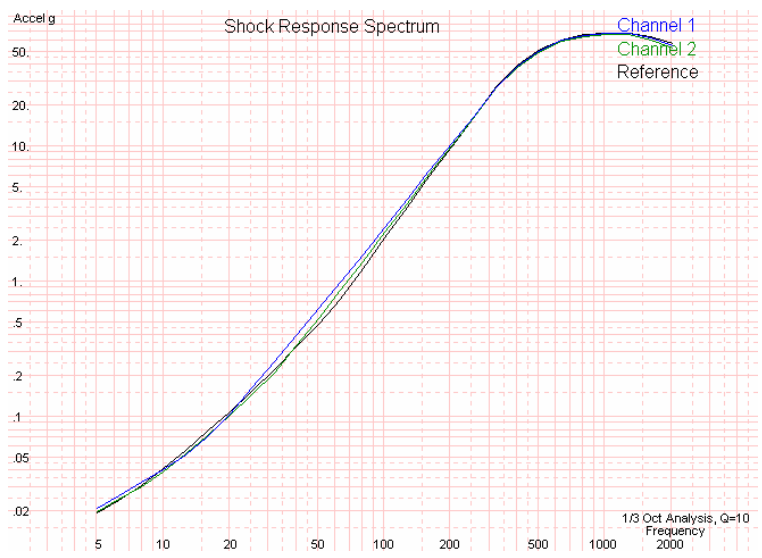

Figure 3.2.2.8 - Shock response, 1/3 Oct, Q:10, SN 442935, - radial, $50 \mathrm{~g}, 1 \mathrm{msec}$ 
Figure 3.2.2.9 - 3.2.2.16 show the test results for Zetec transducer, SN 442935, in the +/- axial and the +/- radial directions for $17 \mathrm{~g}, 20.3 \mathrm{msec}$. pulse.

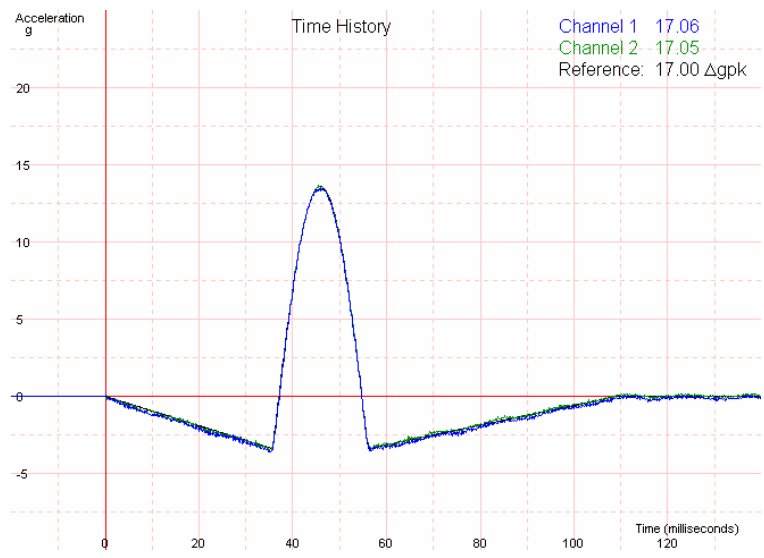

Figure 3.2.2.9 - Shock time history, SN 442935, + axial, 17 g, $20.3 \mathrm{msec}$

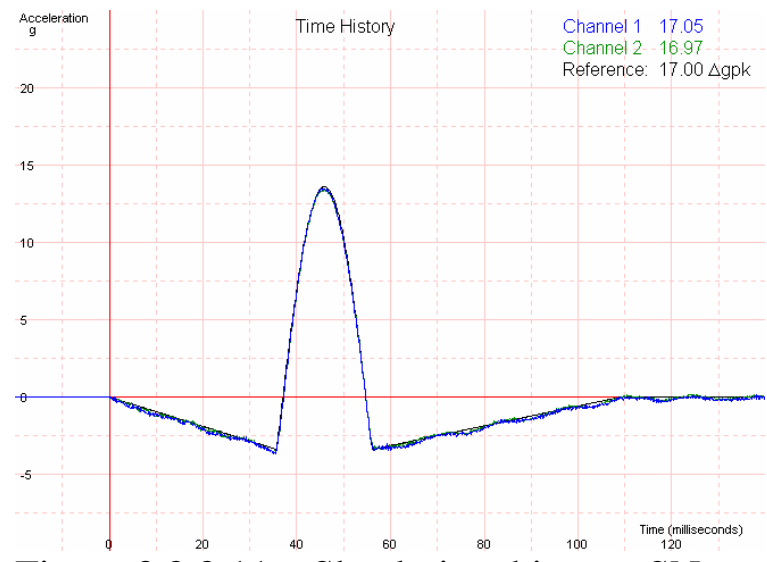

Figure 3.2.2.11 - Shock time history, SN 442935, - axial, 17 g, $20.3 \mathrm{msec}$

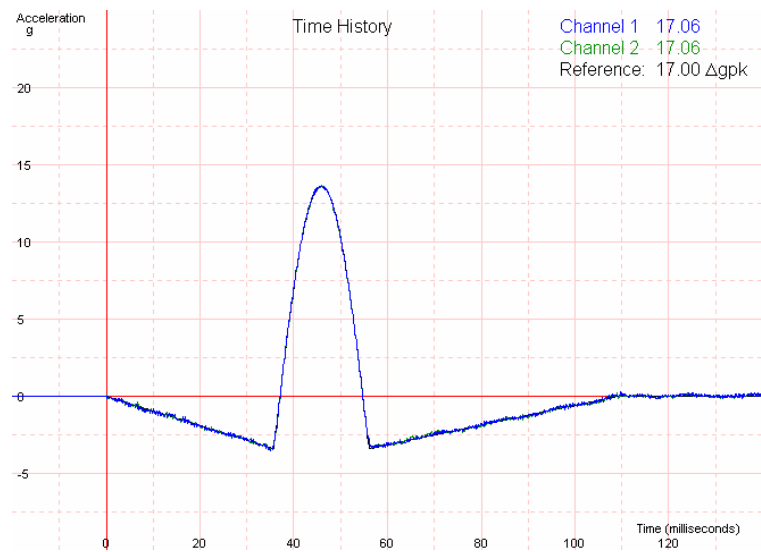

Figure 3.2.2.13 - Shock time history, SN 442935, + radial, 17 g, 20.3 msec

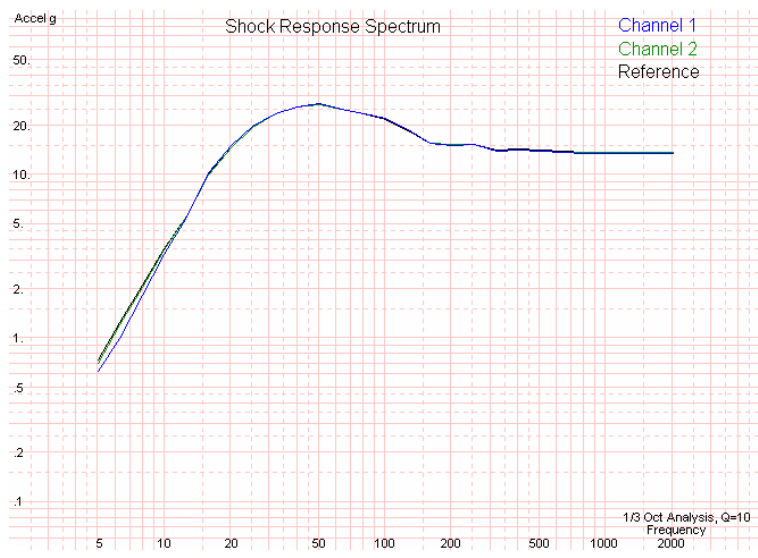

Figure 3.2.2.10 - Shock response, 1/3 Oct, Q:10, SN 442935, + axial, $17 \mathrm{~g}, 20.3 \mathrm{msec}$

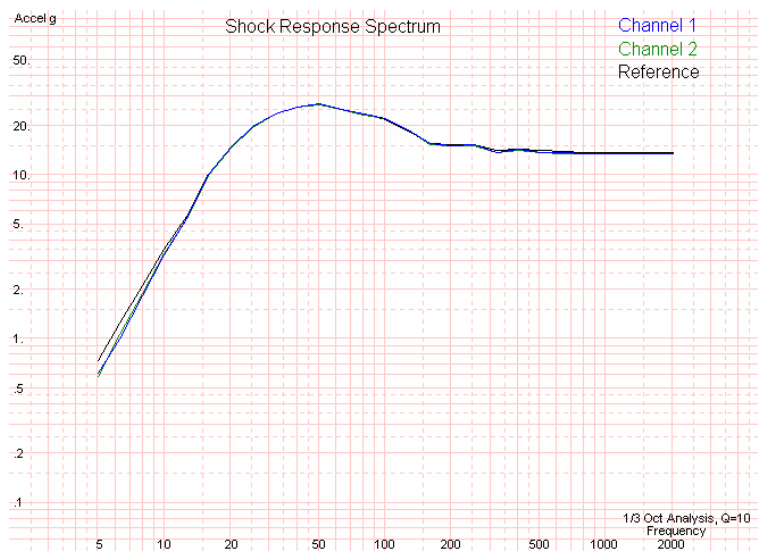

Figure 3.2.2.12 - Shock response, $1 /{ }^{10}{ }^{20}{ }^{100}$ Oct, Q:10, SN 442935, - axial, 17 g, $20.3 \mathrm{msec}$

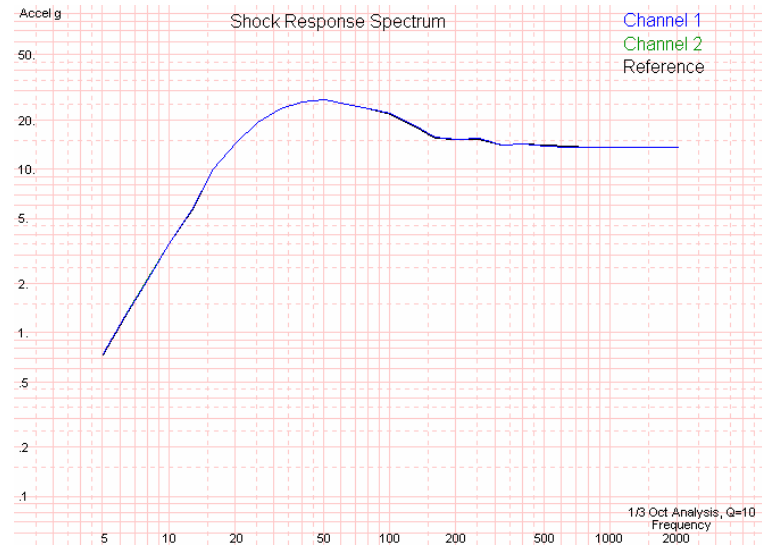

Figure 3.2.2.14 - Shock response, 1/3 Oct, Q:10, SN 442935, + radial, $17 \mathrm{~g}, 20.3 \mathrm{msec}$ 


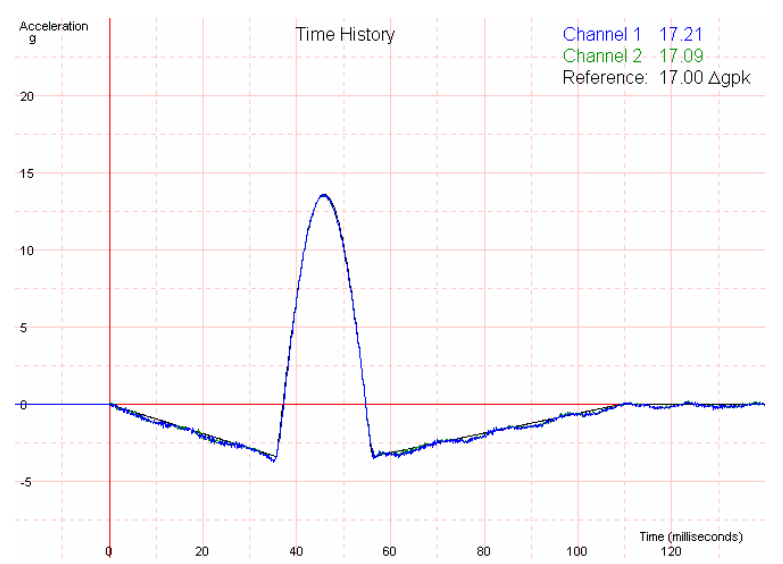

Figure 3.2.2.15 - Shock time history, SN 442935, - radial, 17 g, $20.3 \mathrm{msec}$

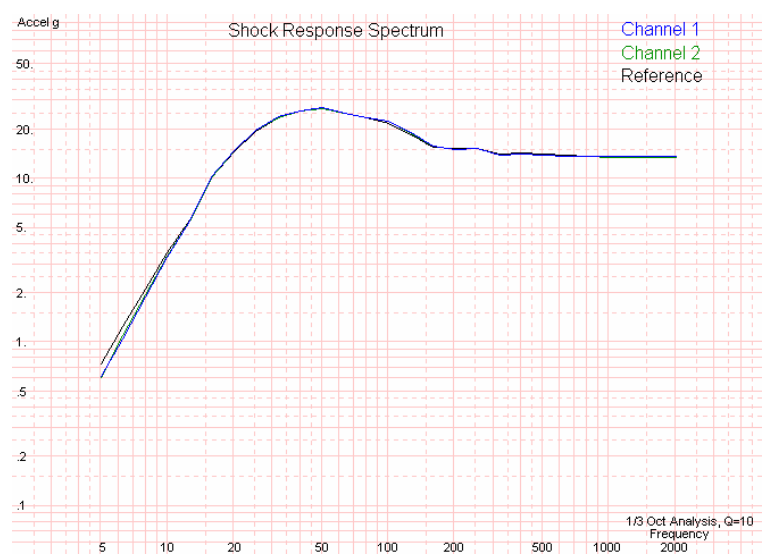

Figure 3.2.2.16 - Shock response, $1 / 3$ Oct, Q:10, SN 442935, - radial, $17 \mathrm{~g}, 20.3 \mathrm{msec}$

Shock time history and shock response data plots for the remaining 13 transducers is similar to the preceding $50 \mathrm{~g}, 1 \mathrm{msec}$. and $17 \mathrm{~g} 20.3 \mathrm{msec}$ data plots for both +/- axial and +/- radial directions. All data plots are available for inspection upon request.

At the completion of the Mechanical Shock Test series, a performance check was done. All 14 transducers passed. The oscilloscope snapshots were saved to computer and archived. To eliminate space in this report, none of these snapshots are shown. However, all snapshots are available for inspection upon request. 


\section{3 - Long Random Vibration Test}

The test consisted of a long random vibration test of the tranducers mounted in Block A and Block B, in the axial and radial directions, with a test duration of 8 hours in each axis. The test was performed at ambient room temperature.

The test spectrum used for the long random vibration qualification test is shown in Figure 3.3.1. The spectrum is defined from $10 \mathrm{~Hz}$ to $2 \mathrm{kHz}$ with a $3.0 \mathrm{~g}_{\mathrm{rms}}$ magnitude.

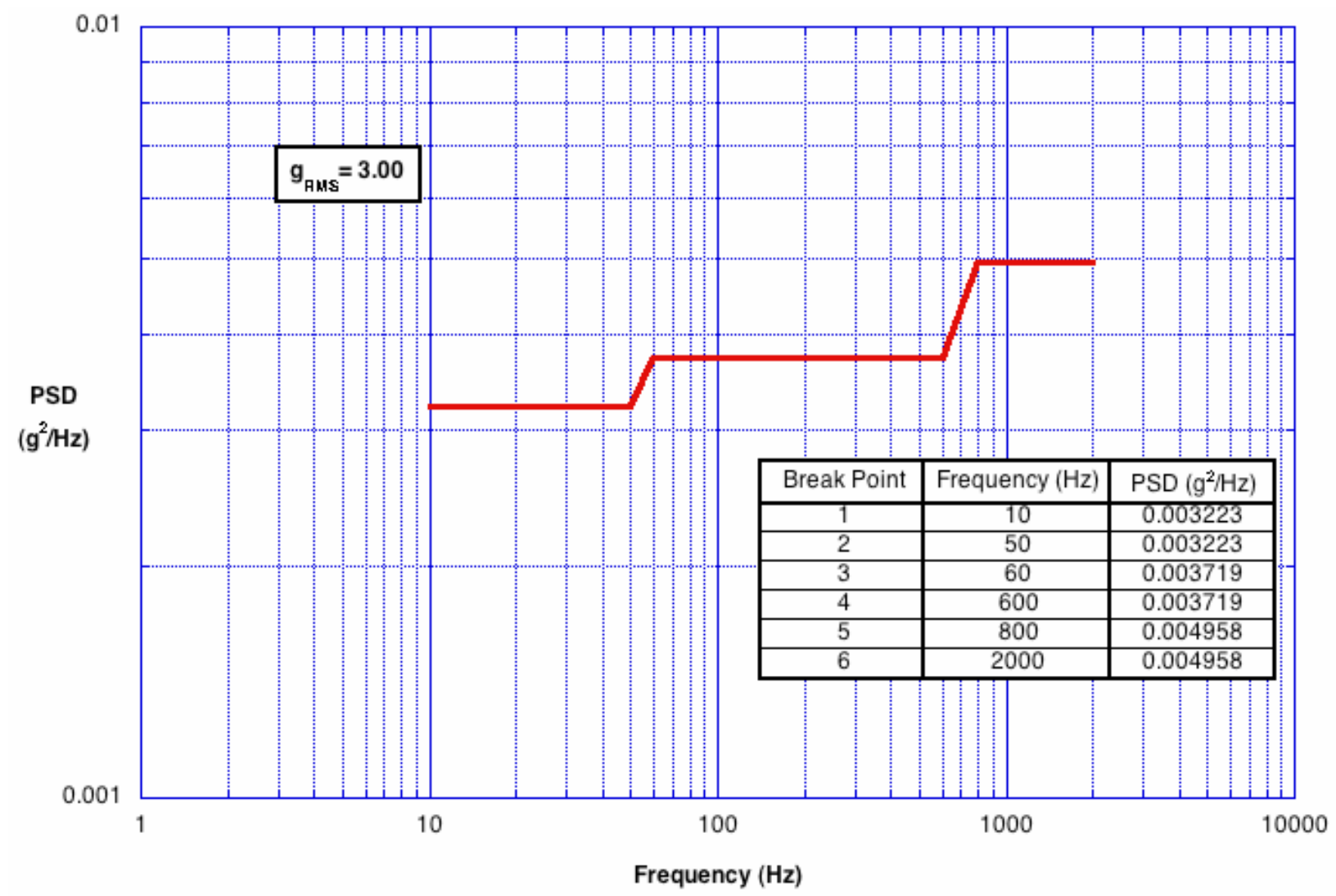

Figure 3.3.1 - Long Random Vibration Qualification Test Spectrum

\subsection{1 - Test Setup and Procedure - Room Temperature}

The test setup and procedure for the Long Random Vibration Test was the same as the test setup and procedure for the Short Random Vibration Test. The only difference was that the long vibration test ran for 8 hours versus the 10 minutes for the short vibration test. Please refer to Section 3, sub-section 3.1.1, for test setup and procedure details.

\subsection{2 - Test Results}

The reference/control accelerometer, channel 1 , is monitored continuously during the testing and provides feedback for the shaker control. Vibration amplitude and the calculated PSD were saved at the start of the test, at 1 hour intervals throughout the test, and at the end of the test when the test automatically stopped after 8 hours. Figures 3.3.2.1 thru Figure 3.3.2.10 show the test results for Block A in the axial direction and the room temperature variation for the duration of the test. The tests were performed on 9 December 2005 through 13 December 2005. 


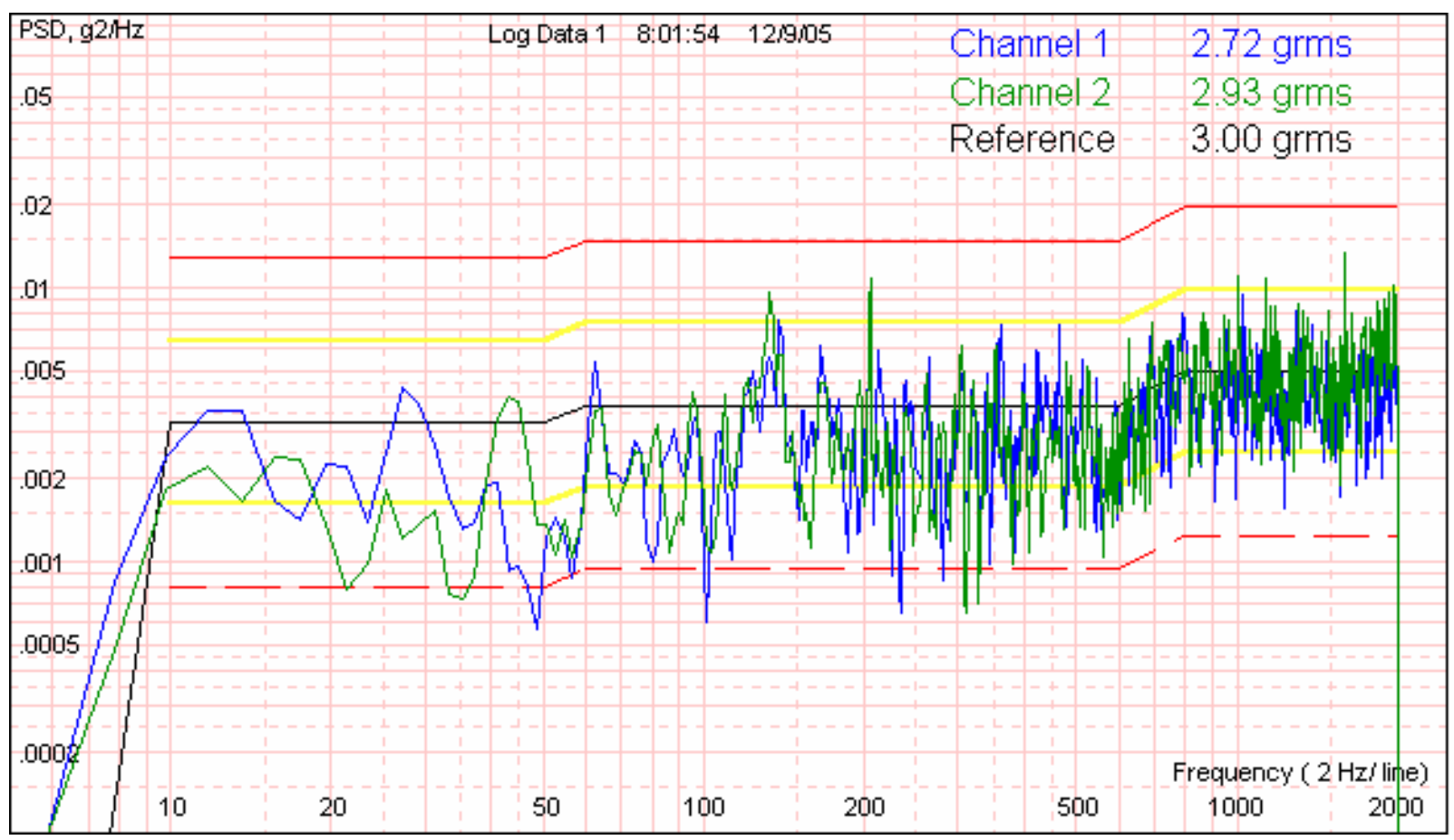

Figure 3.3.2.1- Power Spectral Density plot taken at the beginning of test

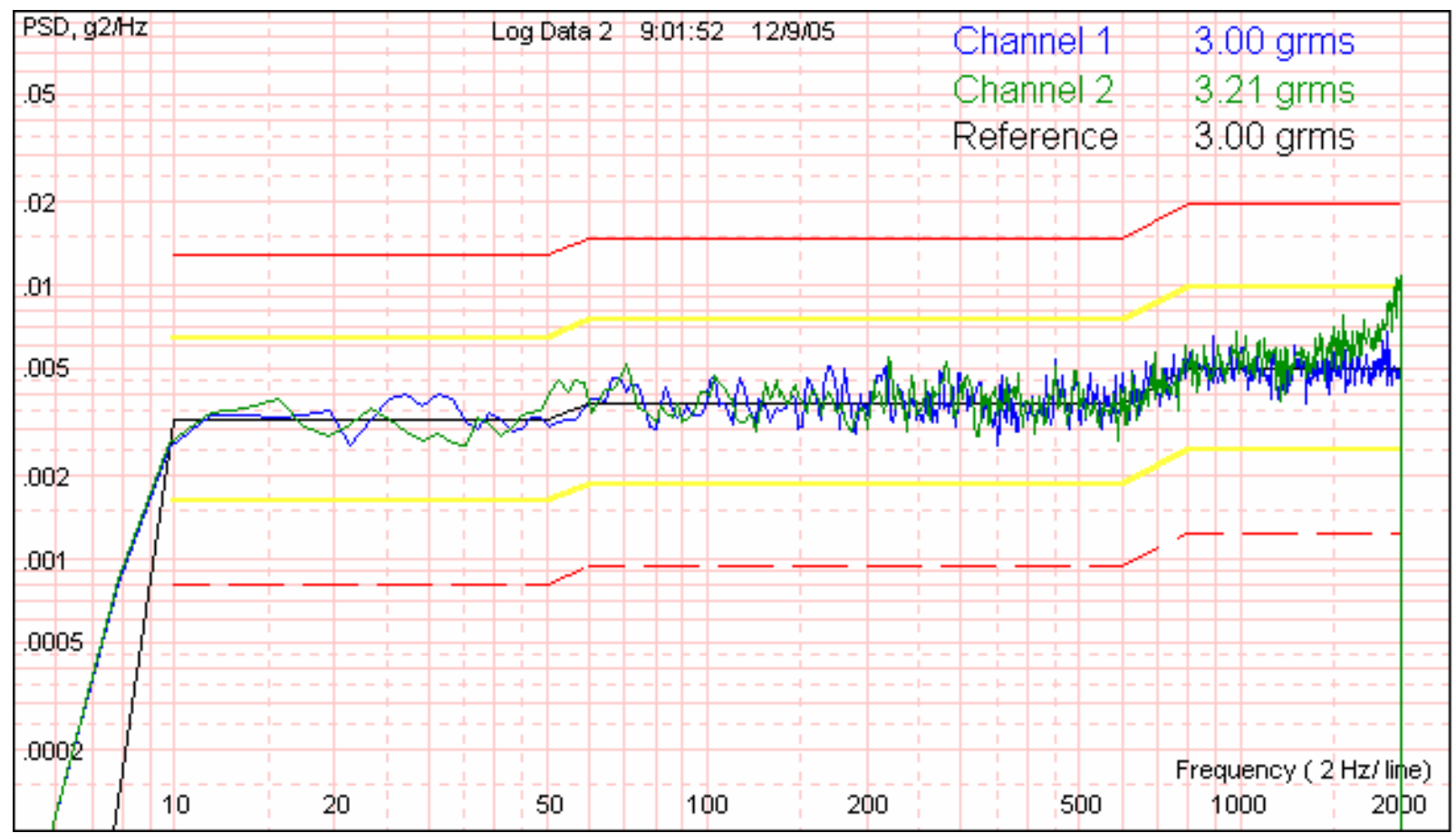

Figure 3.3.2.2 - Power Spectral Density plot taken 1 hour into the test 


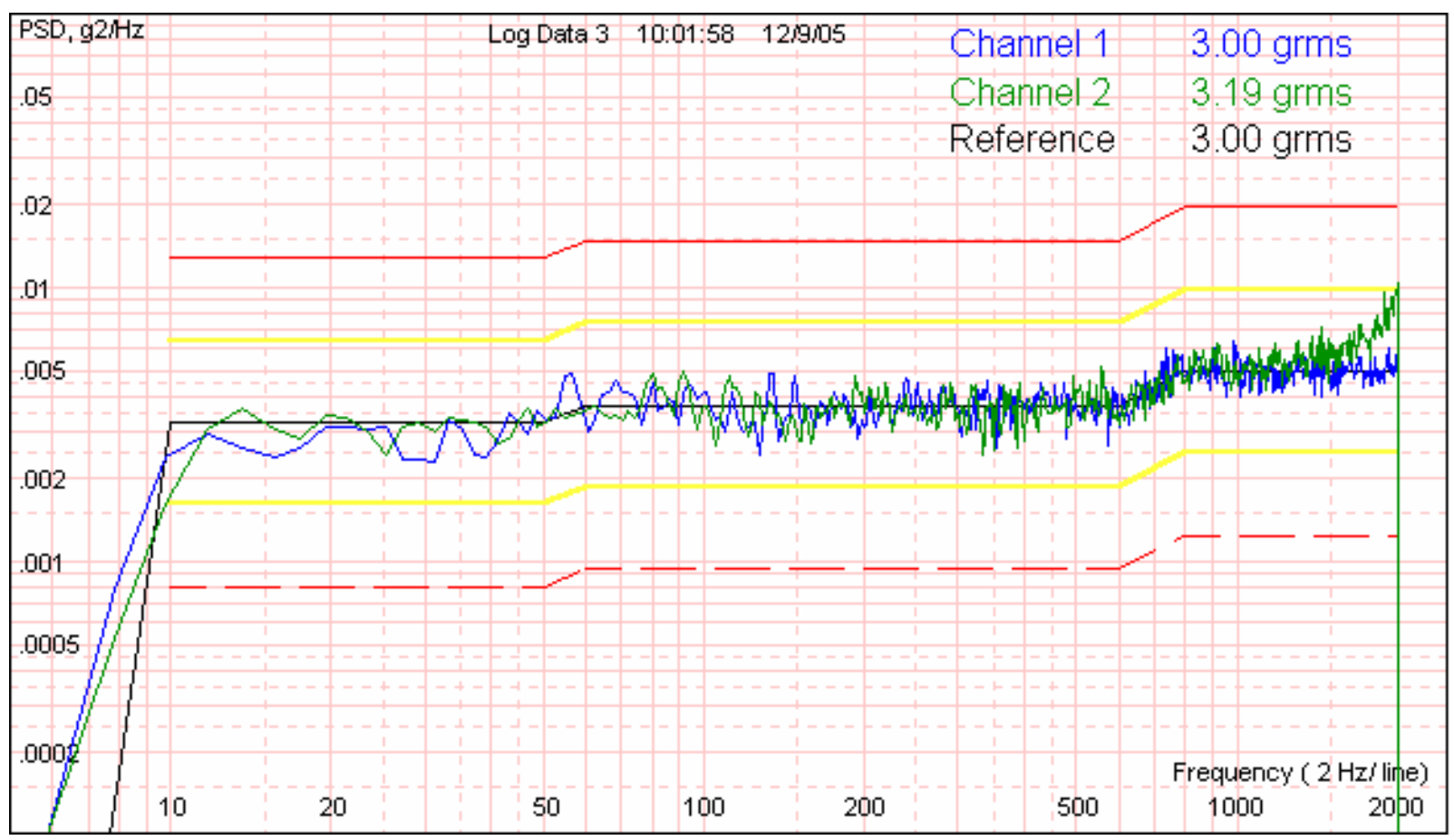

Figure 3.3.2.3 - Power Spectral Density plot taken 2 hours into the test

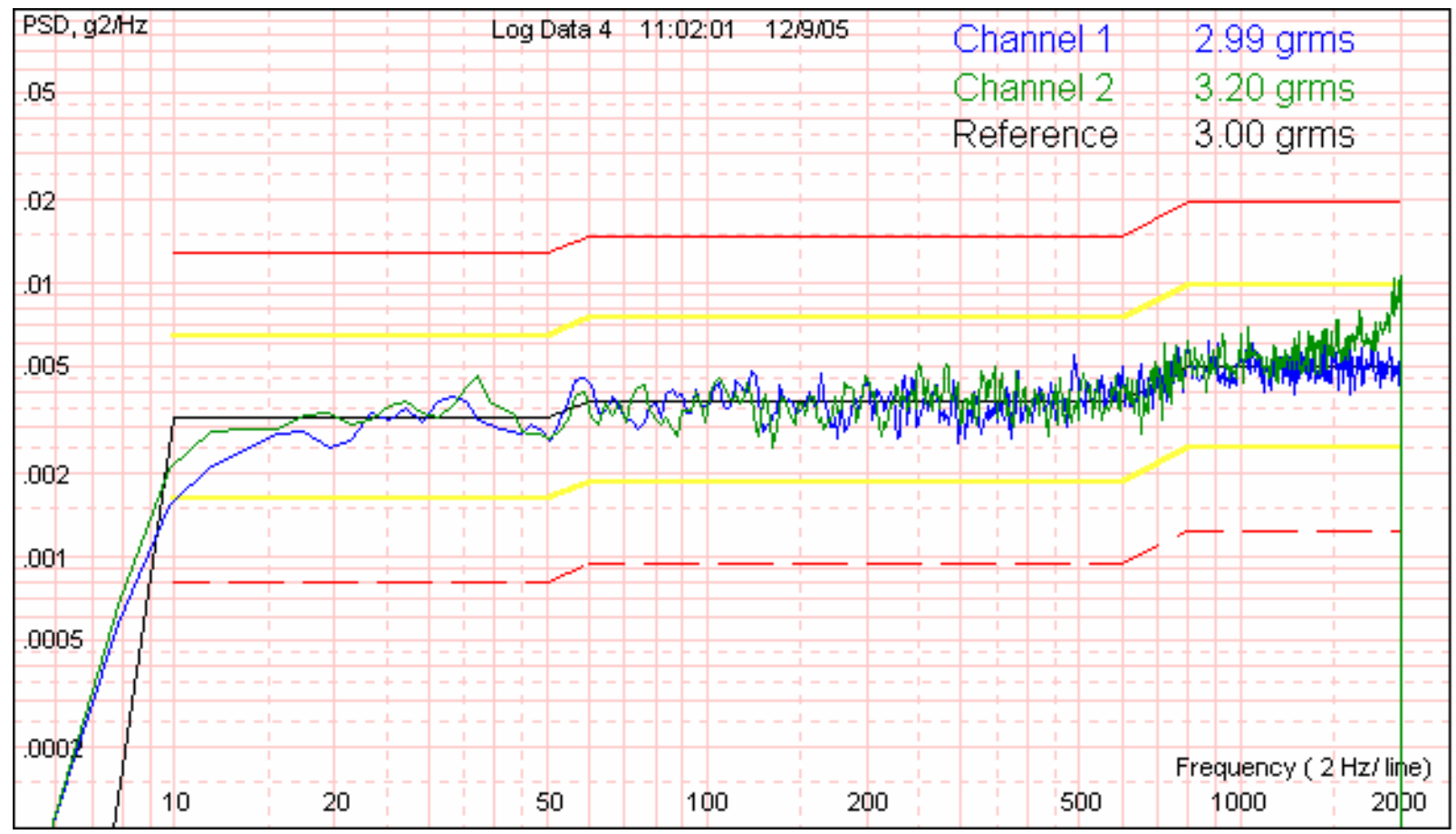

Figure 3.3.2.4 - Power Spectral Density plot taken 3 hours into the test 


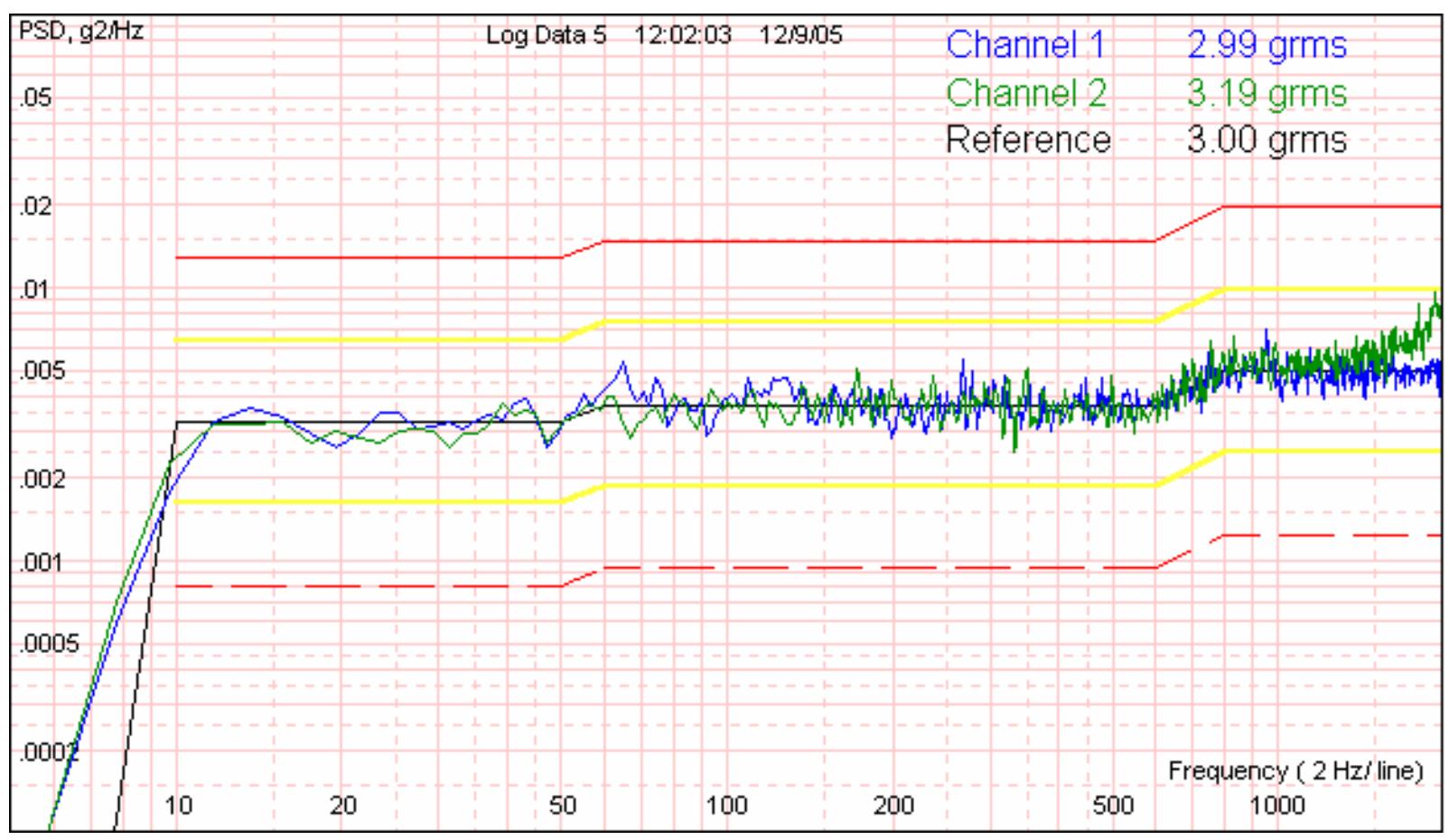

Figure 3.3.2.5 - Power Spectral Density plot taken 4 hours into the test

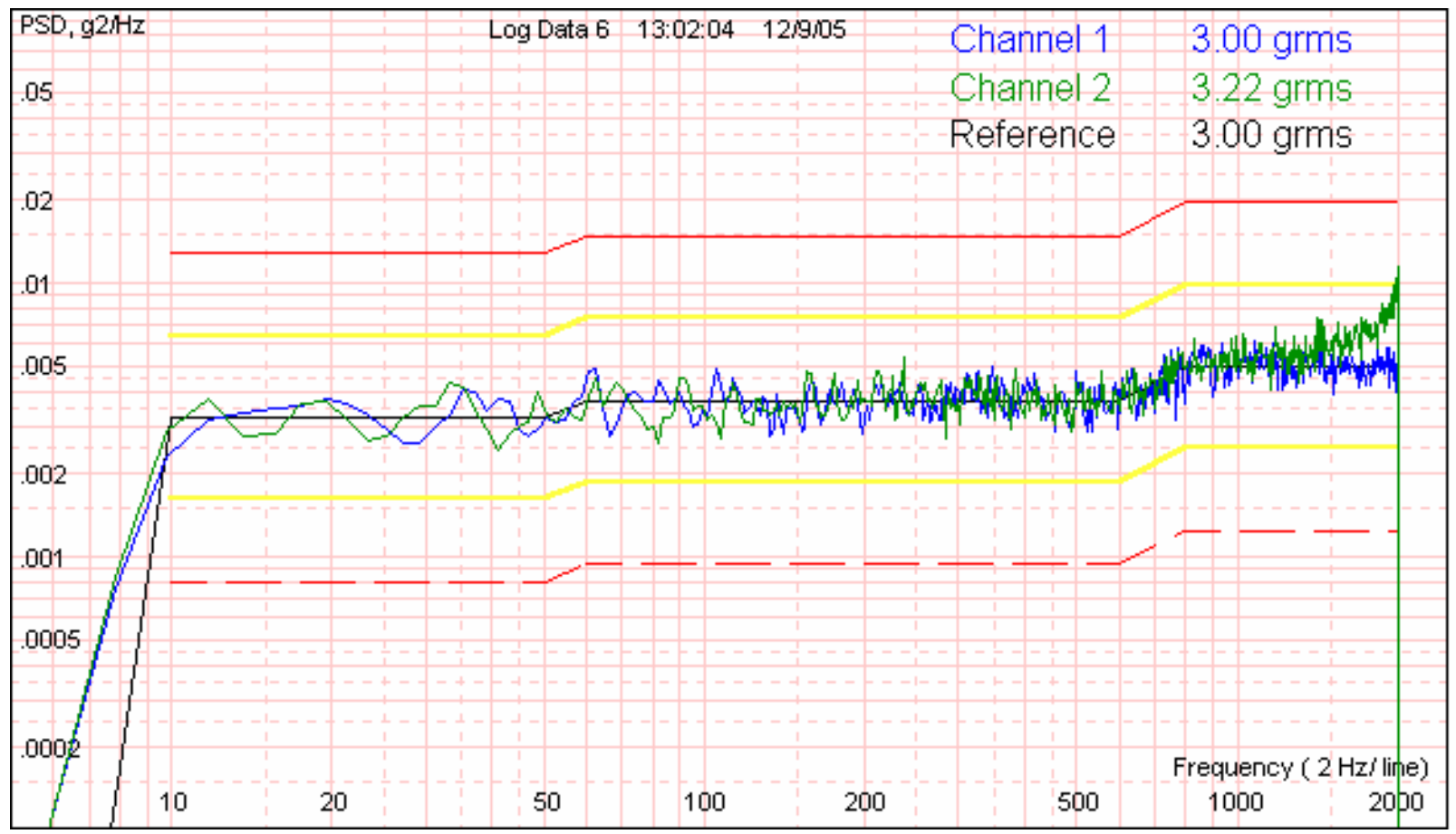

Figure 3.3.2.6 - Power Spectral Density plot taken 5 hours into the test 


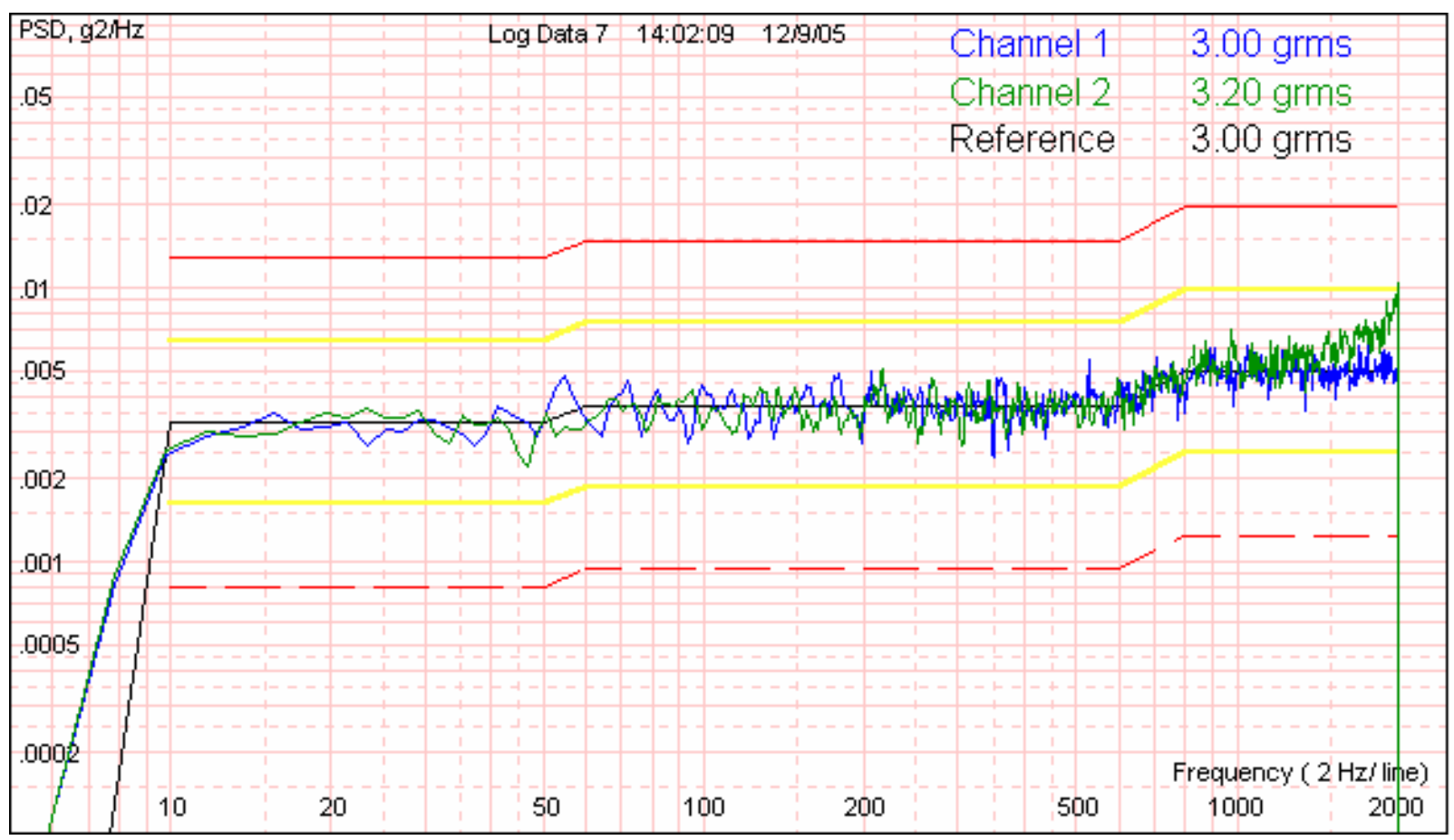

Figure 3.3.2.7 - Power Spectral Density plot taken 6 hours into the test

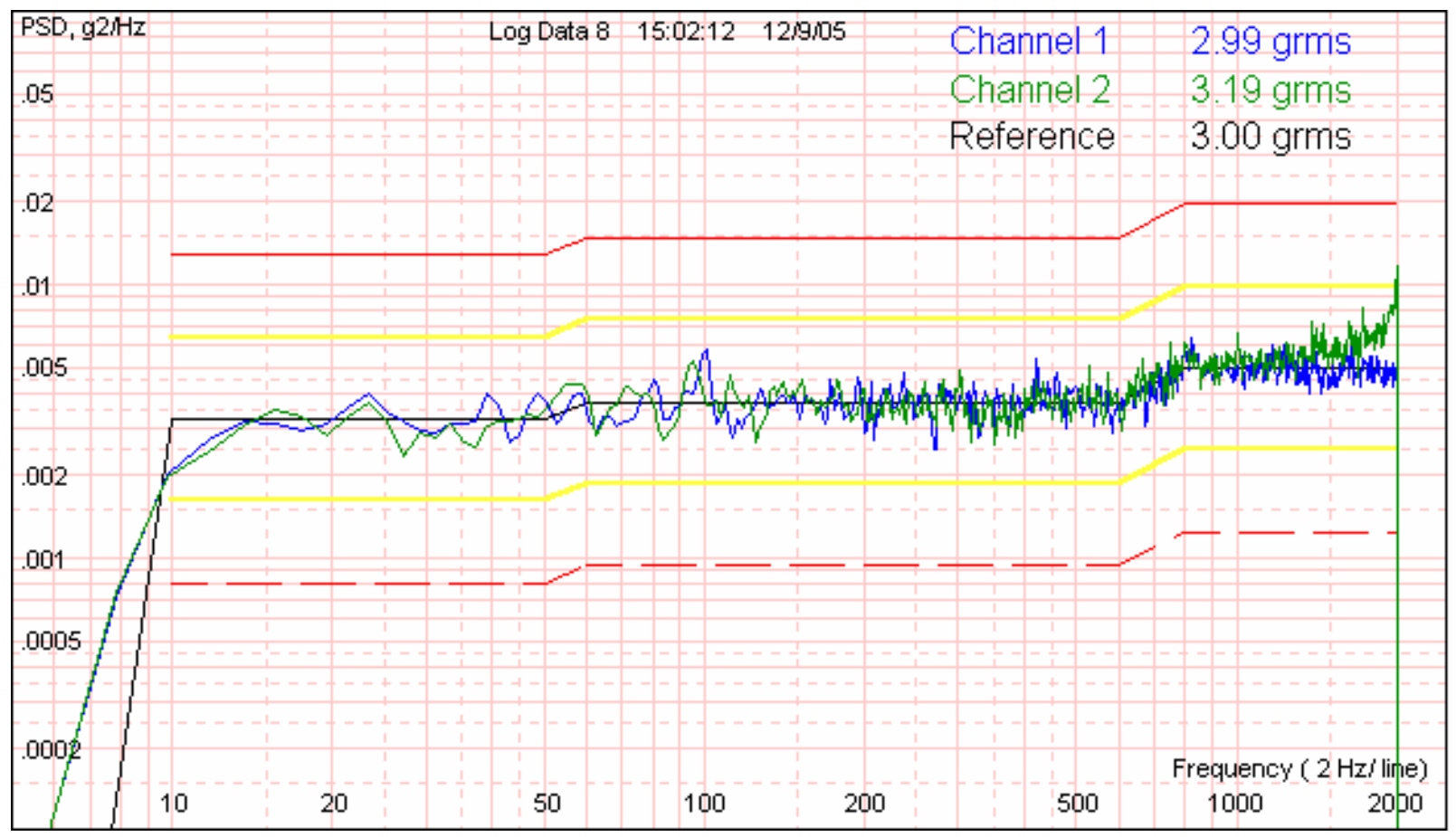

Figure 3.3.2.8 - Power Spectral Density plot taken 7 hours into the test 


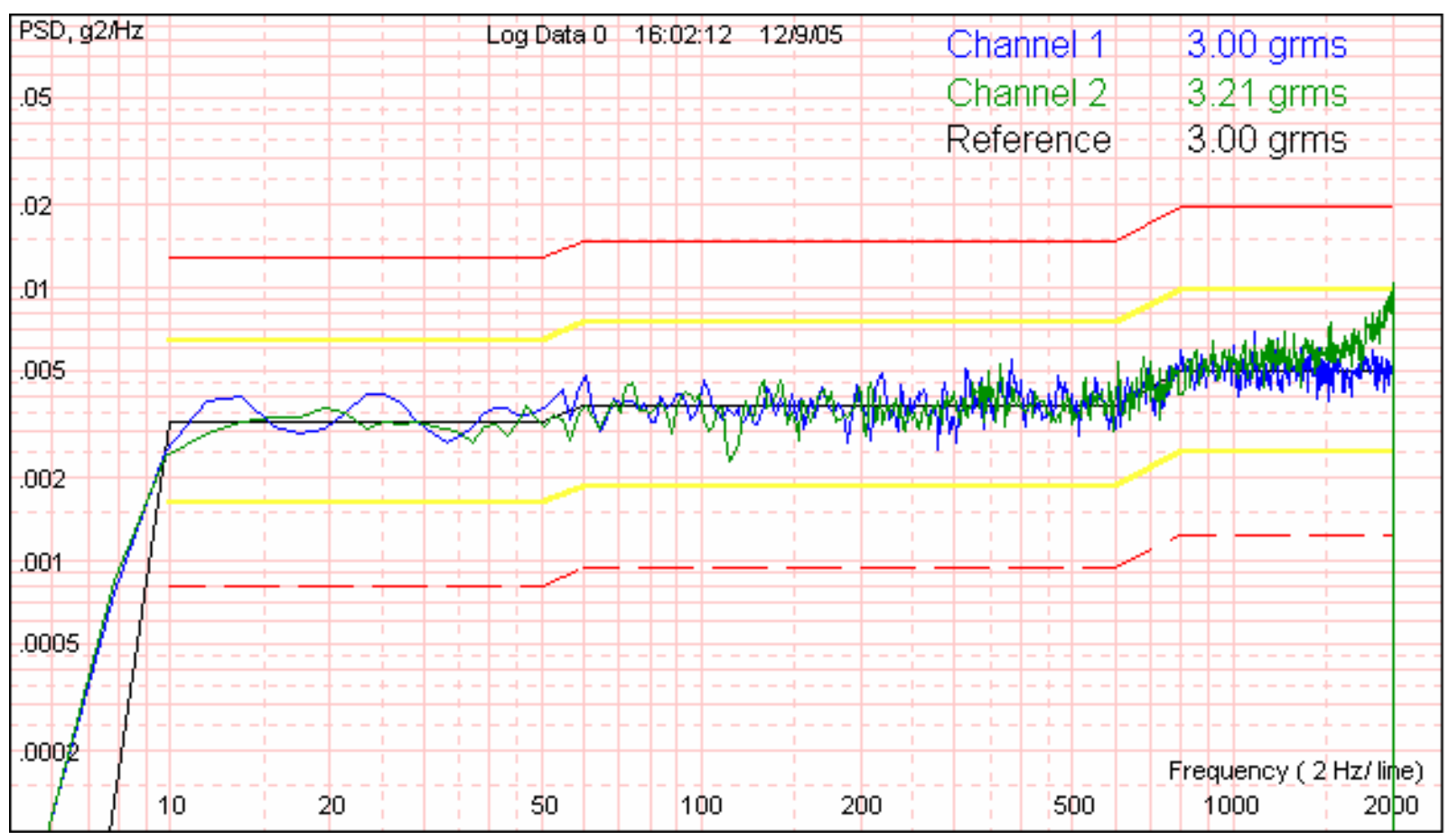

Figure 3.3.2.9 - Power Spectral Density plot taken at the end of test

Temperature and event marker data was downloaded from the Agilent 34970A Data Acquistion/ Switch using H/P Benchlink software and saved in tab delimited format. The data was plotted using KaleidaGraph from Synergy Software and is shown in Figure 3.3.2.10.

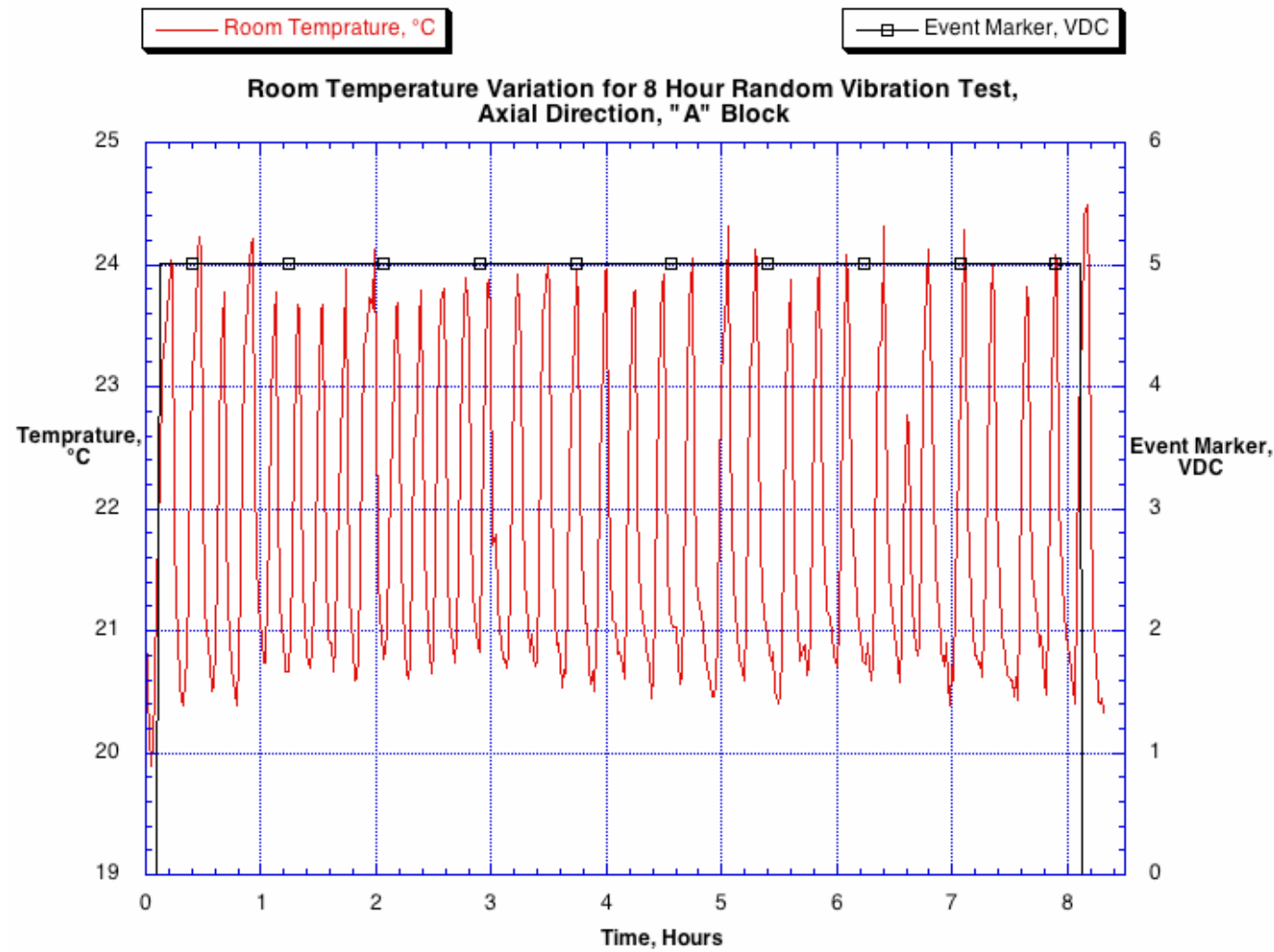

Figure 3.3.2.10 - Room temperature variation for 8 hour test. 
Power Spectral Density plots and temperature data for...

Block A, radial direction

Block B, axial direction

Block B, radial direction

....were similar to the preceding Block A axial direction data. To eliminate space in this report, none of these Power Spectral Density plots and temperature data are presented. However, all data plots and temperature data are available for inspection upon request.

At the completion of the Long Random Vibration Test series, a performance check was done. All 14 transducers passed. The oscilloscope snapshots were saved to computer and archived. To eliminate space in this report, none of these snapshots are shown. However, all snapshots are available for inspection upon request.

\section{4 - Sine Vibration Test}

The test consisted of a sine vibration test for the tranducers mounted in Block A and Block B, in the axial and radial directions, for a single cycle in each axis. The test was performed at ambient room temperature.

The test spectrum used for the sine vibration qualification test is shown in Figure 3.4.1. The spectrum is defined from $10 \mathrm{~Hz}$ to $2 \mathrm{kHz}$ with a $5.0 \mathrm{~g}_{\text {rms }}$ maximum magnitude.

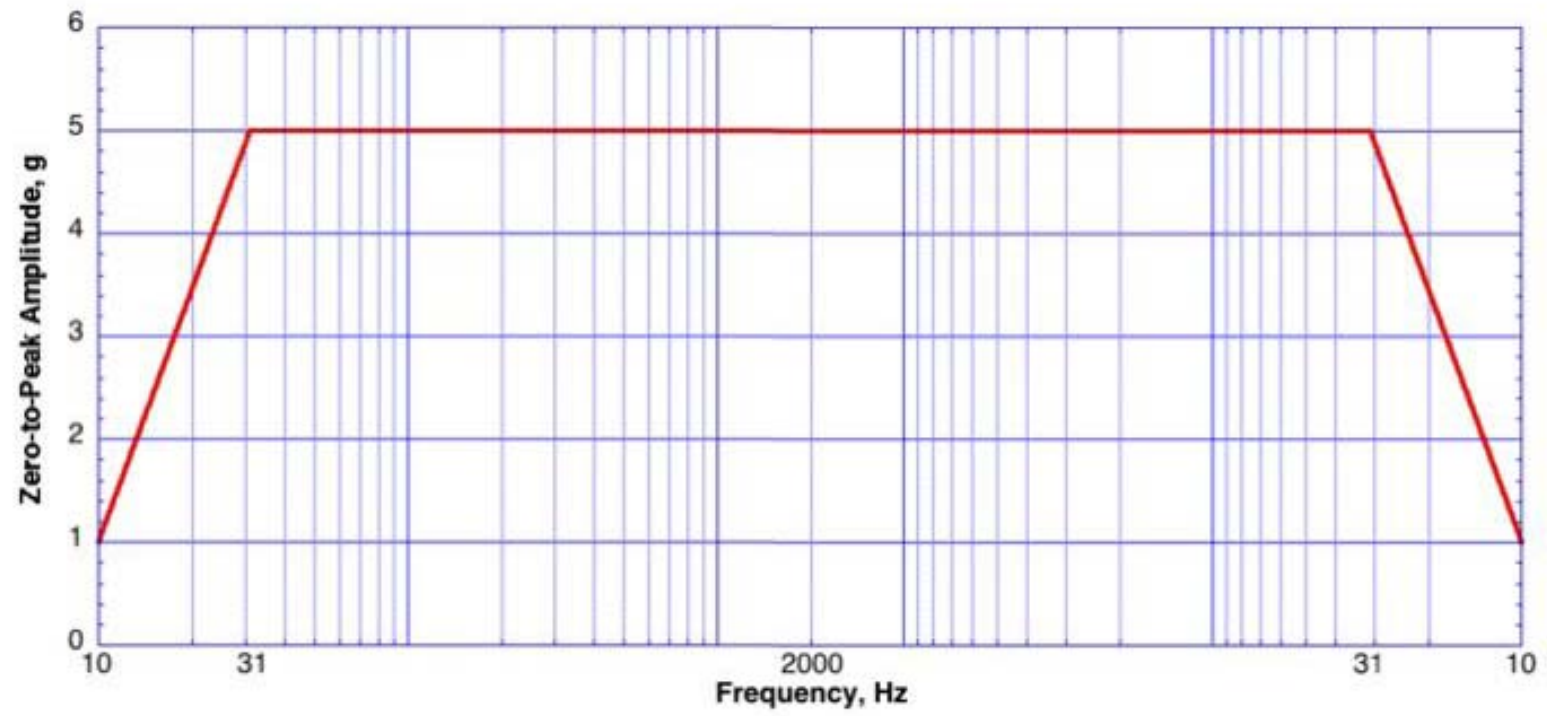

Figure 3.4.1 - Sine Vibration Qualification Frequency Spectrum - one cycle

\subsection{2 - Test Setup and Procedure - Room Temperature}

The test setup and procedure for the Sine Vibration qualification test was the same as the test setup and procedure for the Short Random Vibration Test. The only differences is the control software was in the sine test configuration and the sine vibration test ran for one cycle versus the short vibration test which had the control software in the random test configuration and ran for 10 minutes. Please refer to Section 3, sub-section 3.1.1, for test setup and procedure details. 


\subsection{3 - Test Results}

The reference/control accelerometer, channel 1, is monitored continuously during the testing and provides feedback for the shaker control. The vibration amplitude was saved at the end of the sine vibration test. Figure 3.4.3.1 shows the test result for Block A in the axial direction. Ambient room temperture was $22.0^{\circ} \mathrm{C},+/-2^{\circ} \mathrm{C}$, and was monitored, but not electronically recorded, during the test. The tests were performed on 7 December 2005.

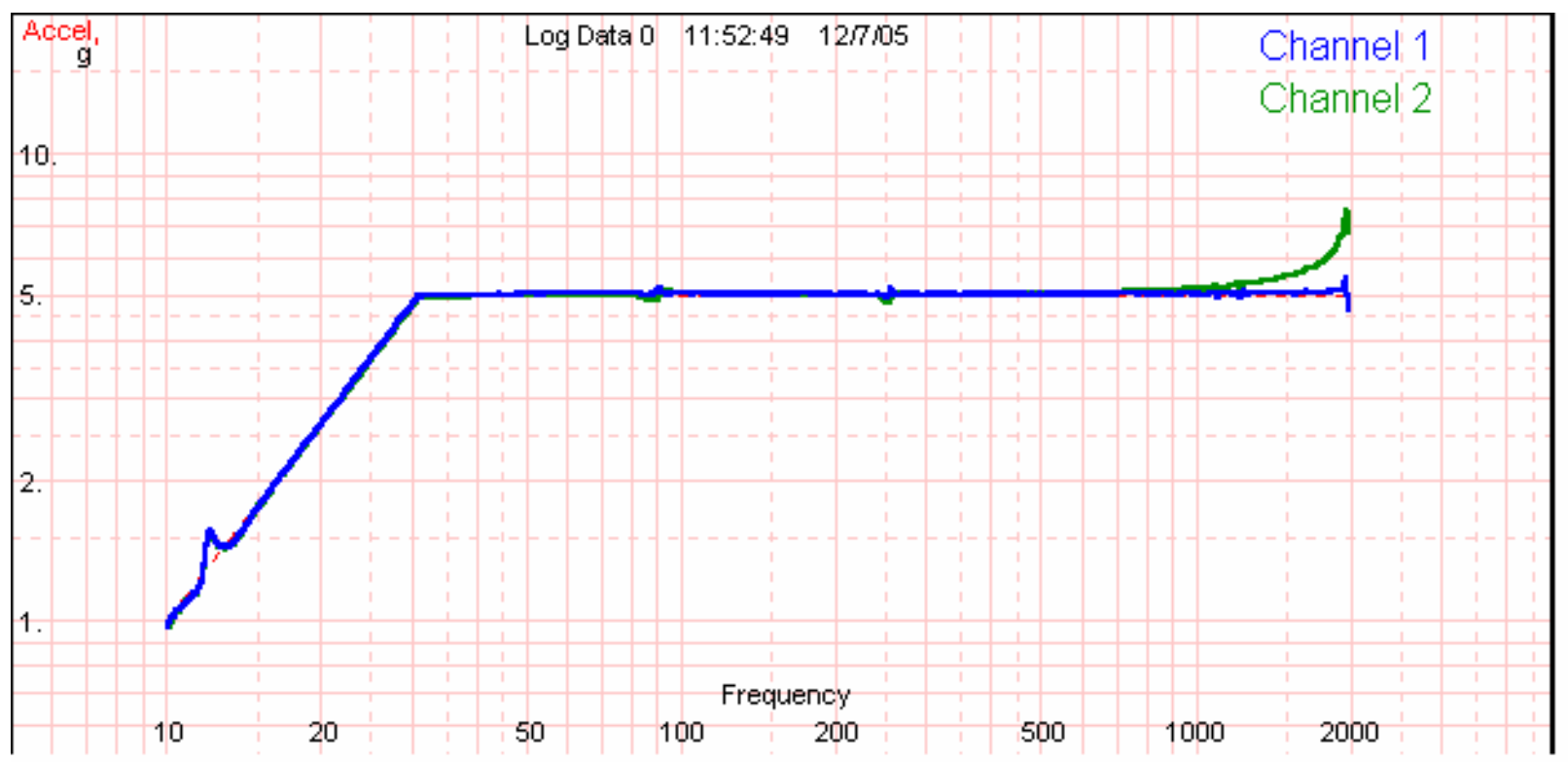

Figure 3.4.3.1 -Sine Vibration Test result for one cycle

The sine vibration test plots for ...

Block A, radial direction

Block B, axial direction

Block B, radial direction

...were similar to the preceding Block A axial direction data. To eliminate space in this report, none of these sine vibration test plots are presented. However, all sine vibration test plots are available for inspection upon request.

At the completion of the Long Random Vibration Test series, a performance check was done. All 14 transducers passed. The oscilloscope snapshots were saved to computer and archived. To eliminate space in this report, none of these snapshots are shown. However, all snapshots are available for inspection upon request. 
---- END OF DOCUMENT ----

Page 43 of 43 